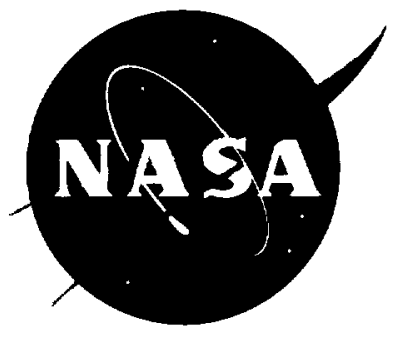

NASA Technical Paper 3508

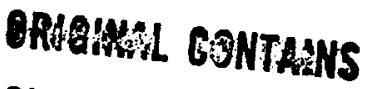 \\ CQLER ILLUGTRATHOiIS
}

\title{
An Inelastic Analysis of a Welded Aluminum Joint
}

R.E. Vaughan

Marshall Space Flight Center $\bullet$ MSFC, Alabama 


\section{TABLE OF CONTENTS}

Page

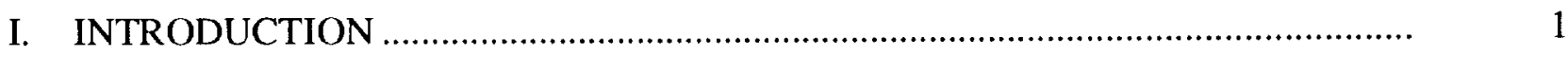

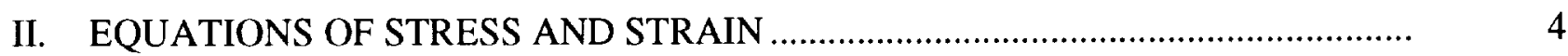

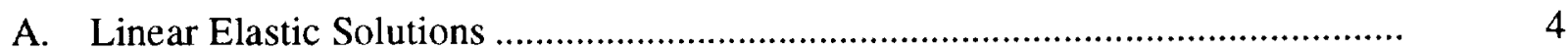

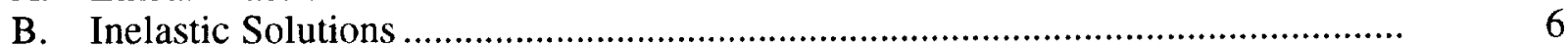

III. ANALYSIS OF A WELD SINGLE-ZONE MATERIAL PROPERTY COUPON USING INCREMENTAL STRAIN THEORY ................................................

IV. COMPUTATIONAL ANALYSIS OF A TENSILE TEST SPECIMEN .................... 15

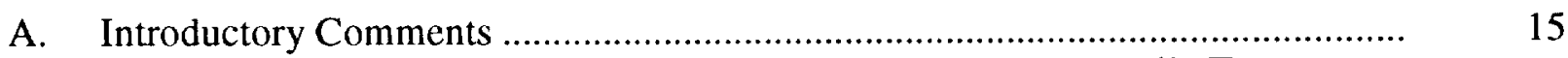

B. The Finite-Element Model for One Material Property in the Tensile Test Specimen ............................................................................................. 15

C. Results of the Finite-Element Analysis for a Single-Zone Material Property Test

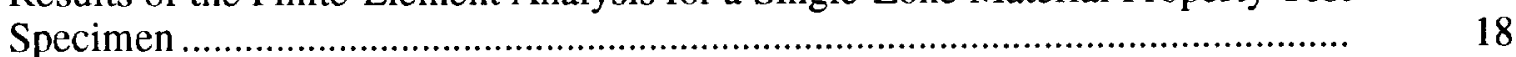

D. The Analysis of Multiple-Zone Material Properties in the Tensile Test Specimen 20

V. CONCLUSIONS AND RECOMMENDATIONS ............................................ 36

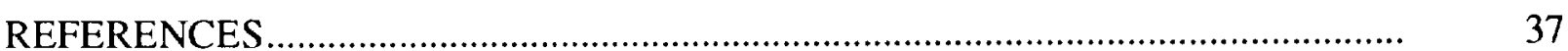

APPENDIX A - REDUCTION OF EXPERIMENTAL DATA ............................... 39

APPENDIX B - ABAQUS MATERIALS PROPERTIES INPUT ..................... 51

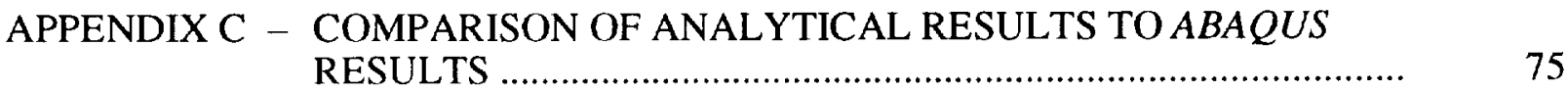




\section{LIST OF ILLUSTRATIONS}

Figure

Title

Page

1. Typical stress-strain curve for welds

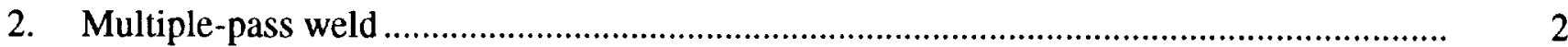

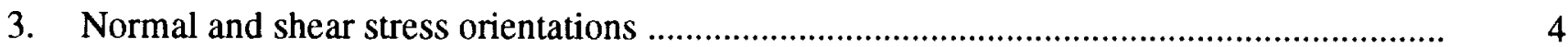

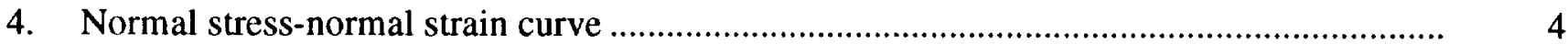

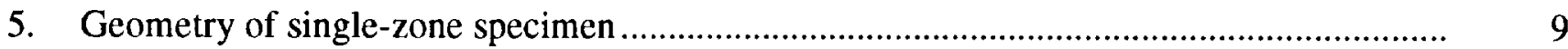

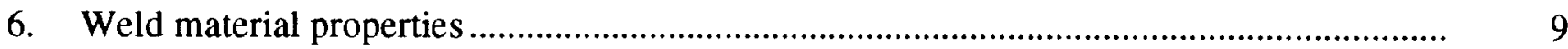

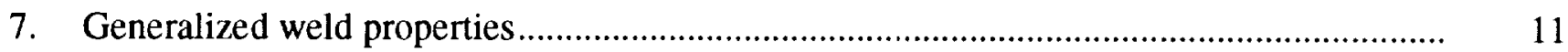

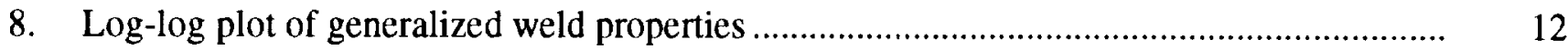

9. Comparison of test data to equation for the weld material ........................................... 13

10. Comparison of test data to equation from incremental strain theory .................................. 14

11. Finite-element model for single-zone material model ...................................................... 15

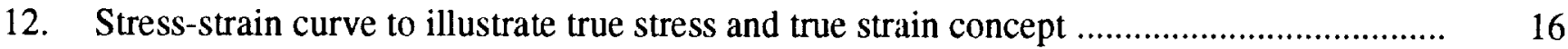

13. Comparison of true stress-strain data to engineering stress-strain data for the weld ........... $\quad 17$

14. Comparison of computational results and analytical predictions ...................................... 19

15. Comparison of computational results and tensile test results ........................................... 19

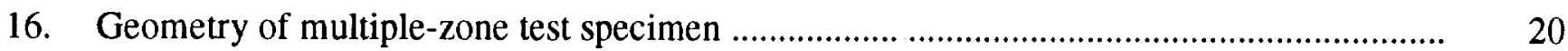

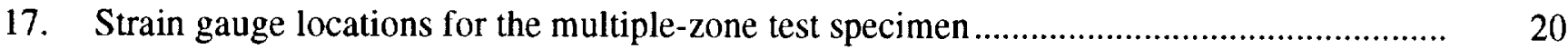

18. Experimental stress-strain curve from the multiple-zone specimen at the centerline.......... 21

19. Experimental stress-strain curve from the multiple-zone specimen at the $1 / 2$-in line .......... 22

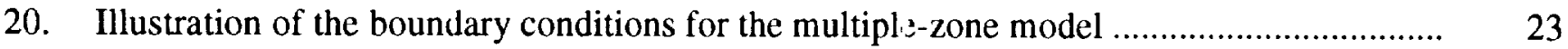

21. Comparison of $X$-direction experimental stress-strain values to finite-element results at the $T O P$

22. Comparison of $X$-direction experimental stress-strain values to finite-element results at $C$ 


\section{LIST OF ILLUSTRATIONS (Continued)}

Figure

Title

Page

23. Comparison of $X$-direction experimental stress-strain values to finite-element results at the $B T M$

24. Comparison of $Y$-direction experimental stress-strain values to finite-element results at the TOP

25. Comparison of $Z$-direction experimental stress-strain values to finite-element results at $C$

26. Piosson's ratio from the finite-element model

27. Piosson's ratio from experimental data

28. Comparison of $Y$-direction experimental stress-strain values to finite-element results at the $B T M$.

29. Photostress evaluation of the weld test specimen as load increases

30. Cross-section view of weld

31. Contour plot of multiple-zone model; deformed shape

32. Contour plot of multiple-zone model; deformed shape and strain in $X$ direction.

33. Contour plot of multiple-zone model; view of weld cross section; deformed shape and strain in $X$ direction

34. Contour plot of multiple-zone model; deformed shape and strain in $Y$ direction

35. Contour plot of multiple-zone model; view of weld cross section; deformed shape and strain in $Y$ direction 


\section{LIST OF TABLES}

Table

Title

Page

1. Weld material properties (ABAQUS ${ }^{*} P L A S T I C$ option).

2. Comparison of analytical and computational methods ... 
TECHNICAL PAPER

\section{AN INELASTIC ANALYSIS OF A WELDED ALUMINUM JOINT}

\section{INTRODUCTION}

Butt-weld joints are common design features of pressure vessels, and are as reliable as the weakest element in the weld chain. In practice, weld material properties are determined from a tensile test specimen and are provided to the stress analyst in the form of a stress versus strain diagram (fig. 1).

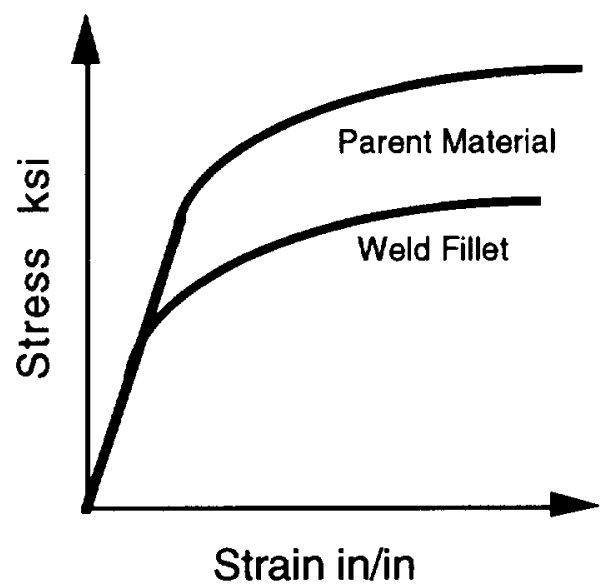

Figure 1. Typical stress-strain curve for welds.

The most common method of analysis assumes the weld is free from residual stresses produced by the welding process and ignores any variation of material properties within the weld. Experimental and analytical investigations of residual stresses and heat-affected zones (HAZ's) are numerous. Rybicki and Stonesifer ${ }^{1}$ developed computational models to calculate the magnitude and distribution of residual stresses for multipass welds. Papzoglou and Masubuchi included phase-transformation effects and thermo-elastic-plastic analysis to develop computational methods of determining residual stresses in welds. ${ }^{2}$ Agapakis et al. $^{3}$ investigated analytical models for the calculation of residual-stress relaxation during stress-relief heat treatments. The softening of material properties in HAZ's has also been studied in great detail. Robertson and Dwight ${ }^{4}$ used classical heat-flow theory to determine the extent of HAZ's for multipass welds.

To date, there has been little effort to study the effects of residual stresses and material property variations for loaded weld joints. Postwelding heat treatments, stress-relief techniques, and thermal controls during the welding process are designed to eliminate the detrimental effects of these processinduced variables. However, experimental studies have shown that these variables may be present in a weld even after efforts have been made to remove them..$^{5-7}$

A good welded joint will usually develop the full strength of the material being joined unless the high temperature necessary for the process changes the properties of the materials. The welding process 
for thick welds requires high temperatures and, therefore, should be suspect for variations in material properties at the weld. The effects of variations in properties through the thickness of the weld and along the width of the weld are difficult to assess because of the inaccessibility of welds in service applications and because of the costs associated with such studies.

A butt weld is a weld in which two members are joined by machining a groove for the weld material and then butting the remaining parent material together at the ends (fig. 2). Depending on the thickness of the material, it is common to require multiple weld passes to fill the groove. In such a weld, the passes start at midthickness and alternate from one side to another in an effort to provide symmetrical material properties throughout the thickness (fig. 2). In addition to variance through the thickness of the weld, the material properties can vary across the width of the weld due to the presence of an HAZ between the weld material and the parent material. Such welds are currently used in a variety of large aerospace structures. Tests of such structures have often resulted in failures of the weld at measured strain values well below those predicted by currently available computational methods (see e.g., reference 8).

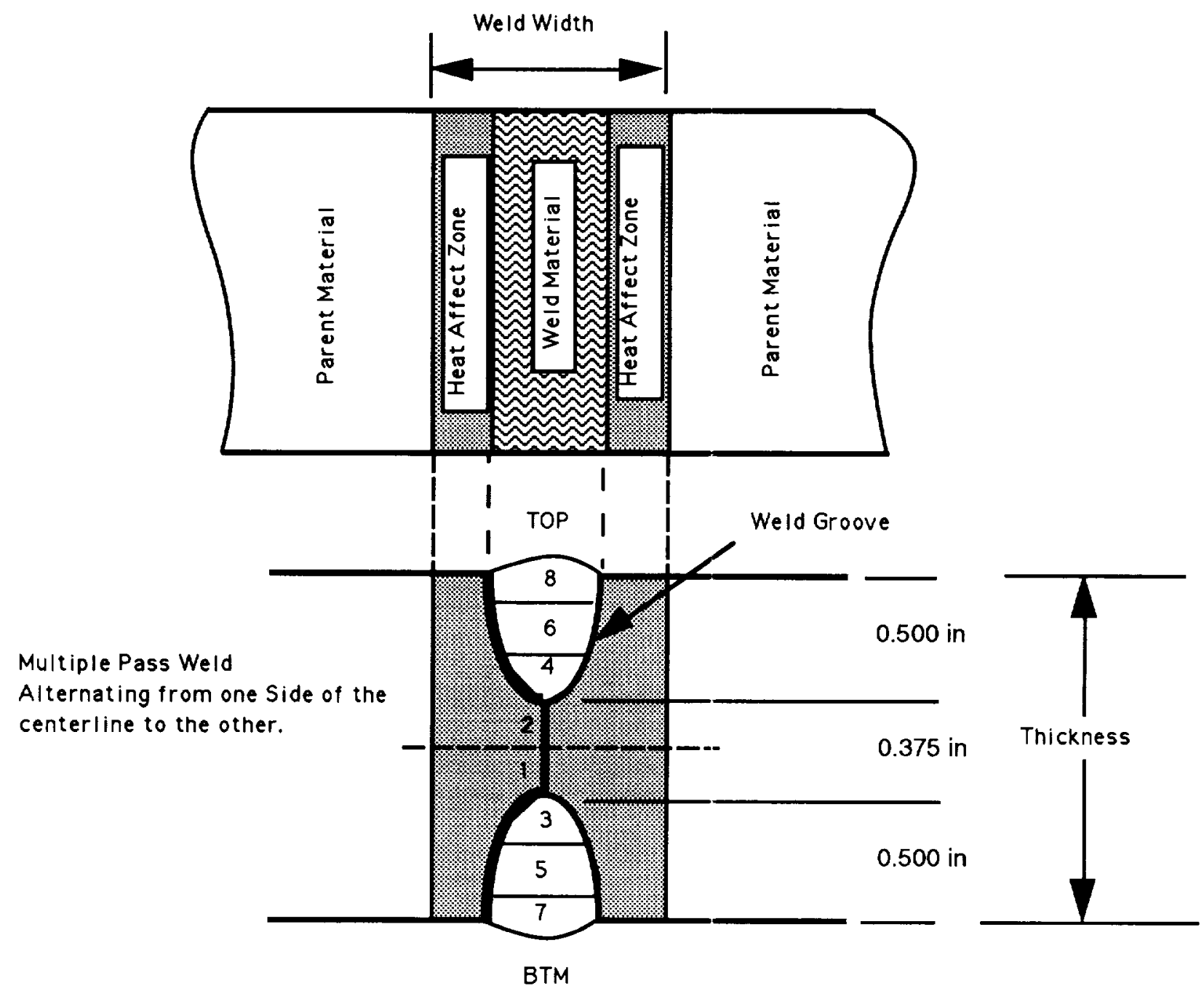

Figure 2. Multiple-pass weld. 
In 1991, a NASA-sponsored experimental research project indicated that 2219-T87 aluminum welds exhibit distinct zones of varying material properties across the HAZ and through the thickness of the weld ${ }^{4-7}$ The project initially involved axially loading $2219-\mathrm{T} 87$ specimens with a welded joint in the center. The tests indicated the weld and the HAZ are much more ductile than the parent material. ${ }^{5} \mathrm{At}$ higher strain values, large amounts of necking is apparent in the weld and HAZ, indicating a complex state of strain in the specimen. Additional investigations using specimens with 1.4-in thickness discovered nonlinear, nonuniform material properties through the weld thickness. One side of the weld specimen was found to be much weaker and more ductile than the other side. ${ }^{6}$ Numerical analysis of these test specimens failed to produce predictions consistent with experimental results. The material modeling and the finite-element code were considered inadequate to simulate the true behavior of the weld joint. 4

The purpose of this study is to investigate analytical and computational methods used for the analysis of a thick weld and to develop an analytical model that can be used to predict the weld response to statically applied loads. The results of the analysis will be compared to experimental data to determine the weld behavior and the accuracy of the analysis methods. The weld considered in this study is a multiple-pass aluminum 2219-T87 butt weld as shown in figure 2. Elasticity and plasticity theory are examined to provide insight into modeling the inelastic properties beyond the weld material elastic limit. A one-dimensional (1-D), single-zone material model is developed to demonstrate the accuracy of the computational method when compared to analytical predictions and to experimental results. The material modeling methods verified in the single-zone material model are then applied to a multiple-zone material model of the same tensile test specimen.

The weld specimen is modeled using the finite-element code $A B A Q U S$. The analysis procedure will begin with a linear analysis of the test specimen. The predictions of the finite-element model will be verified by comparison to theory and to test in the elastic region. The material constants for the inelastic analysis will be determined from available test data (stress-strain curve). An analytical model of the test specimen will be developed to verify the inelastic material modeling methods used in the finite-element model. The predictions of the analytical model and the finite-element model will then be compared to the inelastic test data to verify both models. The single-zone material model will provide a benchmark for developing the multiple-zone material model. The material modeling methods verified in the singlezone material model are repeated for each set of material properties used in the multiple-zone material model. The results of the multiple-zone finite-element model analysis will then be compared to test data. As part of the analysis performed in this study, the finite-element model and tensile test data are both used to determine Poisson's ratio in the inelastic region. The computational value is then compared to the value obtained from test data. The results of the comparisons are used to discuss several aspects of multipass weld behavior and to make recommendations concerning future analysis and testing of welds.

Section I contains a development of the equations to be used for the stress and strain calculations to follow. Linear elastic stress-strain equations are presented and compared against inelastic equations. Section II provides an analysis of a welded tensile test specimen using incremental strain theory. Section III develops the computational model of the tensile test specimen. The first computational model assumes the weld has continuous (single-zone) material properties through the thickness of the specimen. In section IV, the second computational model assumes the weld has varying (multiple-zone) material properties through the thickness. In addition, section IV provides a comparison of the computational predictions and the experimental data. Finally, section $V$ offers conclusions and recommendations for future analyses of thick welds. 


\section{EQUATIONS OF STRESS AND STRAIN}

\section{A. Linear Elastic Solutions}

Linear elastic solutions are the basis for most structural analyses performed in engineering applications. Concepts from linear elastic theory are presented herein to define terms and to identify and understand similarities between elastic and inelastic methods of analysis.

Consider the three-dimensional normal and shear stress acting on a solid volume as illustrated in figure 3.

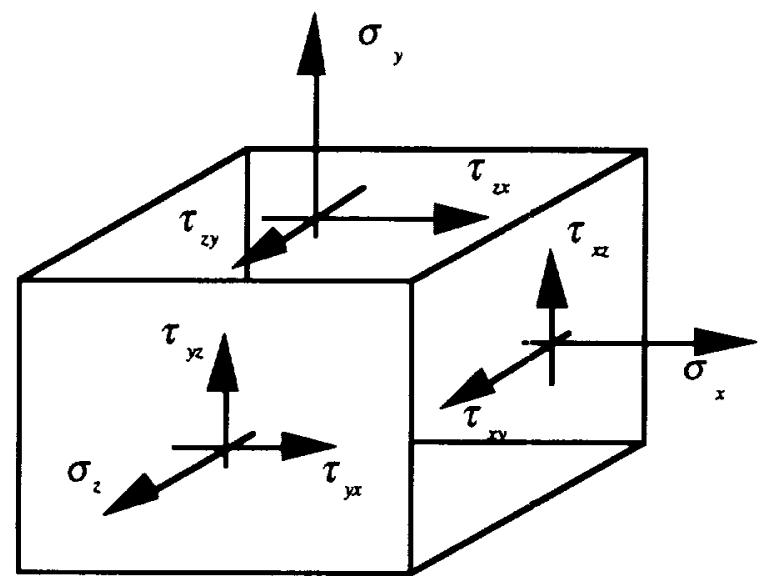

Figure 3. Normal and shear streis orientations.

Engineering stress is defined as the ratio of applied load to the initial cross-sectional area; engineering strain is defined as the ratio of the deflection in the direction of an applied normal load to an original length. The stress-strain diagram of a polycrystalline material in uniaxial tension is illustrated in figure 4.

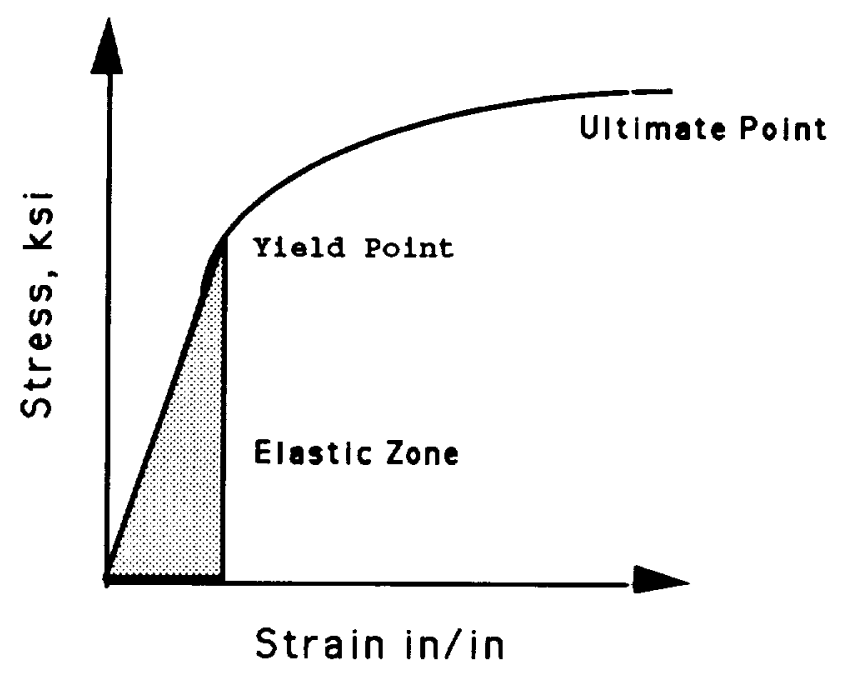

Figure 4. Normal stress-normal strain curve. 
The initial linear portion of the stress-strain diagram is the linear elastic region in which the stress is directly proportional to the strain. This relationship is known as Hooke's law. The ratio of stress to strain in a uniaxial specimen is known as the modulus of elasticity or Young's modulus. The application of a load in a uniaxial direction also causes a contraction in the transverse direction for all homogenous, isotropic materials. The absolute value of the ratio of the lateral strain and the axial strain is Poisson's ratio.

Shear strains are produced in a material by the action of shearing stresses. The shear stress-shear strain diagram is similar to the normal uniaxial relationship in figure 4 , having a linear and nonlinear region. In the linear region the shear stress and shear strain are also proportional; the constant of proportionality is called the shear modulus. The shear modulus is related to the modulus of elasticity as:

$$
G=\frac{E}{2(1+v)}
$$

where $E$ is Young's modulus, $v$ is Poisson's ratio, and $G$ is the shear modulus.

The three-dimensional stress-strain relationships derived from the superposition of 1-D Hooke's laws and Poisson's ratio effects are written as follows:

$$
\begin{gathered}
\varepsilon_{x}=\frac{1}{E}\left[\sigma_{x}-v\left(\sigma_{y}+\sigma_{z}\right)\right], \\
\varepsilon_{y}=\frac{1}{E}\left[\sigma_{y}-v\left(\sigma_{x}+\sigma_{z}\right)\right], \\
\varepsilon_{z}=\frac{1}{E}\left[\sigma_{z}-v\left(\sigma_{x}+\sigma_{y}\right)\right], \\
\gamma_{x y}=G \tau_{x y}, \\
\gamma_{y z}=G \tau_{y z}, \\
\gamma_{x z}=G \tau_{x z} .
\end{gathered}
$$

If only normal stresses are applied to a three-dimensional element, a change in the element volume will result. This volume change can be written in terms of the normal strains as:

$$
\frac{\Delta V}{V}=\varepsilon_{x}+\varepsilon_{y}+\varepsilon_{z}
$$

From equations (2a) through (2f) and (3), the sum of the three normal elastic strains is proportional to the sum of the three normal stress components and is given by:

$$
\varepsilon_{x}+\varepsilon_{y}+\varepsilon_{z}=\frac{1-2 v}{E}\left(\sigma_{x}+\sigma_{y}+\sigma_{z}\right)
$$




\section{B. Inelastic Solutions}

The stress-strain equations for the inelastic analysis to be performed are similar to the linear elastic equations discussed in the previous section. The derivation of the equations to be used can be found in any one of numerous text books addressing the field of incremental strain theory. The equations presented here can be found in reference 9 . Following the procedure in reference 9 , the incremental strain equations for the plastic (inelastic) stress-strain region may be written as:

$$
\begin{gathered}
d \varepsilon_{x}^{p}=\frac{F\left(\tau_{o}\right)}{3 \tau_{o}}\left[\sigma_{x}-\frac{1}{2}\left(\sigma_{y}+\sigma_{z}\right)\right] d \tau_{o}, \\
d \varepsilon_{y}^{p}=\frac{F\left(\tau_{o}\right)}{3 \tau_{o}}\left[\sigma_{y}-\frac{1}{2}\left(\sigma_{x}+\sigma_{z}\right)\right] d \tau_{o}, \\
d \varepsilon_{z}^{p}=\frac{F\left(\tau_{o}\right)}{3 \tau_{o}}\left[\sigma_{z}-\frac{1}{2}\left(\sigma_{x}+\sigma_{y}\right)\right] d \tau_{o}, \\
d \gamma_{x y}^{p}=\frac{F\left(\tau_{o}\right)}{\tau_{o}} \tau_{x y} d \tau_{o}, \\
d \gamma_{y z}^{p}=\frac{F\left(\tau_{o}\right)}{\tau_{o}} \tau_{y z} d \tau_{o}, \\
d \gamma_{z x}^{p}=\frac{F\left(\tau_{o}\right)}{\tau_{o}} \tau_{z x} d \tau_{o},
\end{gathered}
$$

where $F\left(\tau_{o}\right)$ is a function of $\tau_{o}$, the octahedral shear stress. The octahedral shearing stress can be expressed as follows in terms of the normal and shear stress :

$$
\tau_{o}=\frac{1}{3} \sqrt{\left(\sigma_{x}-\sigma_{y}\right)^{2}+\left(\sigma_{y}-\sigma_{z}\right)^{2}+\left(\sigma_{z}-\sigma_{y}\right)^{2}+6\left(\tau_{x y}^{2}+\tau_{y z}^{2}+\tau_{z x}^{2}\right)} .
$$

These stress-strain relations are for loading only and differ from equations (5a) through (5f), the linear stress-strain relations, in the following manner:

1. The engineering strain $\varepsilon_{x}, \varepsilon_{y}, \varepsilon_{z}$ and $\gamma_{x y}, \gamma_{x z}, \gamma_{z y}$ have been replaced by incremental strains $d \varepsilon_{x}^{p}, d \varepsilon_{y}^{p}, d \varepsilon_{z}^{p}$ and $d \gamma_{x y}^{p}, d \gamma_{x z}^{p}, d \gamma_{y z}^{p} ;$

2. Young's Modulus has been replaced by $\frac{3 \tau_{o}}{F\left(\tau_{o}\right)} d \tau_{o}$; and,

3. Poisson's ratio, $v$, has been set equal to $1 / 2$ for all materials.

Bridgman's experiments ${ }^{10}$ substantiated the claim that the change in unit volume due to the increments of plastic strain must be zero. The resulting plastic Poisson's ratio can be computed by 
considering the sum of the incremental strains in terms of an unknown plastic Poisson's ratio as follows: By adding equations (5a) through $(5 c)$ we have

$$
d \varepsilon_{x}^{p}+d \varepsilon_{y}^{p}+d \varepsilon_{z}^{p}=\frac{F\left(\tau_{o}\right)}{3 \tau_{o}}\left[\sigma_{x}-v_{p l}\left(\sigma_{y}+\sigma_{z}\right)+\sigma_{y}-v_{p l}\left(\sigma_{x}+\sigma_{z}\right)+\sigma_{z}-v_{p l}\left(\sigma_{y}+\sigma_{x}\right)\right] d \tau_{o},
$$

which can be rewritten as

$$
d \varepsilon_{x}^{p}+d \varepsilon_{y}^{p}+d \varepsilon_{z}^{p}=\frac{F\left(\tau_{o}\right)}{3 \tau_{o}}\left(1-2 v_{p l}\right)\left(\sigma_{x}+\sigma_{y}+\sigma_{z}\right) d \tau_{o} .
$$

Since the left-hand side of the equation must equal zero, it must follow that $v_{p l}=1 / 2$. This relationship is referred to as the constant-volume assumption.

In order to apply the plastic stress-strain equations, the function $F\left(\tau_{o}\right)$ must be developed. The function $F\left(\tau_{o}\right)$ is a material property and, like most structural material properties, can be derived from a simple tensile test in which $\sigma_{y}=\sigma_{z}=0$, and loads are applied only in the $\sigma_{x}$ direction. In such a case, the octahedral shear stress can be written as:

$$
\tau_{o}=\frac{1}{3} \sqrt{\left(\sigma_{x}\right)^{2}+\left(\sigma_{x}\right)^{2}}=\frac{\sqrt{2}}{3} \sigma_{x},
$$

from which it follows that

$$
d \tau_{o}=\frac{\sqrt{2}}{3} d \sigma_{x}
$$

Now, consider the plastic stress-strain equation for $d \varepsilon_{x}^{p}$, given by equation (5a). For the uniaxial tensile test, the following values are substituted into this equation: $\tau_{o}=\frac{\sqrt{2}}{3} \sigma_{x}, d \tau_{o}=\frac{\sqrt{2}}{3} d \sigma_{x}, \sigma_{y}=\sigma_{z}=0$. The result is as follows:

$$
d \varepsilon_{x}^{p}=\frac{F\left(\frac{\sqrt{2}}{3} \sigma_{x}\right)}{3\left(\frac{\sqrt{2}}{3} \sigma_{x}\right)}\left(\sigma_{x}\right) d\left(\frac{\sqrt{2}}{3} \sigma_{x}\right)=\frac{1}{3} F\left(\frac{\sqrt{2}}{3} \sigma_{x}\right) d \sigma_{x} .
$$

It is shown in reference 9 that a simple tension test can be used to define a function $f\left(\frac{\sqrt{2}}{3} \sigma_{x}\right)$ which is related to $d \varepsilon_{x}^{p}$ through the following equation:

$$
f\left(\frac{\sqrt{2}}{3} \sigma_{x}\right)=\sqrt{2} \varepsilon_{x}^{p}
$$


Taking the derivative of both sides of equation (10a) yields the following equation for incremental plastic strain $d \varepsilon_{x}^{p}$ :

$$
d \varepsilon_{x}^{p}=\frac{1}{3} f^{\prime}\left(\frac{\sqrt{2}}{3} \sigma_{x}\right) d \sigma_{x} .
$$

Equating equations (9) and (10b) gives

$$
F\left(\frac{\sqrt{2}}{3} \sigma_{x}\right)=f^{\prime}\left(\frac{\sqrt{2}}{3} \sigma_{x}\right) .
$$

Therefore, $F\left(\tau_{o}\right)$ is related to $f\left(\tau_{o}\right)$ as follows:

$$
F\left(\tau_{o}\right)=f^{\prime}\left(\tau_{o}\right)=\frac{d f\left(\tau_{o}\right)}{d \tau_{o}} .
$$

Making use of equation (12), equations (5a) through (5f) can be integrated to yield total permanent stresses and strains, as follows:

$$
\begin{gathered}
\varepsilon_{x}^{p}=\frac{f\left(\tau_{o}\right)}{3 \tau_{o}}\left[\sigma_{x}-\frac{1}{2}\left(\sigma_{y}+\sigma_{z}\right)\right], \\
\varepsilon_{y}^{p}=\frac{f\left(\tau_{o}\right)}{3 \tau_{o}}\left[\sigma_{y}-\frac{1}{2}\left(\sigma_{x}+\sigma_{z}\right)\right], \\
\varepsilon_{z}^{p}=\frac{f\left(\tau_{o}\right)}{3 \tau_{o}}\left[\sigma_{z}-\frac{1}{2}\left(\sigma_{x}+\sigma_{y}\right)\right], \\
\gamma_{x y}^{p}=\frac{f\left(\tau_{o}\right)}{\tau_{o}} \tau_{x y}, \\
\gamma_{y z}^{p}=\frac{f\left(\tau_{o}\right)}{\tau_{o}} \tau_{y z}, \\
\gamma_{z x}^{p}=\frac{f\left(\tau_{o}\right)}{\tau_{o}} \tau_{z x} .
\end{gathered}
$$

These equations constitute the "incremental" or "flow" theory for plastic stress-strain relations. The actual form of the function $f\left(\tau_{o}\right)$ will be derived in the rext section. Experimental results from references 11 and 12 indicate that incremental strain theory provides satisfactory accuracy when small strain values are considered. Thus the accuracy of equations (13a) through (13f) is considered sufficient for the analyses to be performed as part of this study. 


\section{ANALYSIS OF A WELD SINGLE-ZONE MATERIAL PROPERTY COUPON USING INCREMENTAL STRAIN THEORY}

A nonlinear analytical method is developed in this section for a single-zone material specimen. The geometry and material of the specimen considered is presented in figure 5.

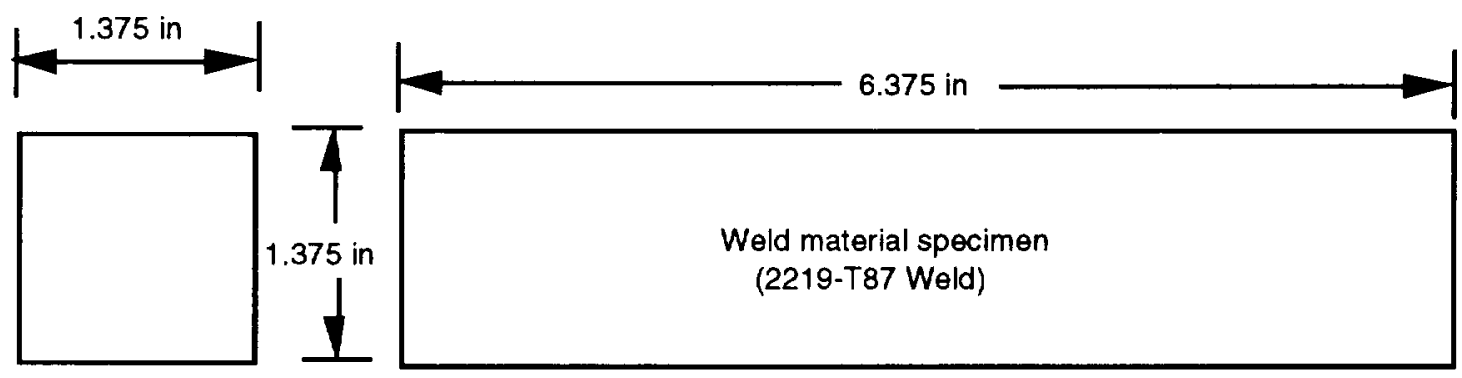

Figure 5. Geometry of single-zone specimen.

The stress-strain curve of the aluminum 2219-T87 weld based on experimental data is shown in figure 6. As indicated in figure 6, the yield stress of the weld material is approximately $10,000 \mathrm{lb} / \mathrm{in}^{2}$. In order to perform the analysis required, it is first necessary to determine an expression for the function $f\left(\tau_{o}\right)$. This function is derived for the weld stress-strain curve in figure 6 as follows.

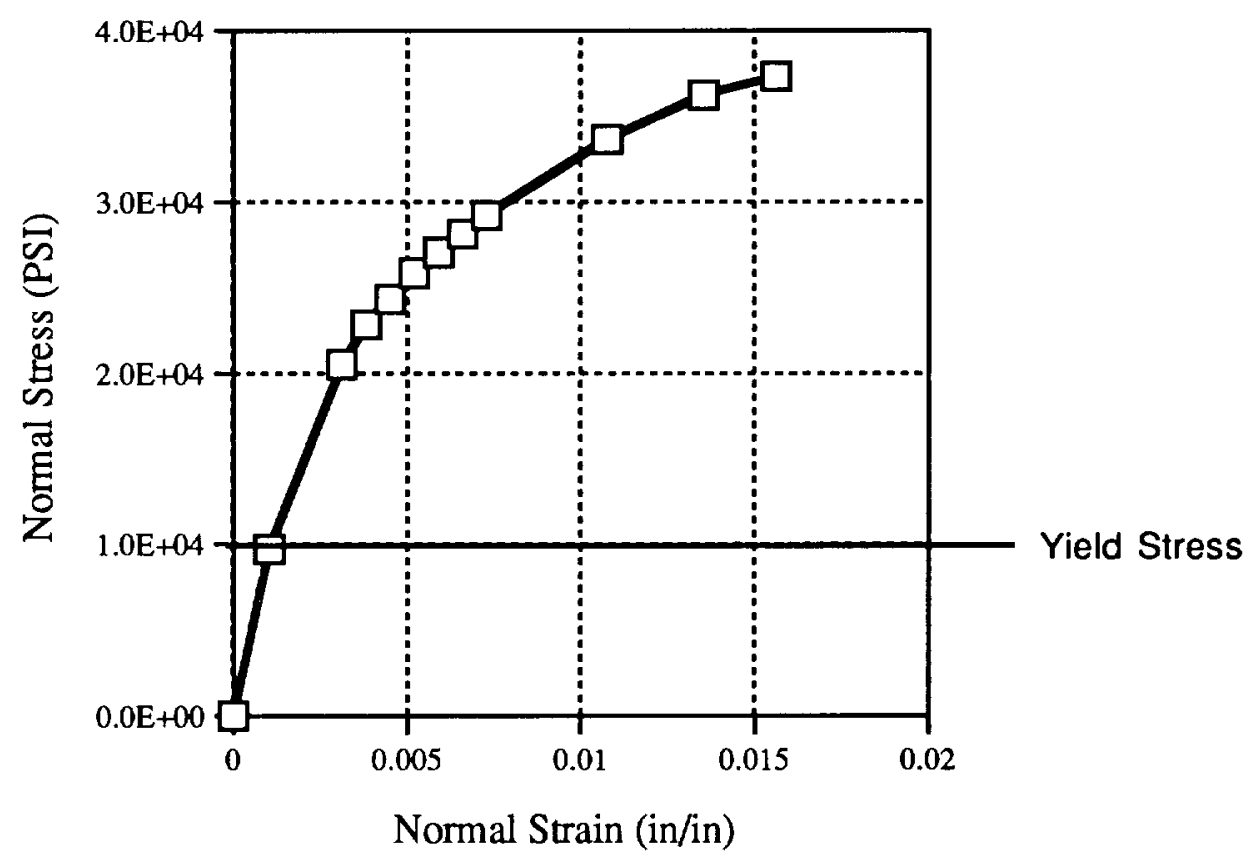

Figure 6. Weld material properties.

Following the procedure in reference 9, we define the generalized plastic strain in terms of incremental plastic strains as follows: 


$$
d \Gamma^{\prime \prime}=\frac{2}{\sqrt{3}} \sqrt{d \varepsilon_{x}^{p 2}+d \varepsilon_{y}^{p 2}+d \varepsilon_{z}^{p 2}+\frac{1}{2}\left(d \gamma_{x y}^{p 2}+d \gamma_{y z}^{p 2}+d \gamma_{z x}^{p 2}\right)} .
$$

Making use of equations (5a) through (5f) and assuming uniaxial loading, equation (14a) defines a uniaxial generalized plastic strain as follows:

$$
d \Gamma_{o}^{\prime \prime}=\frac{2}{\sqrt{3}} \sqrt{\left[\frac{F\left(\tau_{o}\right)}{3 \tau_{o}} \sigma_{x} d \tau_{o}\right]^{2}+\left[\frac{F\left(\tau_{o}\right)}{3 \tau_{o}}\left(-\frac{1}{2} \sigma_{x}\right) d \tau_{o}\right]^{2}+\left[\frac{F\left(\tau_{o}\right)}{3 \tau_{o}}\left(-\frac{1}{2} \sigma_{x}\right) d \tau_{o}\right]^{2}} .
$$

This reduces to

$$
\sqrt{2} d \Gamma_{o}^{\prime \prime}=2 \frac{F\left(\tau_{o}\right)}{3 \tau_{o}} \sigma_{x} d \tau_{o}
$$

When $\tau_{o}=\frac{\sqrt{2}}{3} \sigma_{x}$ is substituted into the above equation the result is,

$$
d \Gamma_{o}^{\prime \prime}=F\left(\tau_{o}\right) d \tau_{o} .
$$

Since, $F\left(\tau_{o}\right)=f^{\prime}\left(\tau_{o}\right)$, equation (14d) becomes

$$
d \Gamma_{o}^{\prime \prime}=f^{\prime}\left(\tau_{o}\right) d \tau_{o} .
$$

Finally both sides of equation (14e) can be integrated to yield

$$
\Gamma_{o}^{\prime \prime}=\int d \Gamma_{o}^{\prime \prime}=\int f^{\prime}\left(\tau_{o}\right) d \tau_{o}=f\left(\tau_{o}\right) .
$$

Thus the quantity $\Gamma_{o}^{\prime \prime}$ is in fact the function $f\left(\tau_{o}\right)$. Continuing the procedure in reference 9 , the quantity $\Gamma_{o}^{\prime \prime}$ is expressed in terms of plastic strain as follows:

$$
\Gamma_{o}^{\prime \prime}=\sqrt{2}\left(\varepsilon_{x}^{p}\right),
$$

where,

$$
\varepsilon_{x}^{p}=\varepsilon_{x}^{\text {total }}-\varepsilon_{x}^{\text {linear }}
$$

and

$$
\varepsilon_{x}^{\text {linear }}=\frac{\sigma_{x}}{E}
$$

Thus, $\Gamma_{o}^{\prime \prime}$ is written as

$$
\Gamma_{o}^{\prime \prime}=\sqrt{2}\left(\varepsilon_{x}^{\text {toat }}-\frac{\sigma_{x}}{E}\right)
$$


Using the data from figure 6, the following stress-strain curve (fig. 7) is now obtained in terms of $\tau_{o}$ and $\Gamma_{0}^{\prime \prime}:$

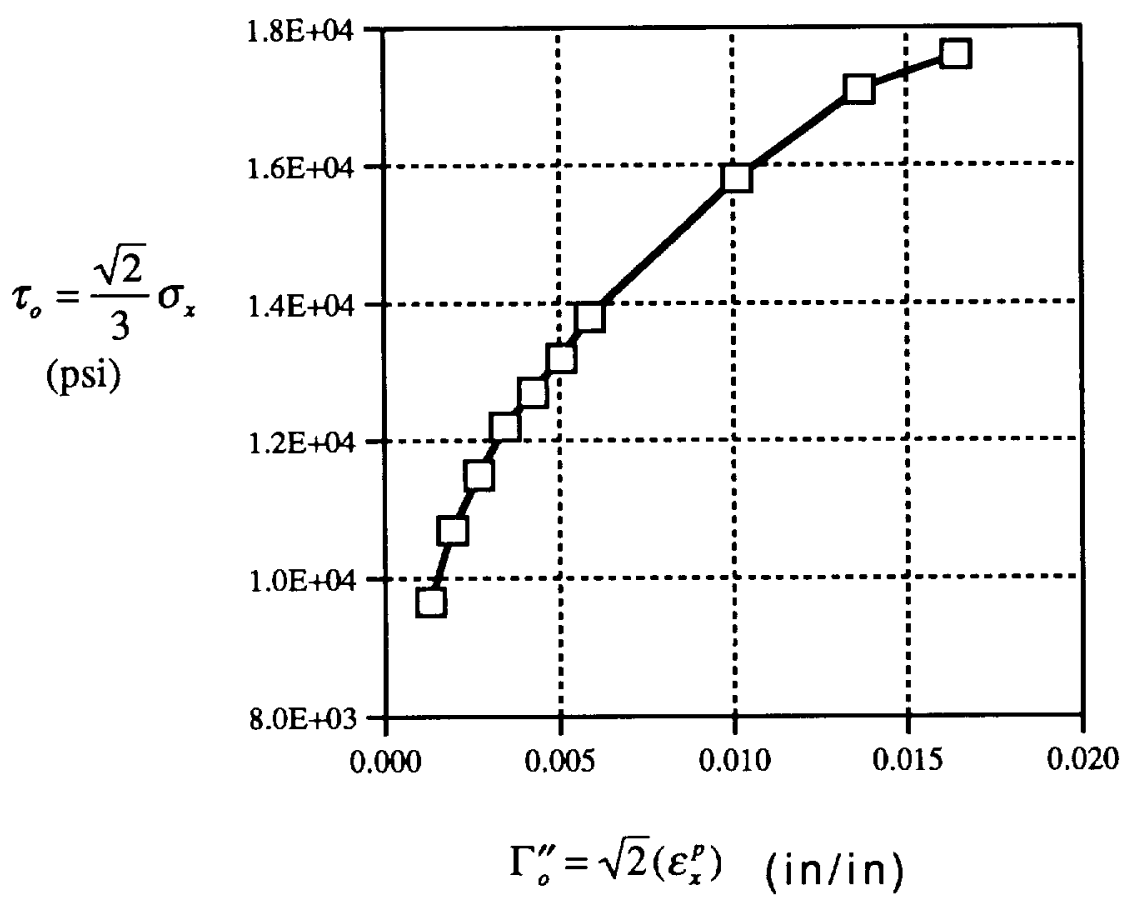

Figure 7. Generalized weld properties.

The shape of the generalized stress-strain curve suggests that $\tau_{o}$ can be written in terms of $\Gamma_{o}^{\prime \prime}$ as $\tau_{o}=a\left(\Gamma_{o}^{\prime \prime}\right)^{b}$. As illustrated in figure 8 , the log plot of the data does in fact yield a reasonably straight line. (It will be shown that the slight imperfection in the line will have negligible effects on the accuracy of the solution.)

To find the value of $a$ and $b$ consider the equation of a straight line, that is, $y=m x+b$. This equation can be applied to figure 8 in the form $\log \left(\tau_{o}\right)=b\left(\log \left(\Gamma_{o}^{\prime \prime}\right)\right)+\log (a)$. Then the slope of the straight line in figure 8 is $b$ and the value of $\log \left(\tau_{0}\right)$ when $\log \left(\Gamma_{o}^{\prime \prime}\right)=0$ is $\log (a)$. Using the data in figure 8 , we have

$$
b=\frac{\log (17.6 e 3)-\log (9.66 e 3)}{\log (1.64 e-2)-\log (1.30 e-3)}=\frac{\log \left(\frac{17.6}{9.66}\right)}{\log \left(\frac{.0164}{.0013}\right)}=\frac{0.261}{1.101}=0.2371
$$

Continuing to solve for the value of $a$ :

$$
a=\frac{\tau_{o}}{\left(\Gamma_{o}^{\prime \prime}\right)^{b}}=\left(\frac{9.183 \times 10^{3}}{(0.0010)^{0.237}}\right)=47.21 \times 10^{3}
$$




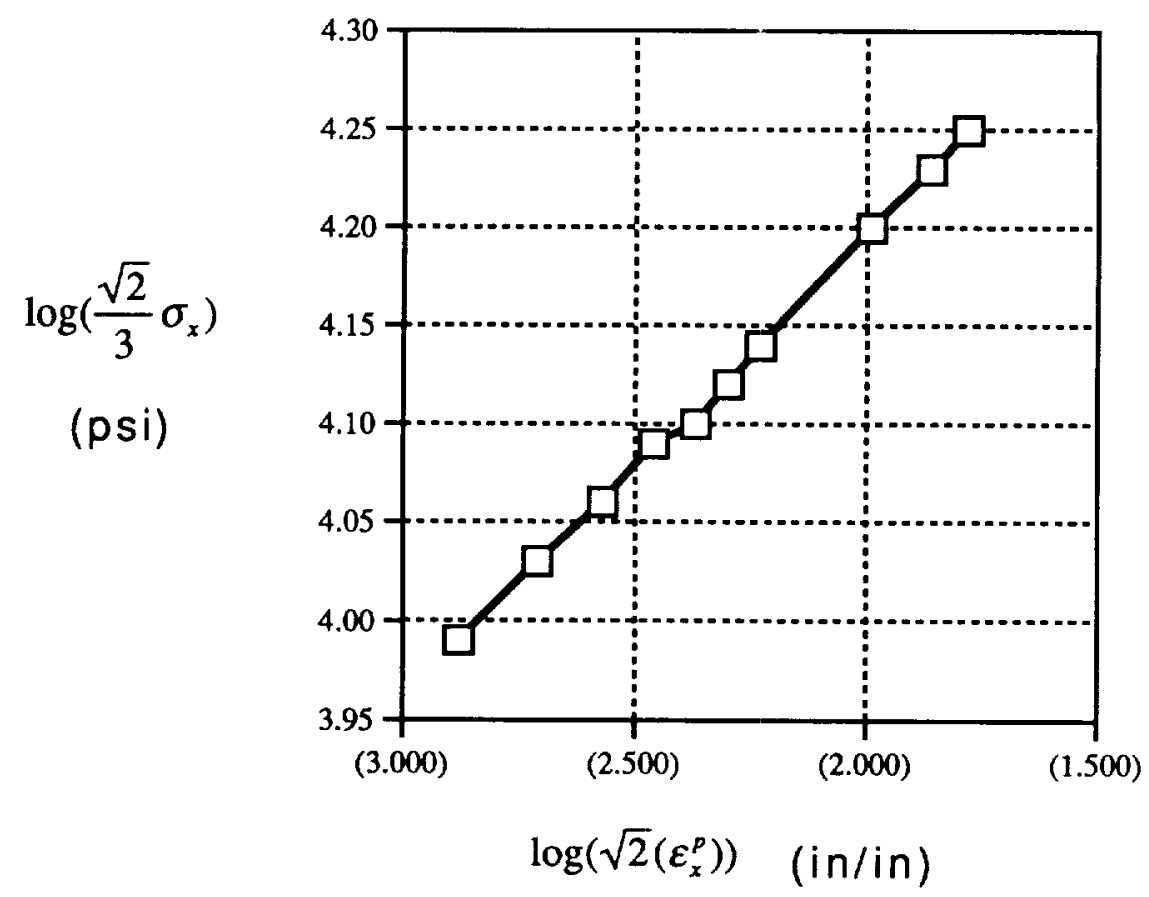

Figure 8. Log-log plot of generalized weld properties.

Thus, the equation for the generalized stress-strain curve for the weld material is:

$$
\tau_{o}=47.21 \times 10^{3}\left(\Gamma_{o}^{\prime \prime}\right)^{0.237} .
$$

Figure 9 shows a comparison of equation (19) with the test data from figure 7.

As can be seen in figure 9, the results of equation (19) compare very well with the experimental data. Following the procedure in reference 9 , this equation can now be combined with the plastic stressstrain equations (13a) through (13f) as follows.

First we write:

$$
\tau_{o}=\frac{\sqrt{2}}{3} \sigma_{x}=a\left(\Gamma_{o}^{\prime \prime}\right)^{l} .
$$

Then making use of equation (15),

From which it follows that

$$
f\left(\tau_{o}\right)=\Gamma_{o}^{\prime \prime}=\left(\frac{\sqrt{2}}{3 a} \sigma_{x}\right)^{\prime} .
$$

$$
\frac{f\left(\tau_{o}\right)}{3 \tau_{o}}=\frac{\left(\frac{\sqrt{2}}{3 a} \sigma_{x}\right)^{\frac{1}{b}}}{\sqrt{2} \sigma_{x}}
$$




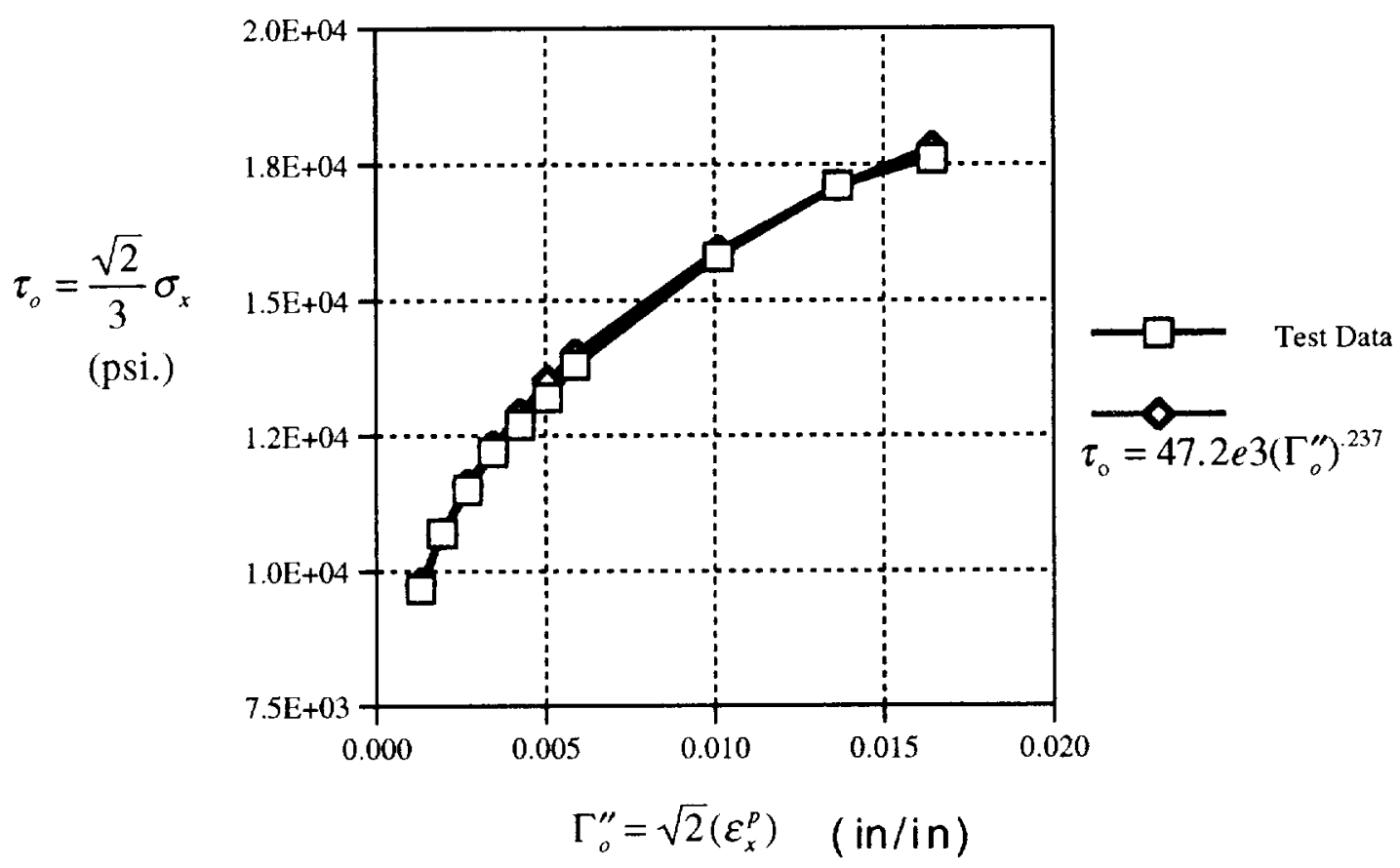

Figure 9. Comparison of test data to equation for the weld material.

Substituting equation (21) into (13a) through (13f), the plastic stress-strain equations can then be written as:

$$
\begin{aligned}
\varepsilon_{x}^{p}= & \frac{\left(\frac{\sqrt{2}}{3 a} \sigma_{x}\right)^{\frac{1}{b}}}{\sqrt{2} \sigma_{x}}\left[\sigma_{x}-\frac{1}{2}\left(\sigma_{y}+\sigma_{z}\right)\right], \\
\varepsilon_{y}^{p}= & \frac{\left(\frac{\sqrt{2}}{3 a} \sigma_{x}\right)^{\frac{1}{b}}}{\sqrt{2} \sigma_{x}}\left[\sigma_{y}-\frac{1}{2}\left(\sigma_{x}+\sigma_{z}\right)\right], \\
\varepsilon_{z}^{p}= & \frac{\left(\frac{\sqrt{2}}{3 a} \sigma_{x}\right)^{\frac{1}{b}}}{\sqrt{2} \sigma_{x}}\left[\sigma_{z}-\frac{1}{2}\left(\sigma_{x}+\sigma_{y}\right)\right], \\
\gamma_{x y}^{p}= & \frac{\left(\frac{\sqrt{2}}{3 a} \sigma_{x}\right)^{\frac{1}{b}}}{\sqrt{2} \sigma_{x}} 3 \tau_{x y},
\end{aligned}
$$




$$
\begin{aligned}
& \gamma_{y z}^{p}=\frac{\left(\frac{\sqrt{2}}{3 a} \sigma_{x}\right)^{\frac{1}{b}}}{\sqrt{2} \sigma_{x}} 3 \tau_{y z}, \\
& \gamma_{z x}^{p}=\frac{\left(\frac{\sqrt{2}}{3 a} \sigma_{x}\right)^{\frac{1}{b}}}{\sqrt{2} \sigma_{x}} 3 \tau_{z x} .
\end{aligned}
$$

Figure 10 compares the results of equation (22a) with $\sigma_{y}=\sigma_{z}=0$ and the experimental stress-strain data from figure 6.

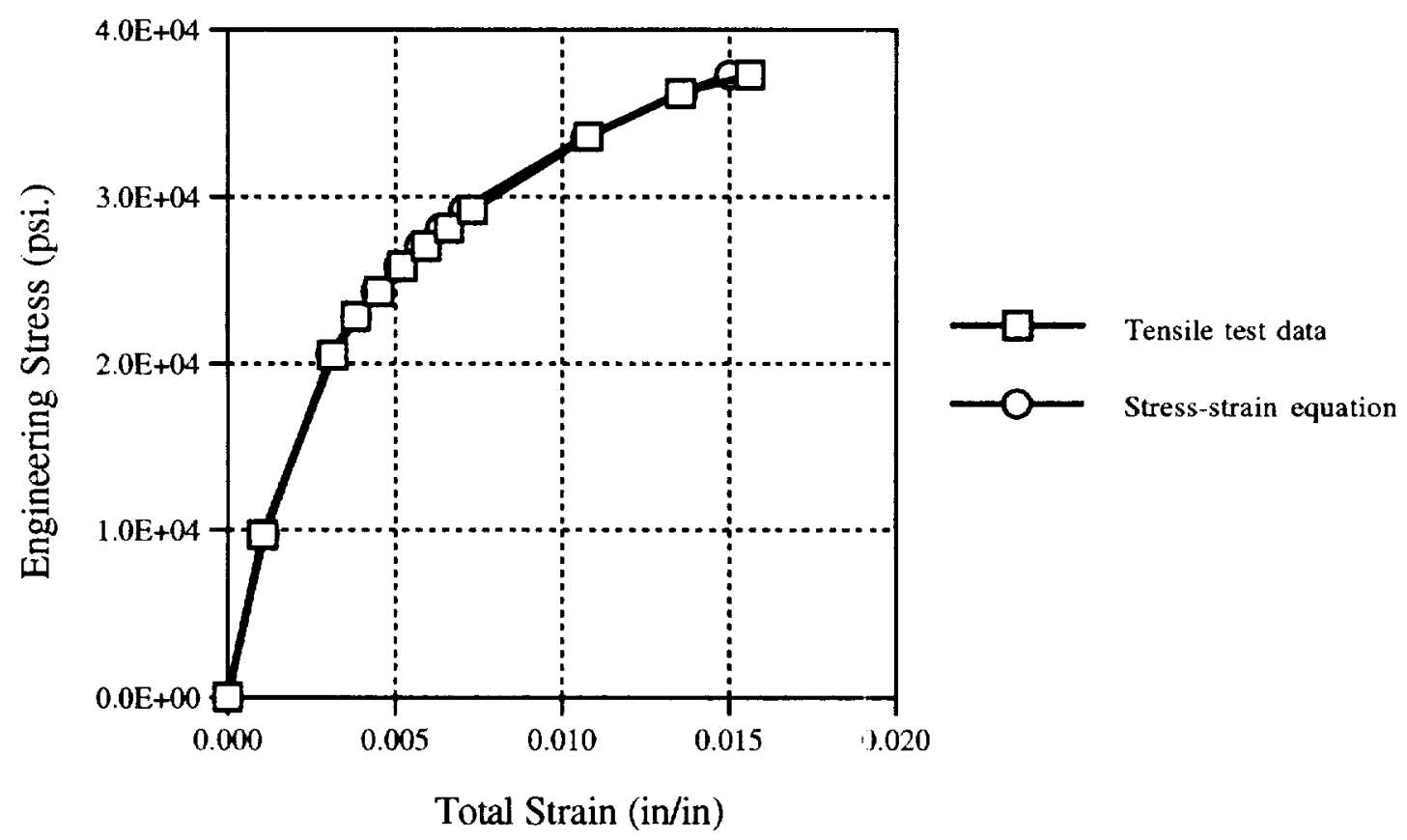

Figure 10. Comparison of test data to equation from incremental strain theory. test data.

As can be seen in figure 10 , the inelastic analytical tquations compare very well to the tensile

The next step is to develop a finite element model of a tensile test specimen and compare its predictions to both this 1-D analytical solution and the tensile test data. The finite-element model and the 1-D analysis will be used to develop the more complicated finite element model of the multizone test specimen in section IV. 


\section{COMPUTATIONAL ANALYSIS OF A TENSILE TEST SPECIMEN}

\section{A. Introductory Comments}

In correlating the analytical, computational, and test results, the goal is to systematically develop a model of a multiple-zone material weld. The single-zone model will be used as a benchmark to develop the more complex multiple-zone model. The material property data input into the finite-element code will be verified by comparison to the previously developed analytical solution and the tensile test data. The methods developed and verified for the single-zone material model will then be repeated for the multiple-zone material model.

\section{B. The Finite-Element Model for One Material Property in the Tensile Test Specimen}

The finite-element analysis program $A B A Q U S$ (version 5.2) is used to model the behavior of a single-zone material test specimen. The mesh geometry of the finite-element model is illustrated in figure 11 .
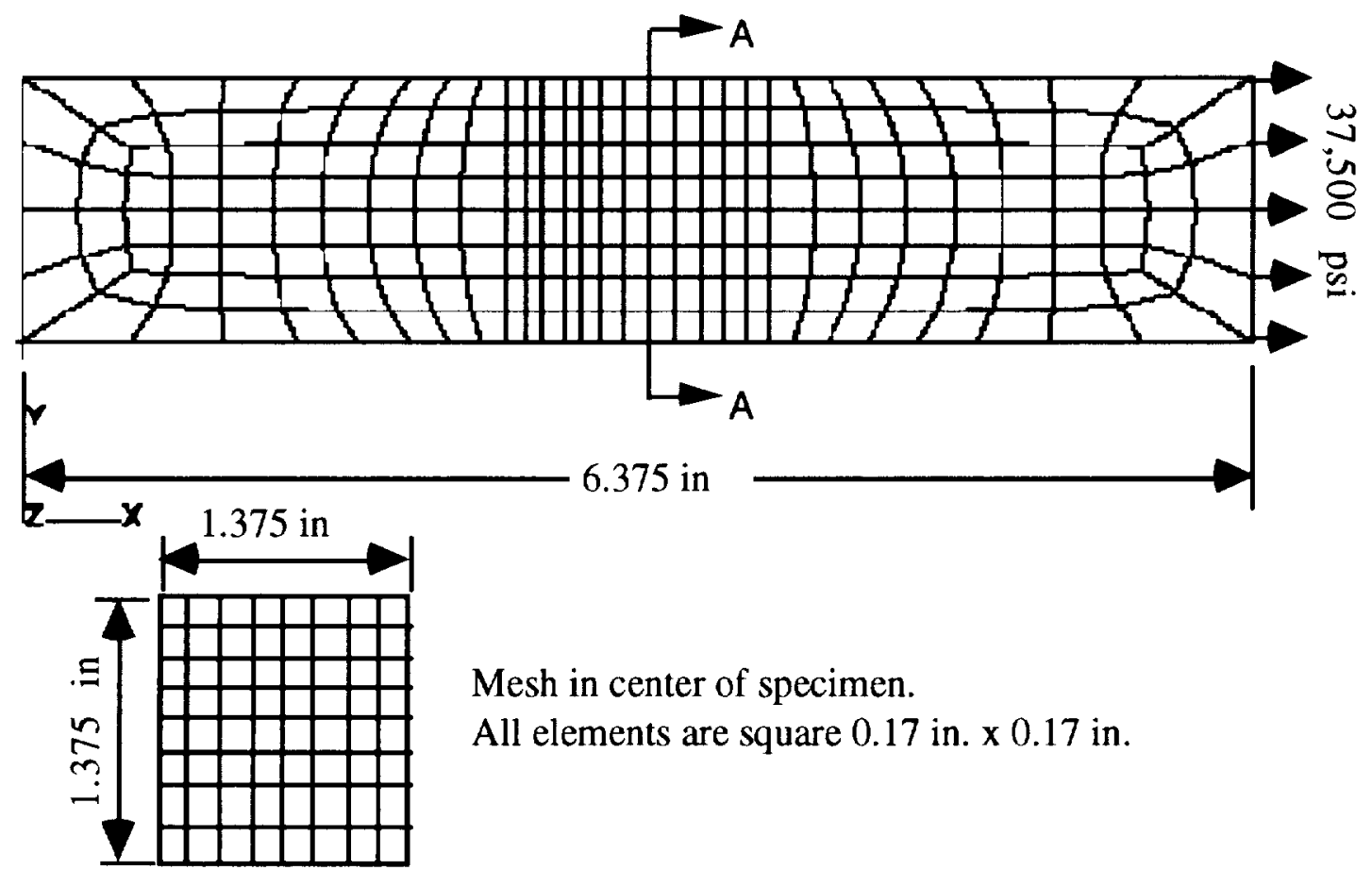

Section A-A

Figure 11. Finite-element model for single-zone material model.

The mesh geometry was developed to provide a high element density in the center of the specimen. Eight brick elements are used through the thickness and the width of the element; each element has an aspect ratio of 1:1. Each node at the left end is constrained in all six degrees of freedom. The loads are applied in 20 load increments from 0 to a maximum load of $37,500 \mathrm{lb} / \mathrm{in}^{2}$.

The computational solution requires the development of material properties to input into the finite-element code. $A B A Q U S$ requires all stress and strain input data in true-stress and true-strain terms. 
The engineering stress-strain curve shown in figure 12 does not give "true" deformation characteristics because it is based on the original dimensions of the test specimen. During a test, the original dimensions are continuously changing until the specimen becomes unstable and necks down before ultimate failure. The true stress value is based on the actual cross-sectional area of the specimen. The true stress versus true strain curve indicates that the stress-strain curve increases monotonically until the specimen fractures.

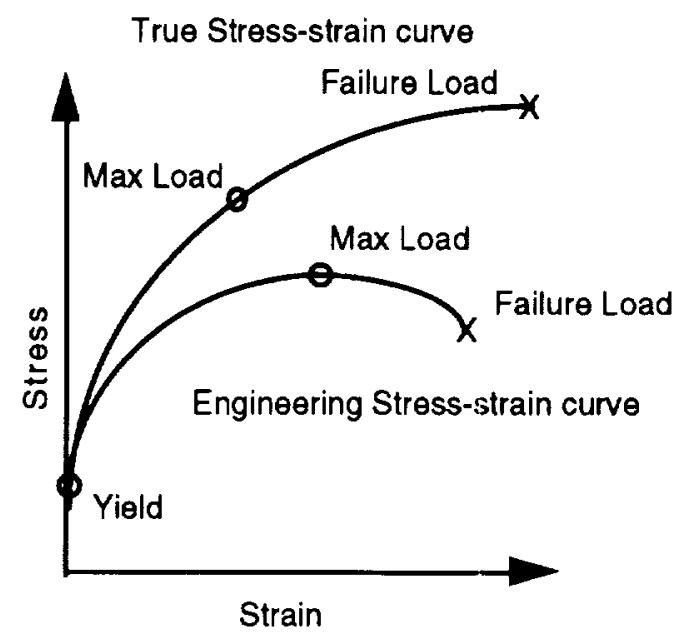

Figure 12. Stress-strain curve to illustrate true stress and true strain concept.

The true-stress equation is derived assuming the volume of the test specimen remains constant or $\varepsilon_{x}^{p}+\varepsilon_{y}^{p}+\varepsilon_{z}^{p}=0$. This equation is only good until necking or unstable stress begins to appear in the specimen.

True stress, $\sigma^{\text {sue }}$, is expressed in terms of the engineering stress, $\sigma$, by:

$$
\sigma^{\text {true }}=\sigma(\varepsilon+1),
$$

where

$$
\sigma=\frac{P}{A_{o}},
$$

is the engineering stress. The true strain, $\varepsilon^{\text {true }}$, may be determined from the engineering strain, $\varepsilon$, by:

$$
\varepsilon^{\text {true }}=\ln (\varepsilon+1) .
$$

Figure 13 shows a plot of the true stress-true strain data and the engineering stress-engineering strain for the weld material properties (fig. 6). Apparently, the difference between the "true" data and the "engineering" data is small for the strain levels considered in this study.

In addition to requiring true-stress and true-strain input data, $A B A Q U S$ requires that the numerical value of strain at the yield point must be zero. Therefore, the linear portion of strain must be subtracted from total strain as shown in equation (25). 


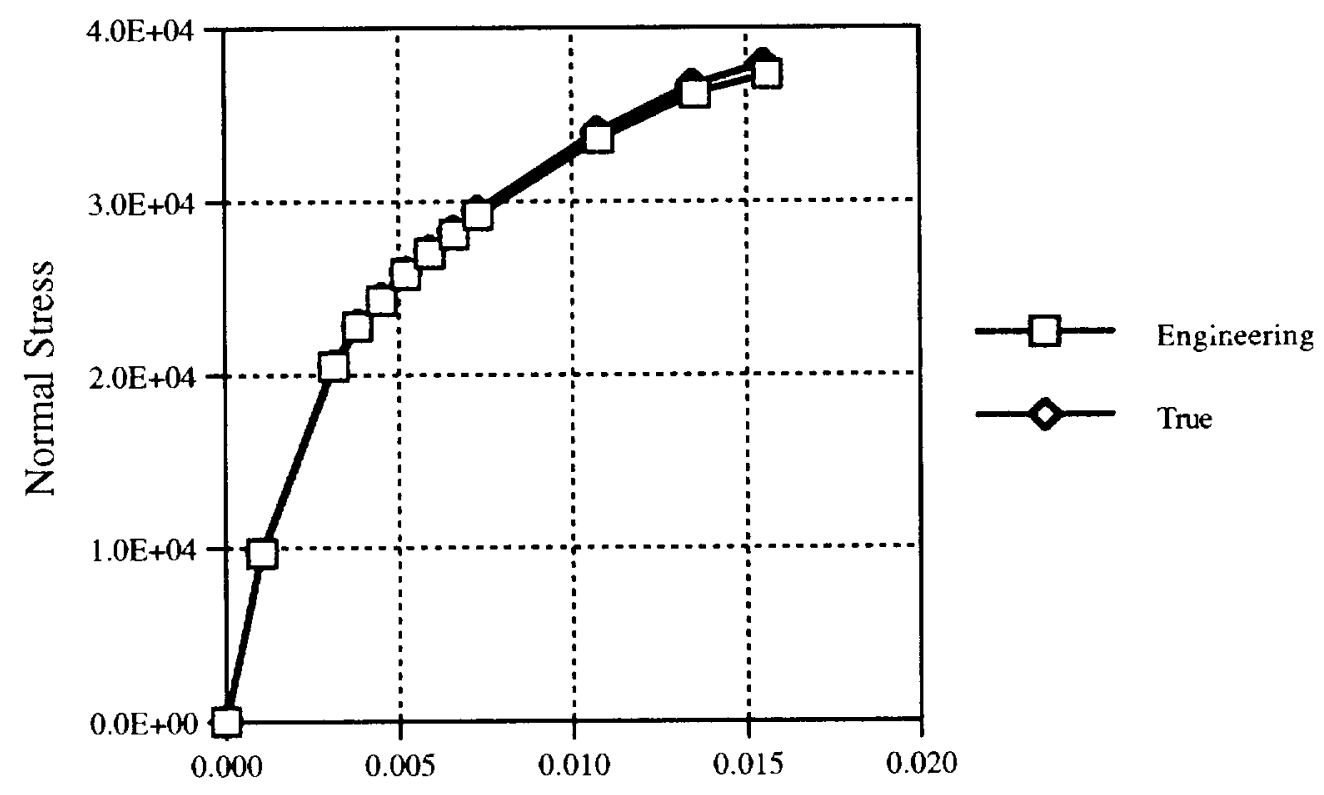

Normal Strain

Figure 13. Comparison of true stress-strain data to engineering stress-strain data for the weld.

$$
\varepsilon^{\text {inue }}=\ln (\varepsilon+1)-\left(\frac{\sigma}{E}\right)
$$

The equations to convert the engineering stress-strain data into $A B A Q U S$ compatible data is given by equations (23) and (25). The ABAQUS*PLASTIC solution was chosen for this analysis because it is an incremental plasticity solution in which the mechanical strain rate is decomposed into an elastic part and a plastic (inelastic) part. This solution is consistent with the incremental-strain theory discussed previously. The *PLASTIC option is used to specify the plastic part of the material model for elastic-plastic materials that use the Mises or Hill yield surface. The ABAQUS input data for the *PLASTIC option is given in table 1.

Table 1. Weld material properties (ABAQUS *PLASTIC option)

\begin{tabular}{|c|r|r|c|r|r|}
\hline Strain & \multicolumn{1}{|c|}{ Stress } & True Strain & True Stress & \multicolumn{2}{|c|}{ *PLASTIC } \\
\hline $0.00 \mathrm{E}+00$ & 0 & $0.00 \mathrm{E}+00$ & 0 & & \\
$1.04 \mathrm{E}-03$ & 9,700 & $-7.66 \mathrm{E}-07$ & 9,710 & $0.00 \mathrm{E}+00$ & 9,710 \\
$3.13 \mathrm{E}-03$ & 20,500 & $9.18 \mathrm{E}-04$ & 20,564 & $9.18 \mathrm{E}-04$ & 20,564 \\
$3.82 \mathrm{E}-03$ & 22,800 & $1.36 \mathrm{E}-03$ & 22,887 & $1.36 \mathrm{E}-03$ & 22,887 \\
$4.51 \mathrm{E}-03$ & 24,300 & $1.89 \mathrm{E}-03$ & 24,410 & $1.89 \mathrm{E}-03$ & 24,410 \\
$5.21 \mathrm{E}-03$ & 25,800 & $2.42 \mathrm{E}-03$ & 25,934 & $2.42 \mathrm{E}-03$ & 25,934 \\
$5.90 \mathrm{E}-03$ & 27,000 & $2.99 \mathrm{E}-03$ & 27,159 & $2.99 \mathrm{E}-03$ & 27,159 \\
$6.60 \mathrm{E}-03$ & 28,100 & $3.56 \mathrm{E}-03$ & 28,285 & $3.56 \mathrm{E}-03$ & 28,285 \\
$7.29 \mathrm{E}-03$ & 29,200 & $4.13 \mathrm{E}-03$ & 29,413 & $4.13 \mathrm{E}-03$ & 29,413 \\
$1.08 \mathrm{E}-02$ & 33,600 & $7.10 \mathrm{E}-03$ & 33,962 & $7.10 \mathrm{E}-03$ & 33,962 \\
$1.35 \mathrm{E}-02$ & 36,200 & $9.56 \mathrm{E}-03$ & 36,690 & $9.56 \mathrm{E}-03$ & 36,690 \\
$1.56 \mathrm{E}-02$ & 37,300 & $1.15 \mathrm{E}-02$ & 37,883 & $1.15 \mathrm{E}-02$ & 37,883 \\
\hline
\end{tabular}




\section{Results of the Finite-Element Analysis for a Single-Zone Material Property Test Specimen}

The finite-element model is verified by a series of checks contained in the preprocessor and postprocessor code PATRAN 3.0 . PATRAN is used to create and process the entire finite-element model.

The results of the finite-element model for plastic strain are compared to both analytical equation predictions and tensile test data. The analytical values are obtained by using equations (20a) through (20f), with $a=47.21 \times 10^{3}$ and $b=0.237$. Table 2 compares the analytical predictions and the ABAQUS results. These results are plotted in figure 14. As evident in figure 14, the agreement is excellent between the predictions of the analytical model and the predictions of the $A B A Q U S$ model. Furthermore, it is noted that the data in table 2 shows the constant-volume rule is maintained by the analytical solution and the computational solution. This in turn implies that the Poisson's ratio for plastic strain calculations must be 0.5 .

Table 2. Comparison of analytical and computational methods.

\begin{tabular}{|c|c|c|c|c|c|c|c|}
\hline \multicolumn{4}{|c|}{ Analytical Equations } & \multicolumn{4}{|c|}{$A B A Q U S$ results (Converted to English data) } \\
\hline Strain $X$ & Strain $Y$ & Strain $Z$ & $\varepsilon_{x}^{p}+\varepsilon_{y}^{p}+\varepsilon_{z}^{p}$ & Strain $X$ & Strain $Y$ & Strain $Z$ & $\varepsilon_{x}^{p}+\varepsilon_{y}^{p}+\varepsilon_{z}^{p}$ \\
\hline $0.00 \mathrm{E}+00$ & $0.00 \mathrm{E}+00$ & $0.00 \mathrm{E}+00$ & 0.0000 & $0.00 \mathrm{E}+00$ & $0.00 \mathrm{E}+00$ & $0.00 \mathrm{E}+00$ & 0.0000 \\
\hline $3.63 \mathrm{E}-08$ & $-1.82 \mathrm{E}-08$ & $-1.82 \mathrm{E}-08$ & 0.0000 & $0.00 \mathrm{E}+00$ & $0.00 \mathrm{E}+00$ & $0.00 \mathrm{E}+00$ & 0.0000 \\
\hline $6.77 \mathrm{E}-07$ & $-3.38 E-07$ & $-3.38 \mathrm{E}-07$ & 0.0000 & $0.00 \mathrm{E}+00$ & $0.00 \mathrm{E}+00$ & $0.00 \mathrm{E}+00$ & 0.0000 \\
\hline $3.74 \mathrm{E}-06$ & $-1.87 \mathrm{E}-06$ & $-1.87 \mathrm{E}-06$ & 0.0000 & $0.00 \mathrm{E}+00$ & $0.00 \mathrm{E}+00$ & $0.00 \mathrm{E}+00$ & 0.0000 \\
\hline $1.26 \mathrm{E}-05$ & $-6.30 \mathrm{E}-06$ & $-6.30 \mathrm{E}-06$ & 0.0000 & $0.00 \mathrm{E}+\mathrm{C} 0$ & $0.00 \mathrm{E}+00$ & $0.00 \mathrm{E}+00$ & 0.0000 \\
\hline $3.23 \mathrm{E}-05$ & $-1.62 \mathrm{E}-05$ & $-1.62 \mathrm{E}-05$ & 0.0000 & $0.00 \mathrm{E}+\mathrm{C} 0$ & $0.00 \mathrm{E}+00$ & $0.00 \mathrm{E}+00$ & 0.0000 \\
\hline $6.97 \mathrm{E}-05$ & $-3.49 E-05$ & $-3.49 E-05$ & 0.0000 & $1.30 \mathrm{E}-0.4$ & $-6.51 E-05$ & $-6.51 E-05$ & 0.0000 \\
\hline $1.34 \mathrm{E}-04$ & $-6.68 E-05$ & $-6.68 E-05$ & 0.0000 & $2.89 \mathrm{E}-0.4$ & $-1.44 \mathrm{E}-04$ & $-1.44 \mathrm{E}-04$ & 0.0000 \\
\hline $2.34 \mathrm{E}-04$ & $-1.17 \mathrm{E}-04$ & $-1.17 \mathrm{E}-04$ & 0.0000 & $4.47 \mathrm{E}-0.4$ & $-2.24 \mathrm{E}-04$ & $-2.24 \mathrm{E}-04$ & 0.0000 \\
\hline $3.85 \mathrm{E}-04$ & $-1.93 \mathrm{E}-04$ & $-1.93 \mathrm{E}-04$ & 0.0000 & $6.06 \mathrm{E}-0.4$ & $-3.03 E-04$ & $-3.03 \mathrm{E}-04$ & 0.0000 \\
\hline $6.00 \mathrm{E}-04$ & $-3.00 E-04$ & $-3.00 \mathrm{E}-04$ & 0.0000 & $7.65 \mathrm{E}-0.4$ & $-3.82 \mathrm{E}-04$ & $-3.82 \mathrm{E}-04$ & 0.0000 \\
\hline $8.96 \mathrm{E}-04$ & $-4.48 E-04$ & $-4.48 E-04$ & 0.0000 & $9.30 \mathrm{E}-0.4$ & $-4.65 \mathrm{E}-04$ & $-4.65 \mathrm{E}-04$ & 0.0000 \\
\hline $1.29 \mathrm{E}-03$ & $-6.46 \mathrm{E}-04$ & $-6.46 \mathrm{E}-04$ & 0.0000 & $1.29 \mathrm{E}-03$ & $-6.43 E-04$ & $-6.43 E-04$ & 0.0000 \\
\hline $1.81 \mathrm{E}-03$ & $-9.03 E-04$ & $-9.03 E-04$ & 0.0000 & $1.88 \mathrm{E}-03$ & $-9.38 \mathrm{E}-04$ & $-9.38 E-04$ & 0.0000 \\
\hline $2.46 \mathrm{E}-03$ & $-1.23 E-03$ & $-1.23 \mathrm{E}-03$ & 0.0000 & $2.57 \mathrm{E}-03$ & $-1.28 \mathrm{E}-03$ & $-1.28 E-03$ & 0.0000 \\
\hline $3.28 \mathrm{E}-03$ & $-1.64 \mathrm{E}-03$ & $-1.64 \mathrm{E}-03$ & 0.0000 & $3.48 \mathrm{E}-0.3$ & $-1.74 \mathrm{E}-03$ & $-1.74 \mathrm{E}-03$ & 0.0000 \\
\hline $4.29 \mathrm{E}-03$ & $-2.15 \mathrm{E}-03$ & $-2.14 \mathrm{E}-03$ & 0.0000 & $4.52 \mathrm{E}-03$ & $-2.25 \mathrm{E}-03$ & $-2.25 \mathrm{E}-03$ & 0.0000 \\
\hline $5.51 \mathrm{E}-03$ & $-2.76 E-03$ & $-2.75 E-03$ & 0.0000 & $5.75 \mathrm{E}-03$ & $-2.87 \mathrm{E}-03$ & $-2.86 \mathrm{E}-03$ & 0.0000 \\
\hline $6.98 \mathrm{E}-03$ & $-3.49 E-03$ & $-3.49 \mathrm{E}-03$ & 0.0000 & $6.98 \mathrm{E}-03$ & $-3.48 \mathrm{E}-03$ & $-3.47 E-03$ & 0.0000 \\
\hline $8.70 \mathrm{E}-03$ & $-4.35 E-03$ & $-4.35 \mathrm{E}-03$ & 0.0000 & $8.63 \mathrm{E}-03$ & $-4.29 \mathrm{E}-03$ & $-4.29 E-03$ & 0.0001 \\
\hline $1.07 E-02$ & $-5.35 \mathrm{E}-03$ & $-5.34 \mathrm{E}-03$ & 0.0000 & $1.09 \mathrm{E}-02$ & $-5.42 E-03$ & $-5.41 E-03$ & 0.0001 \\
\hline
\end{tabular}

Figure 15 is a comparison of the tensile test data and the results from the computational analysis. The excellent agreement establishes that the method of developing the material model input for $A B A Q U S$ is correct.

The methods used to develop the single-zone material model will now be extended to develop a multiple-zone material model. The validity of the multiple-zone model will be determined by comparing the results of the multiple-zone model to experiment data obtained from reference 6. 


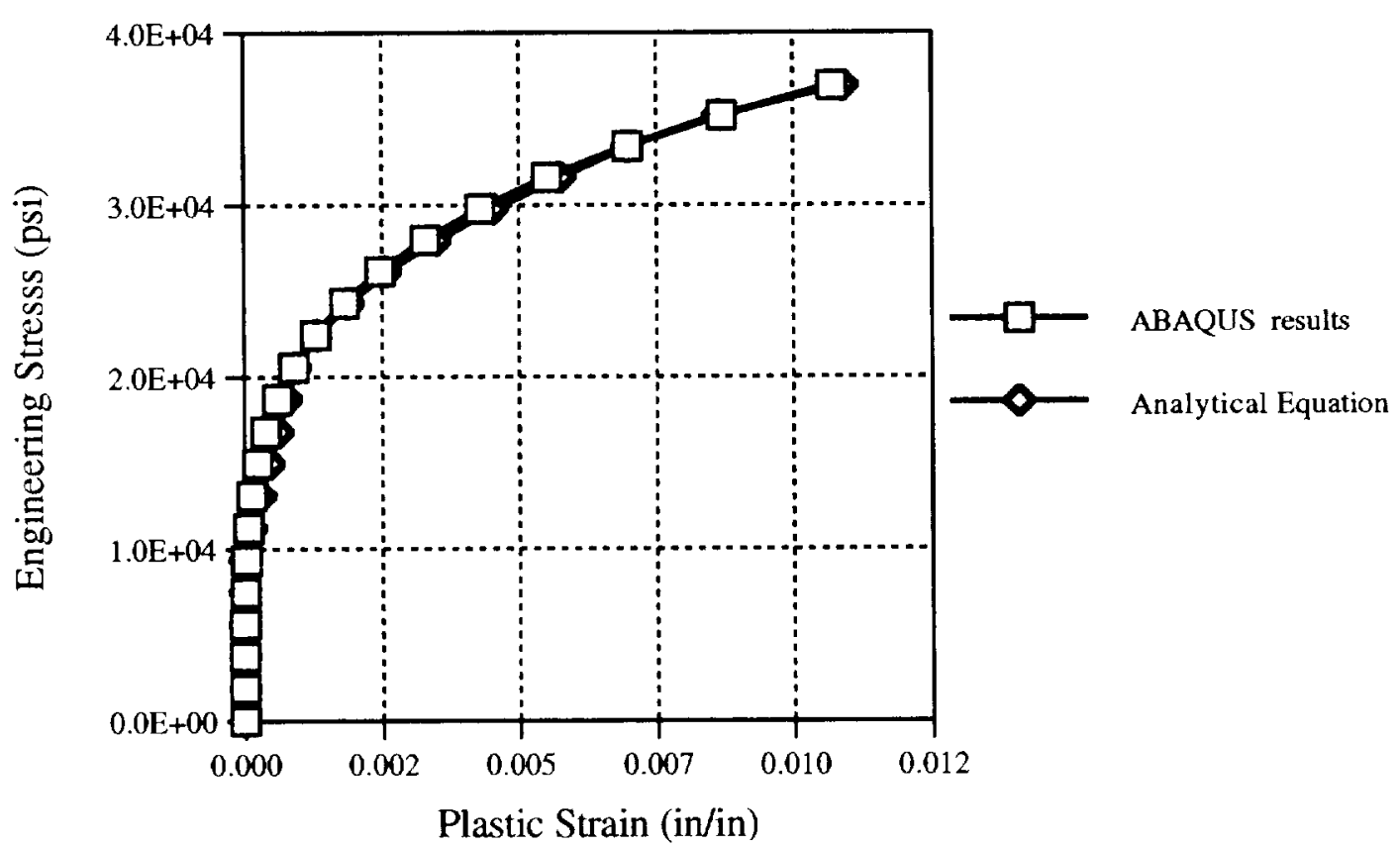

Figure 14. Comparison of computational results and analytical predictions.

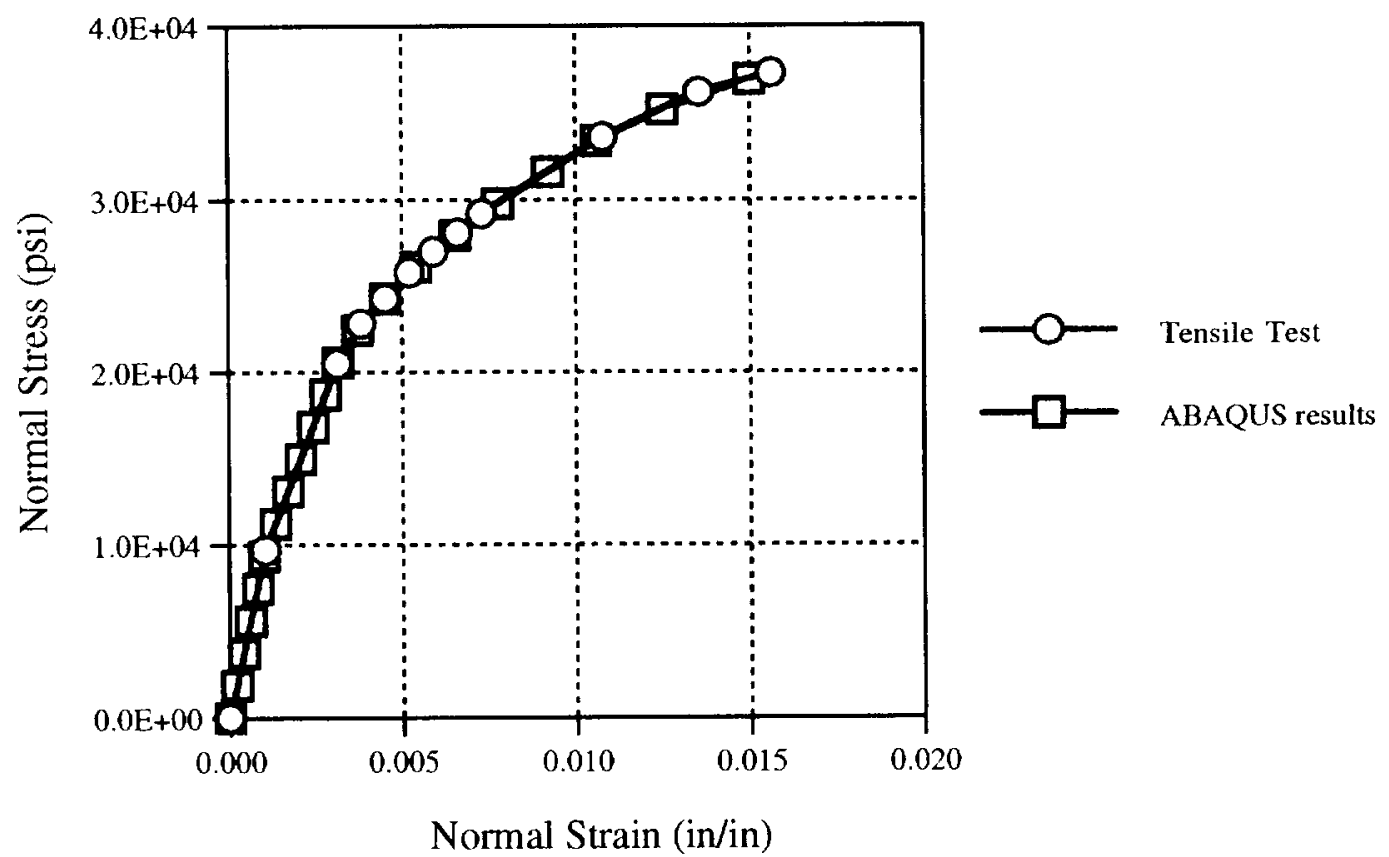

Figure 15. Comparison of computational results and tensile test results. 


\section{The Analysis of Multiple-Zone Material Properties in the Tensile Test Specimen}

1. Experimental Results. The geometry of the specimen to be considered for the computational models is illustrated in figure 16 . As can be seen in figure 16 , the specimen can have multiple material properties.

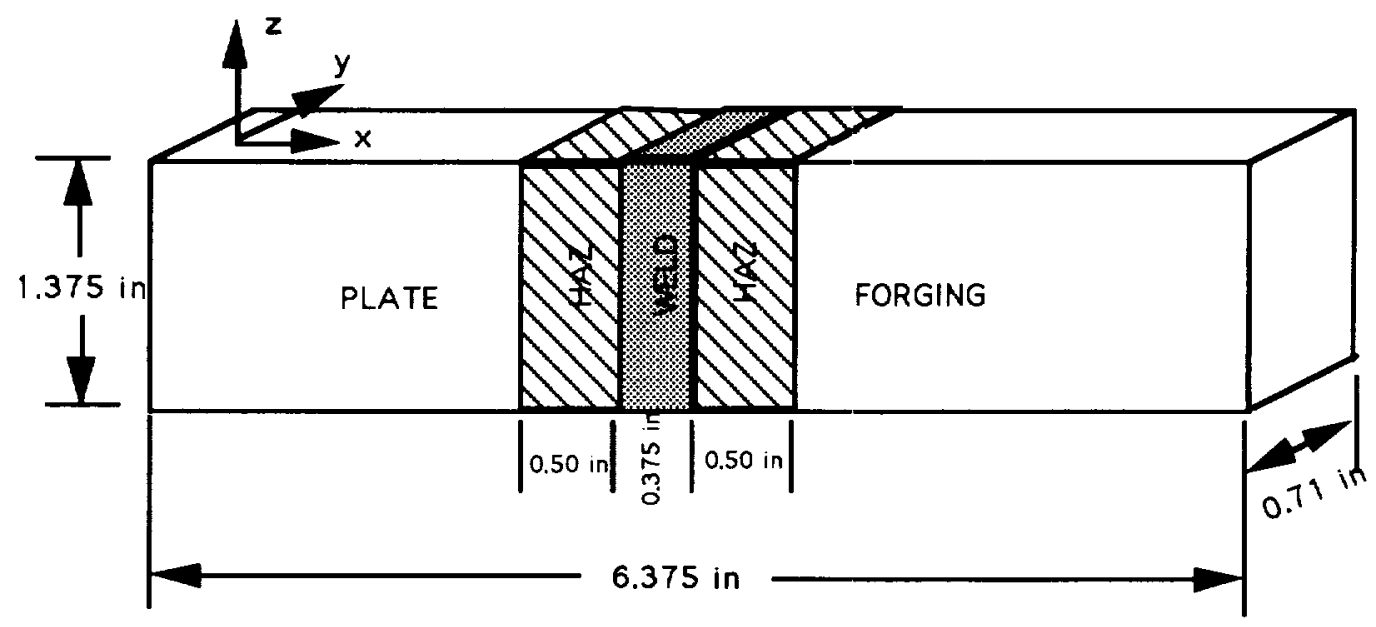

Figure 16. Geometry of multiple-zone test specimen.

The dimensions of the specimen were chosen to ensure that the plane stress $\left(\sigma_{y}=\sigma_{z}=0\right)$ condition was maintained when one material was used in the finite-element model. The nomenclature used in the development of the multiple-zone material specimen is illustrated in figure 17.

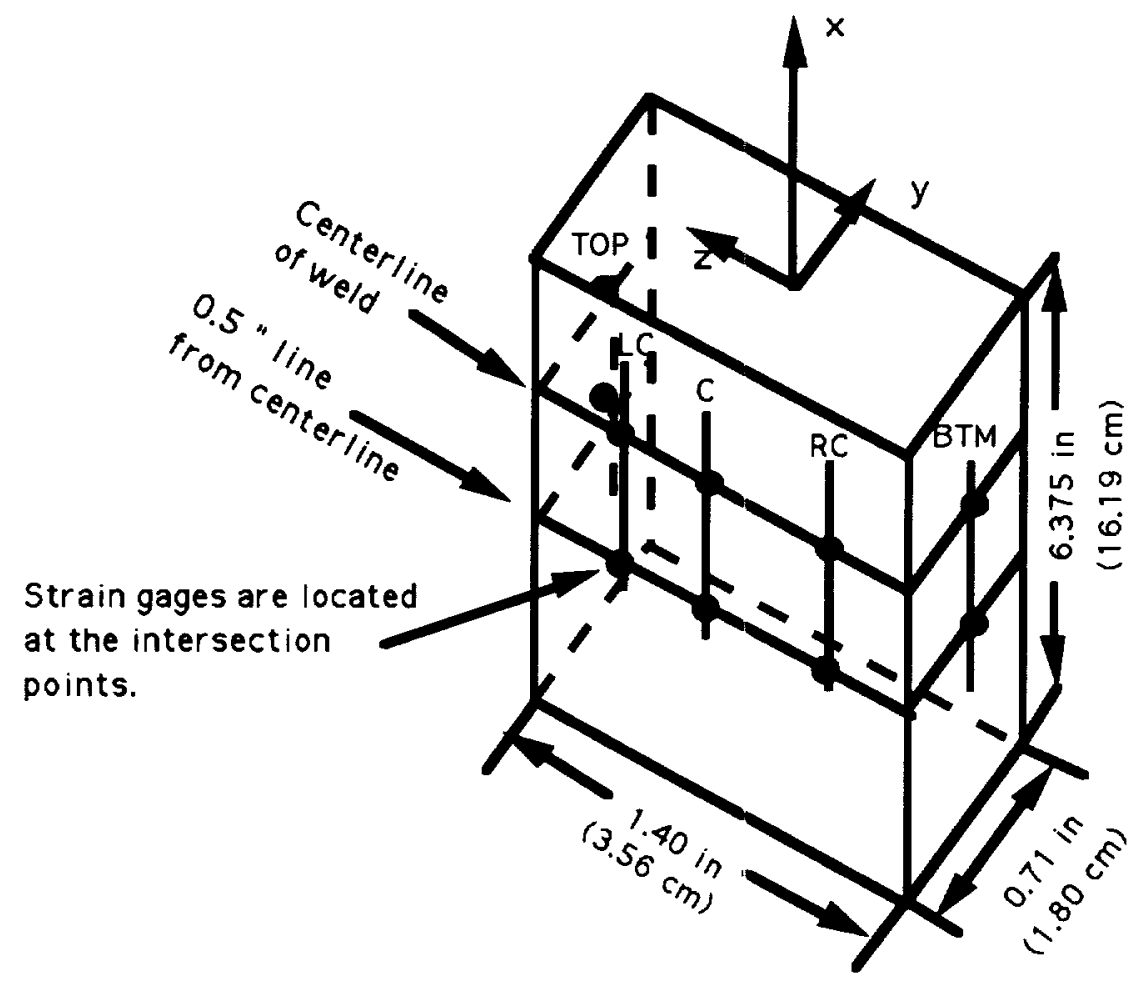

Figure 17. Strain gauge locations for the multiple-zone test specimen. 
Strain gauge data was collected at points along the centerline of the weld and at points $1 / 2$ inch from the centerline. The data points are referred to by the label of the intersecting lines, i.e., centerline at C.

Stress-strain curves were experimentally obtained for each of the intersection points shown in figure 17. Centerline curves are given in figure 18, while figure 19 shows the curves for the various locations $1 / 2$ inch away from the centerline. The data represents the average of two test specimens; no visible neckdown occurred during the test and the specimens were not loaded to failure. The strain values were recorded at increasing loads during each experiment, and the corresponding stress values were obtained by dividing the load by the initial area of the specimen. It should be noted that the experimental data indicate a variation in Young's modulus across the specimen. At the center of the specimen Young's modulus corresponds to the expected value for aluminum $\left(10.6 \times 10^{6} \mathrm{lb} / \mathrm{in}^{2}\right)$. However, at locations toward the $T O P$ of the specimen Young's modulus decreases to $6.7 \times 10^{6} \mathrm{lb} / \mathrm{in}^{2}$. Conversely at locations toward the BTM of the specimen Young's modulus increases to $15.6 \times 10^{6} \mathrm{lb} / \mathrm{in}^{2}$. This is an indication that the specimens were not in a uniform state of stress. For the purposes of this investigation, the experimental data will be used as is, recognizing that the material properties for this specimen are derived under a nonuniform state of stress. The stress-strain data was converted to the input format required by $A B A Q U S$ using the methods benchmarked in the previous section.

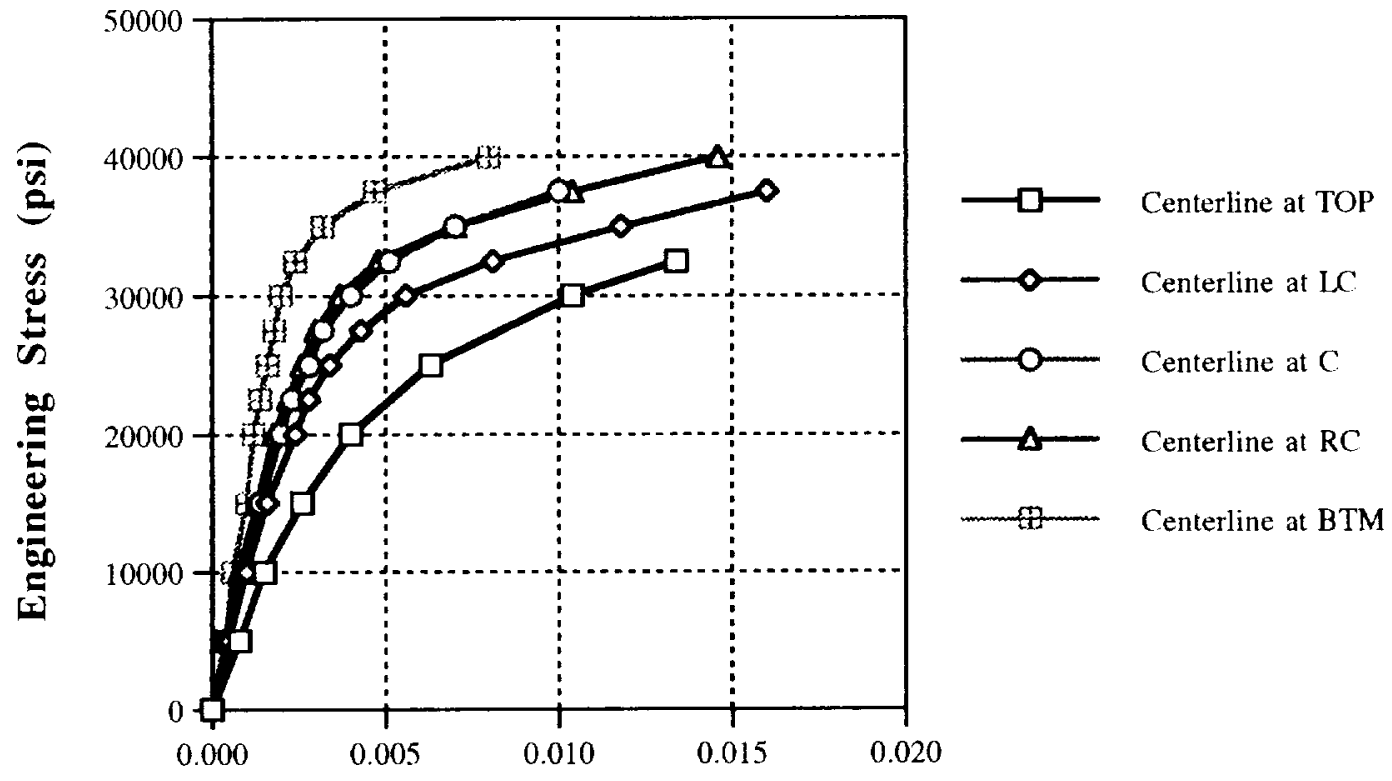

Engineering Strain (in/in)

Figure 18. Experimental stress-strain curve from the multiple-zone specimen at the centerline.

The data in figure 18 indicates a large variation in response along the centerline from the TOP side of the specimen to the BTM side. In addition, the data at the centerline of the weld is different than that at the $1 / 2$-in line. As can be seen in figure 19 , the data at the $1 / 2$-in line is more uniform than the data shown in figure 18. The material properties are expected to be more uniform at points away from the weld because eventually the data will become the uniform parent material properties. In fact, the data in figure 19 can be approximated by a single curve for stress values below $30 \mathrm{ksi}$. 


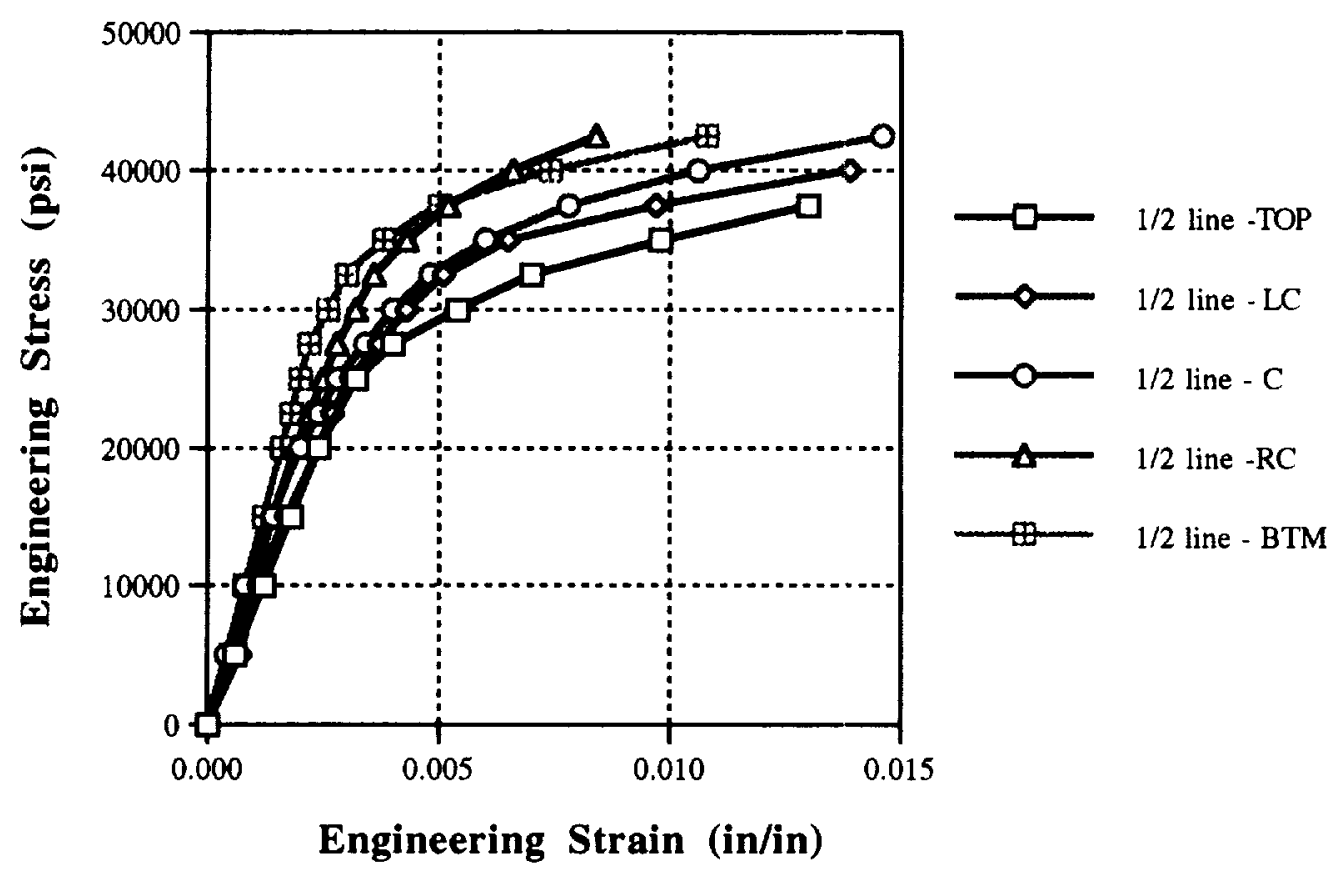

Figure 19. Experimental stress-strain curve from the multiple-zone specimen at the $1 / 2$-in line.

2. Finite-Element Modeling and Results for the Multiple-Zone Specimen. The finite-element model is composed of 16 elements from the TOP side to the BTM side of the specimen. The stress-strain data for locations between those at which experimental data were obtained are given by linear interpolation of the experimental data. For example, the strain at a location between TOP and $L C$ is calculated using the following set of equations:

$$
\begin{gathered}
\text { Strain }=\left[\frac{\Delta R}{R_{T O P}-R_{L C}}\left(N_{e}\right)\right]\left(\varepsilon_{T O P}-\varepsilon_{L C}\right), \\
\text { Young's Modulus }=\left[\frac{\Delta R}{R_{T O P}-R_{L C}}\left(N_{\iota}\right)\right]\left(E_{T O P}-E_{L C}\right),
\end{gathered}
$$

where $\Delta R$ is the length between elements, $N_{e}$ is the element increment number from $T O P$, and $R_{T O P}-R_{L C}$ is the length between TOP and $L C$. In this manner, the model provides a smooth transition between the various material properties.

The stiffness change associated with a sequential yield process induces a nonuniform stress field across the width of the specimen and produces bending in the specimen under an uniaxial loading. However, the tensile test equipment used to generate the data in figures 18 and 19 maintains alignment between the clamped and loading ends of the specimen. To n Imerically replicate the testing conditions, the specimen finite-element model was constrained laterally as shown in figure 20. 


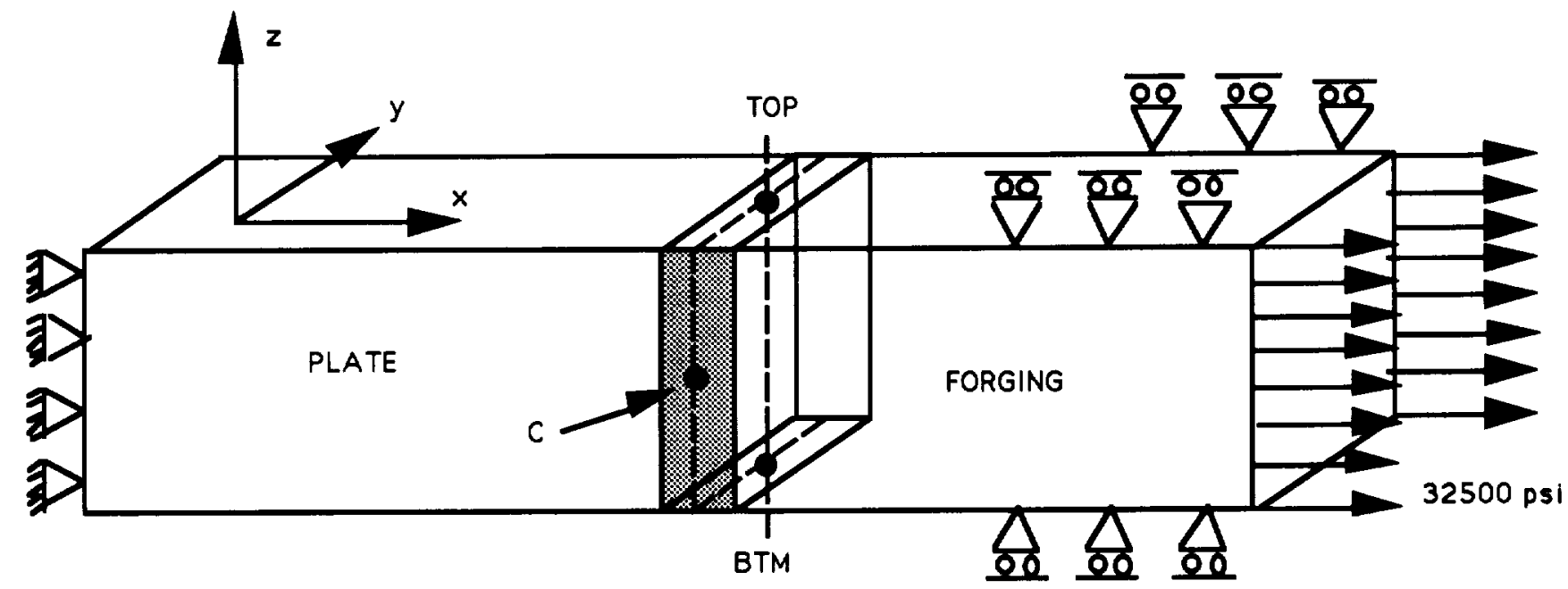

Figure 20. Illustration of the boundary conditions for the multiple-zone model.

The results of the finite-element model are compared to the experimental results across the centerline of the weld. Figures 21 through 24 compare experimental data to the finite-element predictions in the $X$ direction at the TOP, $C$, and $B T M$ locations, respectively. As can be seen in these figures, the $A B A Q U S$ results compared well to the experimental data in the direction of the load.

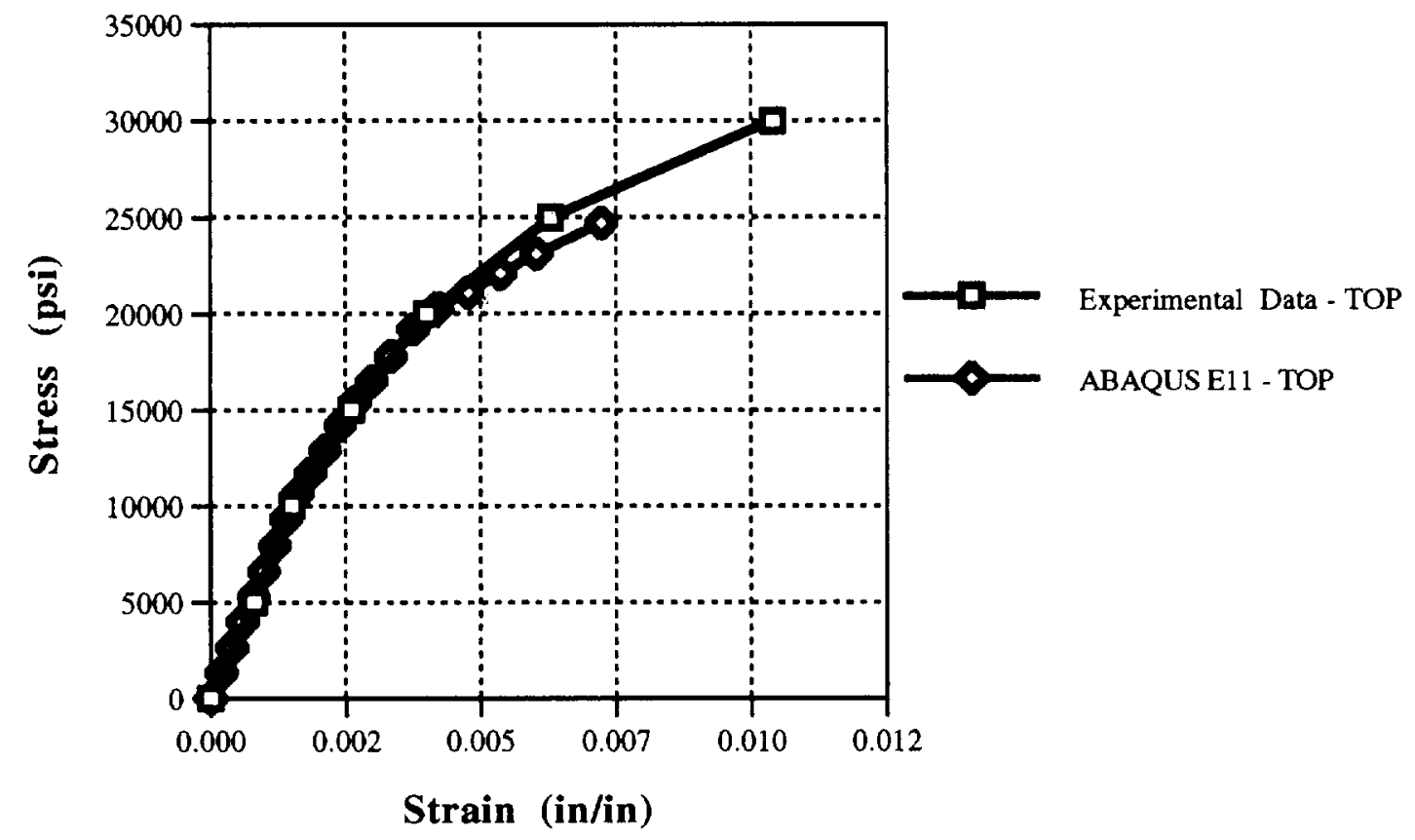

Figure 21. Comparison of $X$-direction experimental stress-strain values to finite-element results at the TOP. 


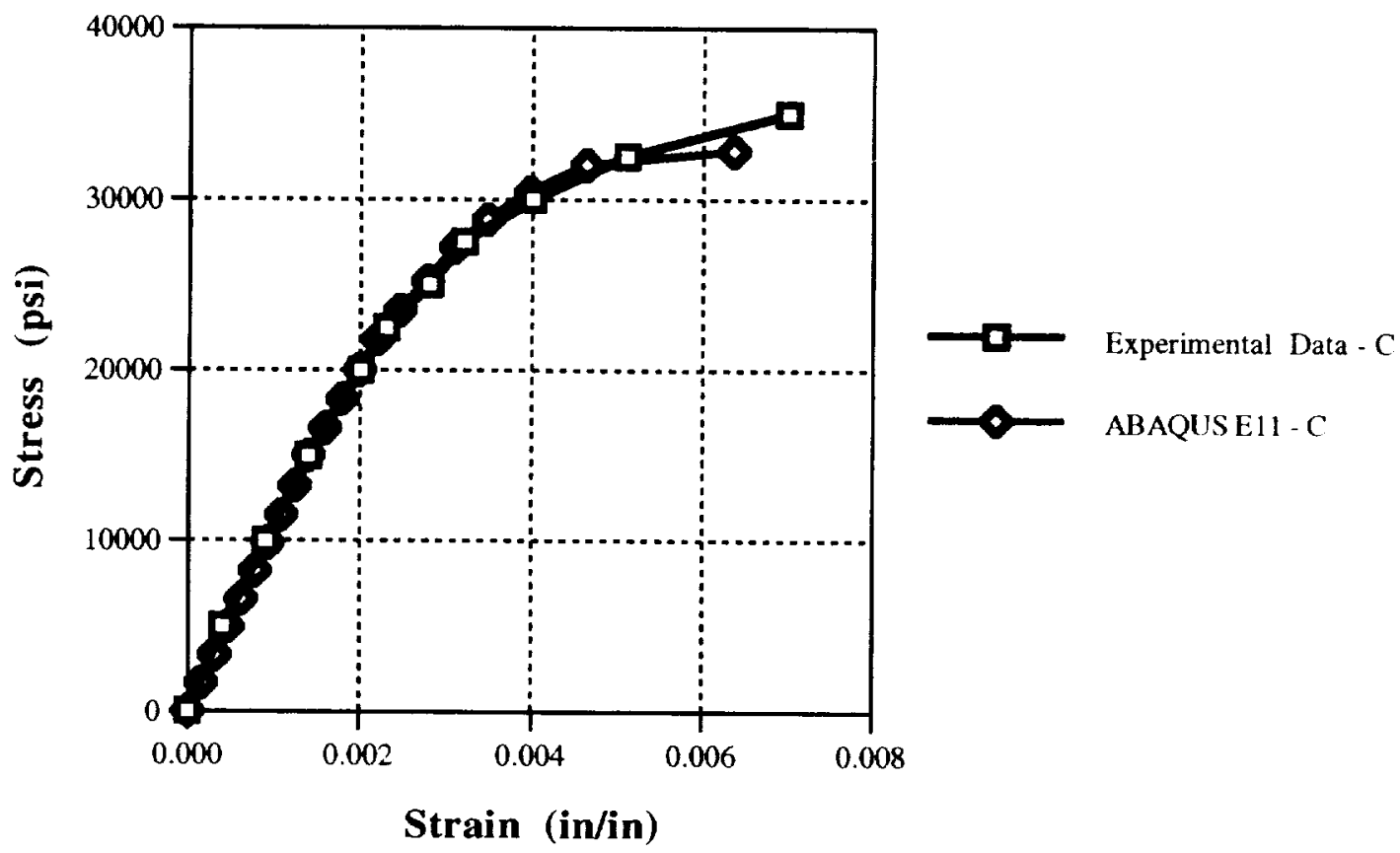

Figure 22. Comparison of $X$-direction experimental stress-s rain values to finite-element results at $C$.

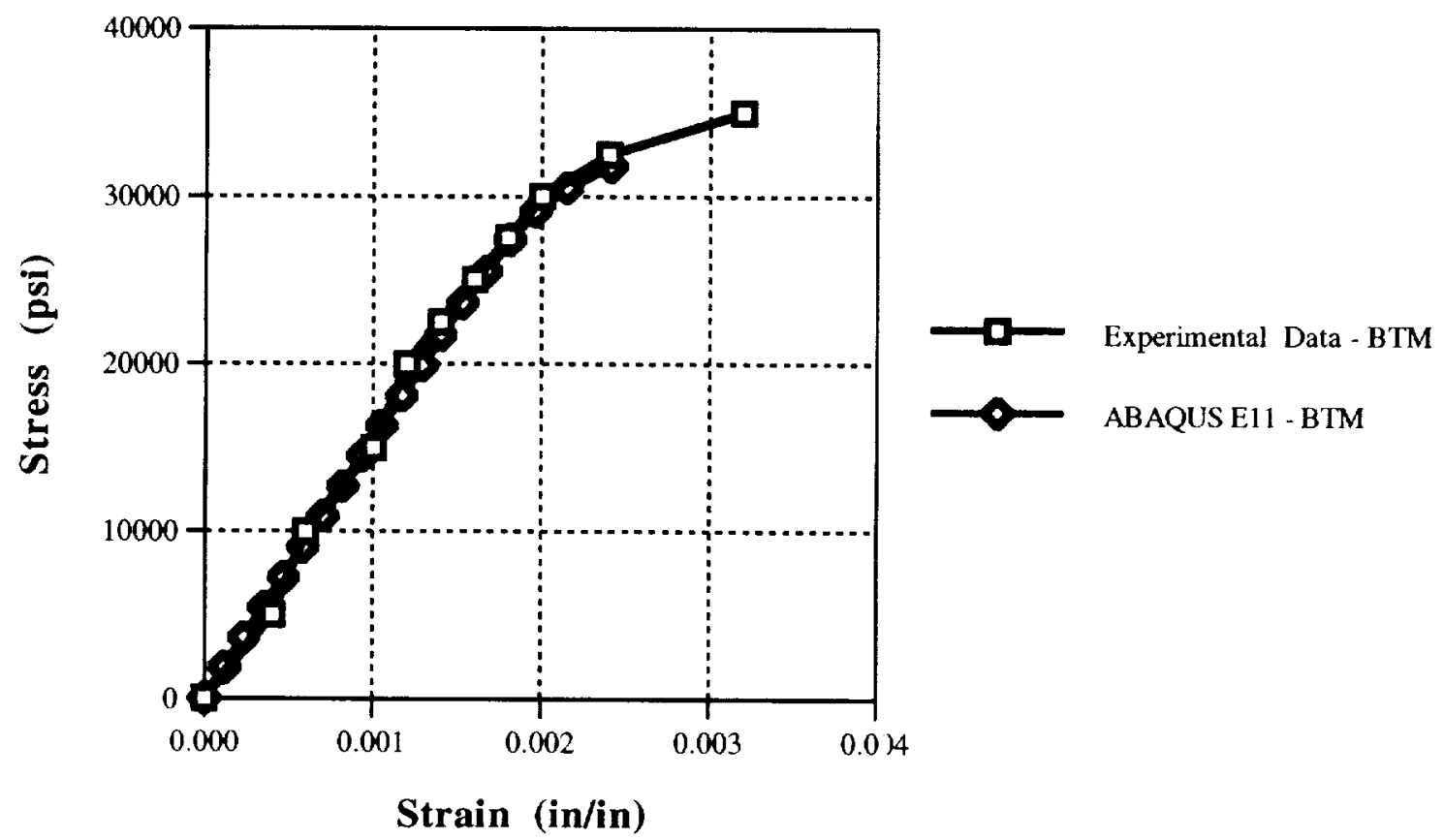

Figure 23. Comparison of $X$-direction experimental stress-strain values to finite-element results at the $B T M$. 


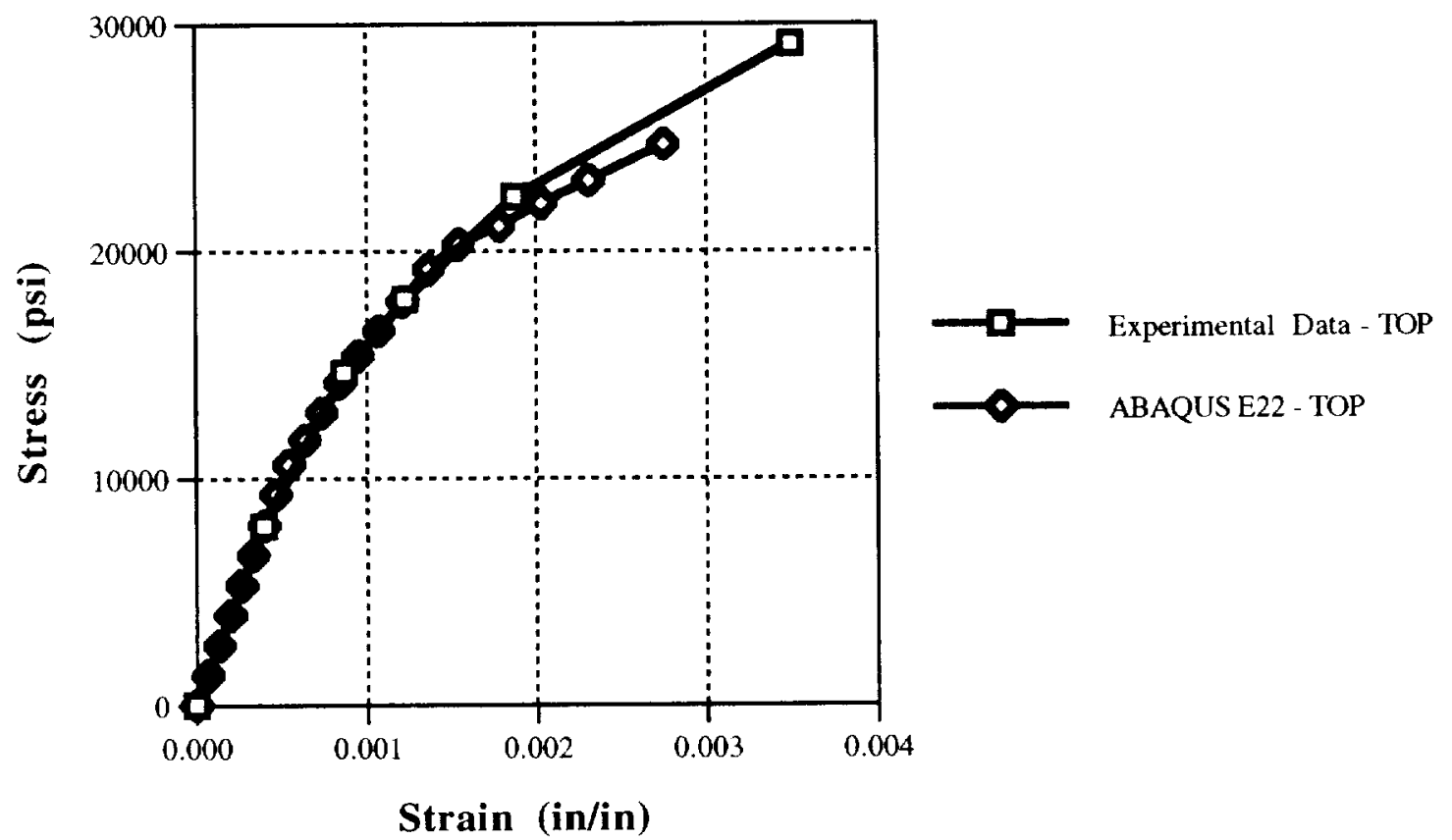

Figure 24. Comparison of $Y$-direction experimental stress-strain values to finite-element results at the TOP.

A comparison of the experimental results and the finite-element predictions in the $Y$ direction at the TOP location (fig. 24), also indicates good agreement. At stress levels above $20 \mathrm{ksi}$ it is noted that the model begins to slightly underpredict the experimental stress values for a given strain value.

At the $C$ location, the $A B A Q U S$ model is in good agreement for the linear range of the response (fig. 25). However, the model overpredicts the strain at stress levels above yield. As discussed in the previous section, the incremental strain theory and $A B A Q U S$ both rely on the constant volume assumption, that is $\varepsilon_{x}^{p}+\varepsilon_{y}^{p}+\varepsilon_{z}^{p}=0$; the implication of the constant volume assumption is that Poisson's ratio will be 0.5 for plastic strain. The plot of Poisson's ratio for the $C$ location confirms that the Poisson's ratio is approximately 0.5 for the ABAQUS results in the plastic regime (fig. 26). However, in figure 27 the plot of Poisson's ratio from the experimental data indicates that Poisson's ratio is decreasing at location $C$ as the load increases. This indicates that this weld specimen does not respond to applied load with constant volume deformations.

At the BTM location the $A B A Q U S$ results and the experimental results compared well in the linear region but also diverged when the response became inelastic (fig. 28). In the linear region, the slight divergence is probably caused by scatter in the experimental data. ${ }^{7}$ However, at stress levels above yield the divergence cannot be explained by any experimental inaccuracy. ${ }^{7}$ The experimental data in figure 27, shows that Poisson's ratio at this point in the specimen increased beyond the constant-volume assumption value of 0.5 . This indicates that the deformation in the axial direction is not proportional to the deformation in the lateral directions. Physically, the specimen is deforming more in the $Y$ direction than is being predicted and, as shown in figure 25 , the specimen is deforming less in the $Z$ direction than predicted. 


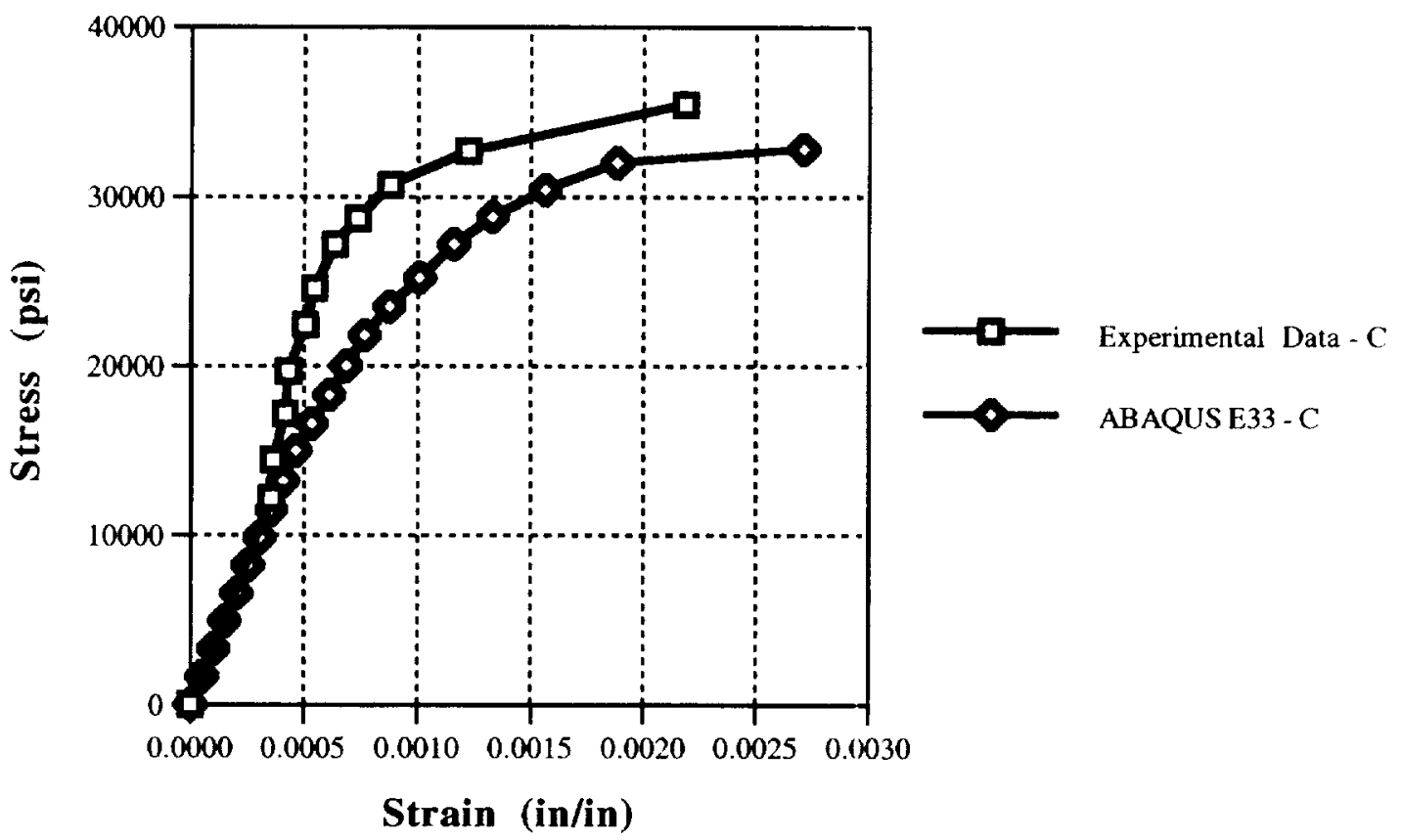

Figure 25. Comparison of $Z$-direction experimental stress-strain values to finite-element results at $C$.

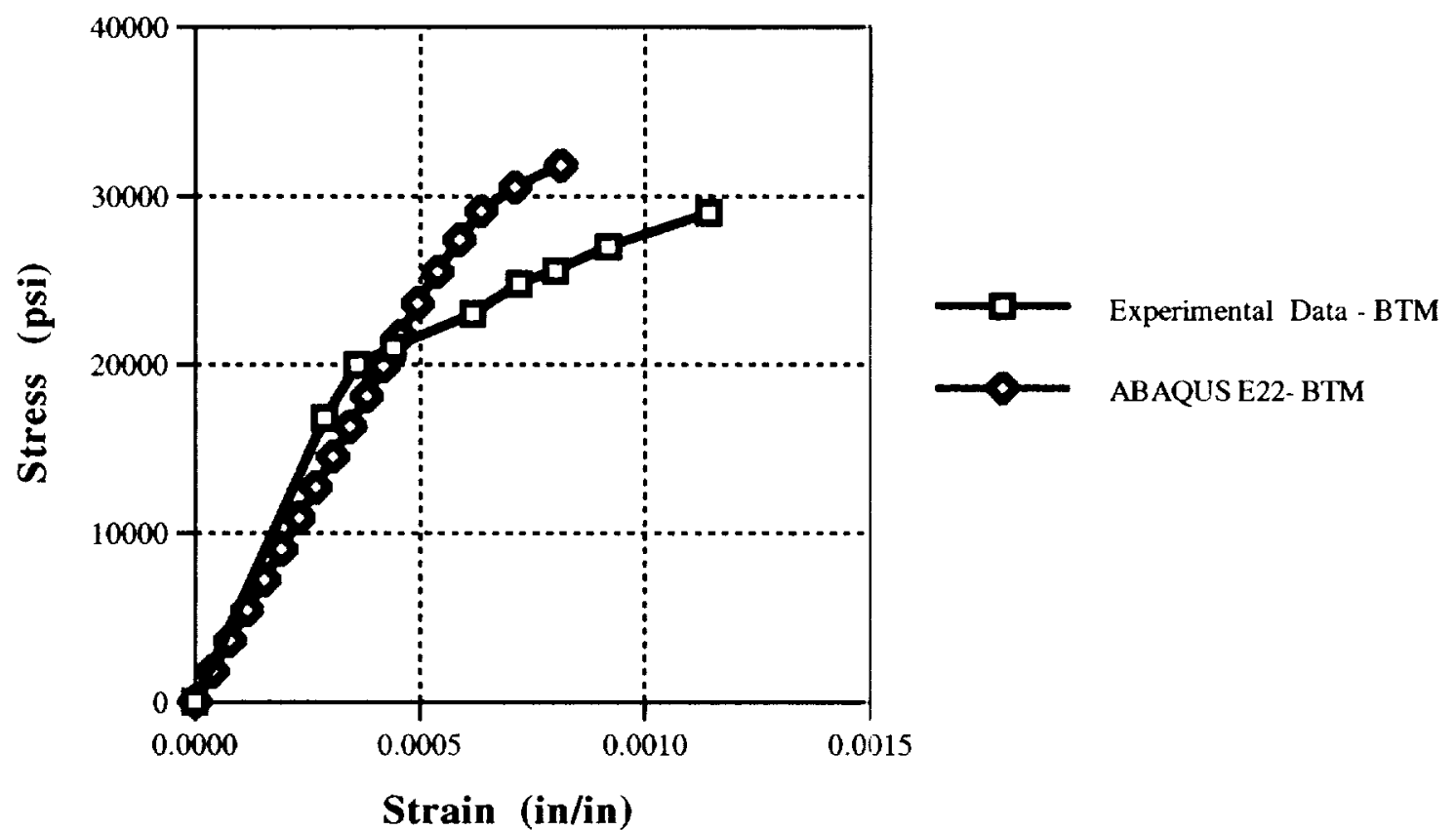

Figure 26. Poisson's ratio from the finite-element model. 


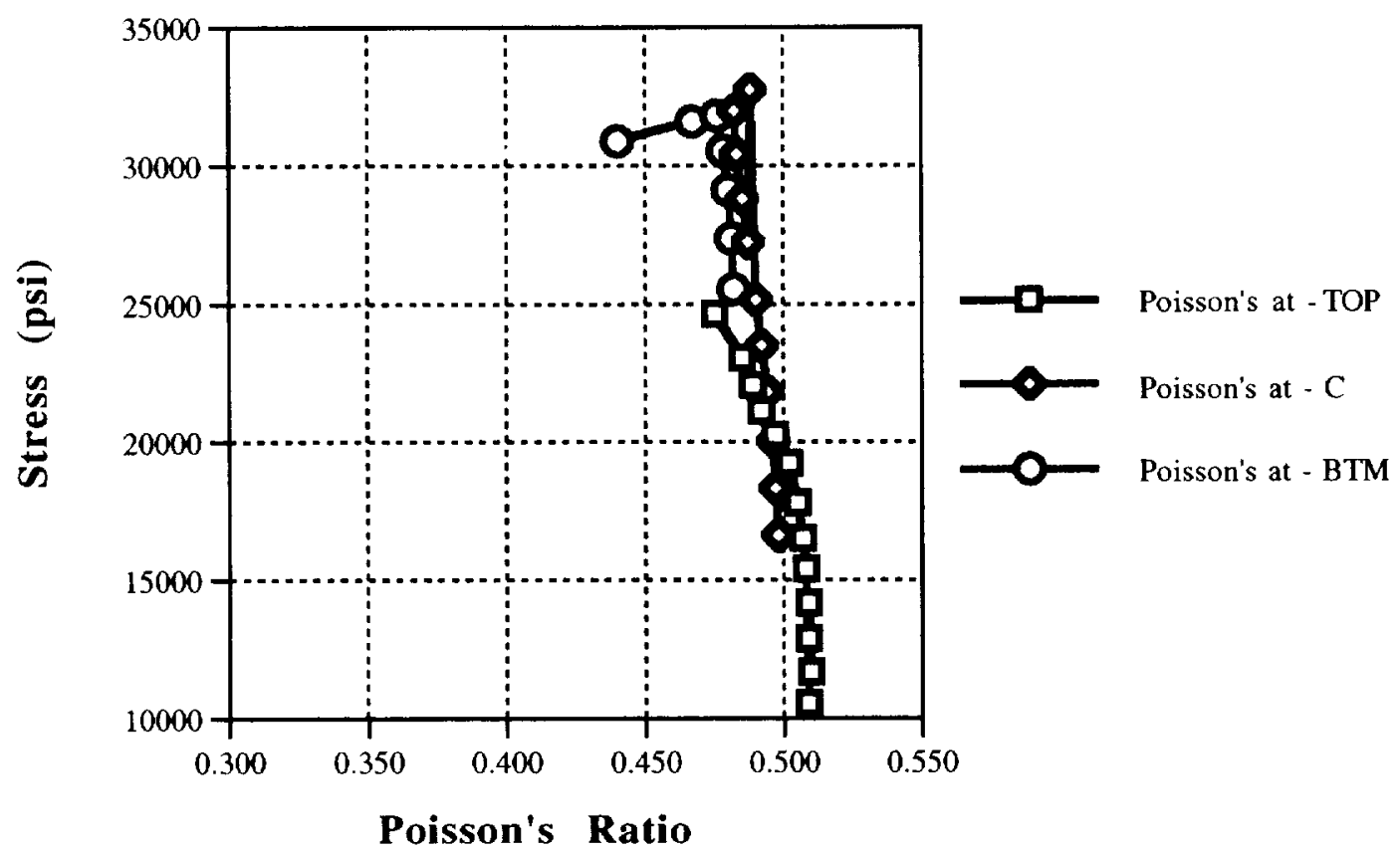

Figure 27. Poisson's ratio from experimental data.

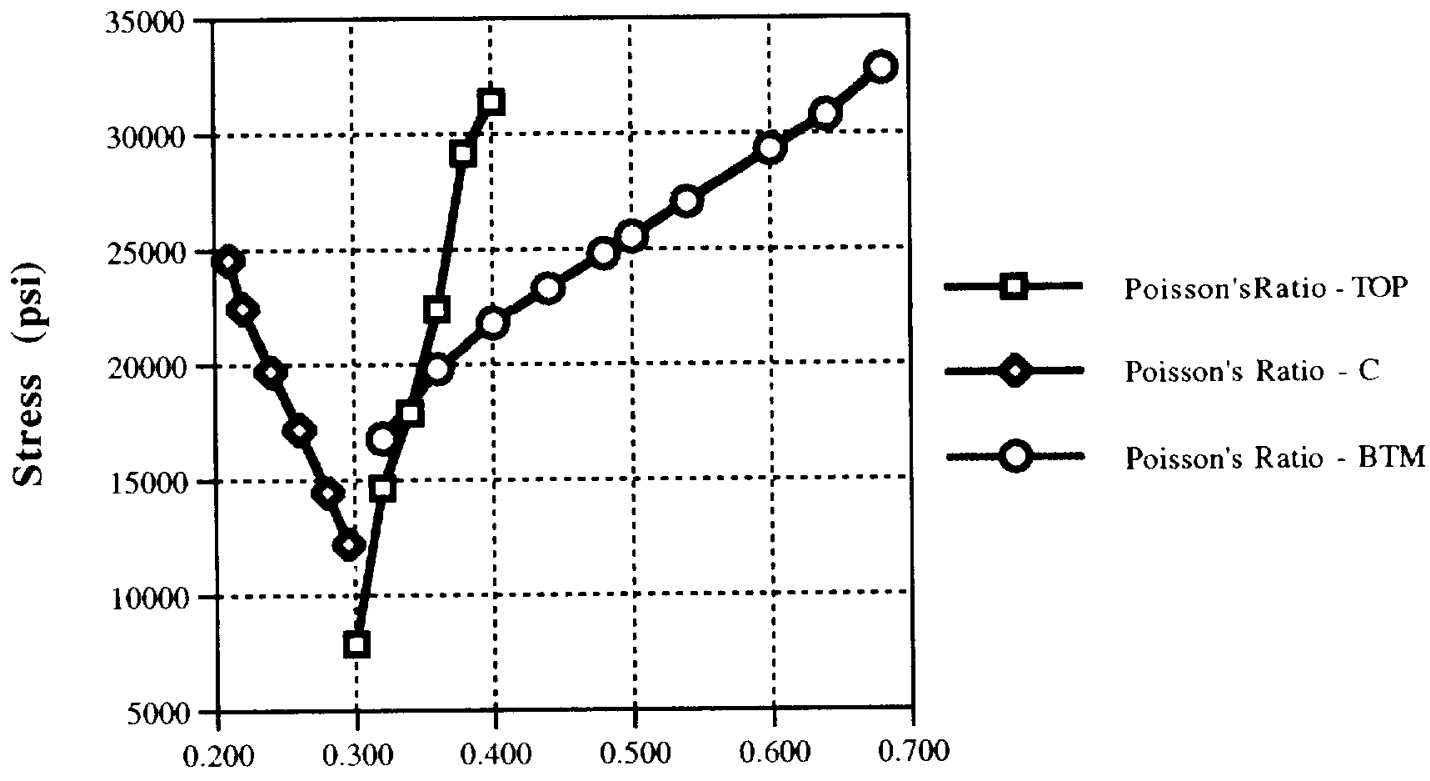

Poisson's Ratio

Figure 28. Comparison of $Y$-direction experimental stress-strain values to finite-element results at the $B T M$. 
3. Experimental and Computational Contour Plots. F gure 29 shows experimental contour plots obtained during a photostress evaluation of the weld specimen. ${ }^{6}$ The aluminum 2219 -T87 weld specimens used in the photoelastic study were over 1 in thick (fig. 30). Multiple weld passes started at midthickness and alternated from one side to another in an effort to provide symmetrical material properties throughout the thickness. Figure 29 illustrates the progressive shear strain through the thickness of the weld resulting from increasingly applied axial stress. The peak strains on the outer edge due to a 24-ksi, uniaxially-applied load, indicates the presence of a residual stress induced during the weld process. As the applied stress increases, the residual stress becomes less prominent and the strain field becomes more uniform across the width of the weld.

The specimen used in the photoelastic study was instrumented with strain gauges and photoelastic stress film. Though a uniform progressive axial tension stress was externally applied on the specimen, a concentrated strain was initially noted on one side of the weld which continued to spread to the other side until the whole thickness sustained a uniform strain. In other words, the uniform axial stress unexpectedly initiated a gradient strain across the weld thickness which grew into a more uniform strain field with increasing axial stress. Hardness tests proved the initially high-strained weld side was a weaker material than the opposite side. The weaker side was also noted to have had the last weld pass.

The most likely explanation for this phenomena is that the alternating weld passes from one side to the other caused the material of the last pass to shrink and lock in strains, while cooling stresses are forcing the opposite weld side to stretch and cold work. The result is a weld with gradient material properties and an anisotropic Poisson's ratio across the thickness. It might be suspected that the very large thermal coefficient of expansion of aluminum intensifies the cold work phenomenon over steel welds. The specimens were heat treated to relieve the thermal induced strains. However, because the weld joins an aluminum plate alloy to an aluminum forging alloy, extensive heat treatment would degrade the properties of the aluminum forging.

The results of the finite-element model are presented as contour plots of strain in figures 31 through 35. These figures are included here to provide a clearer understanding of the behavior of the weld under an axial load. The deformation plot in figure 31 illustrates that the specimen model necks down at the center line of the weld. The uniform deflection across the weld is maintained by the constraints which prevent bending of the specimen. Figure 32 is the contour plot of the axial strains which illustrates the variation of the material properties from the $T O P$ point to the $B T M$ point. Figure 33 is a cross-sectional view of the centerline of the weld. Note tha: the strains are maximum over a region within the top center portion of the specimen model. The strairs are not peaking across the surface of the weld where strain gauges would be located during a typical terisile test (i.e., points $L C, C$ or $R C$ ). This is significant in that any subsurface flaws would be subjected to higher loads than measured by surface strain gauges. Figures 34 and 35 illustrate the strain in the $Y$ direction. These figures indicate that a significant amount of shear is generated by the constraints appliec to prevent bending. 

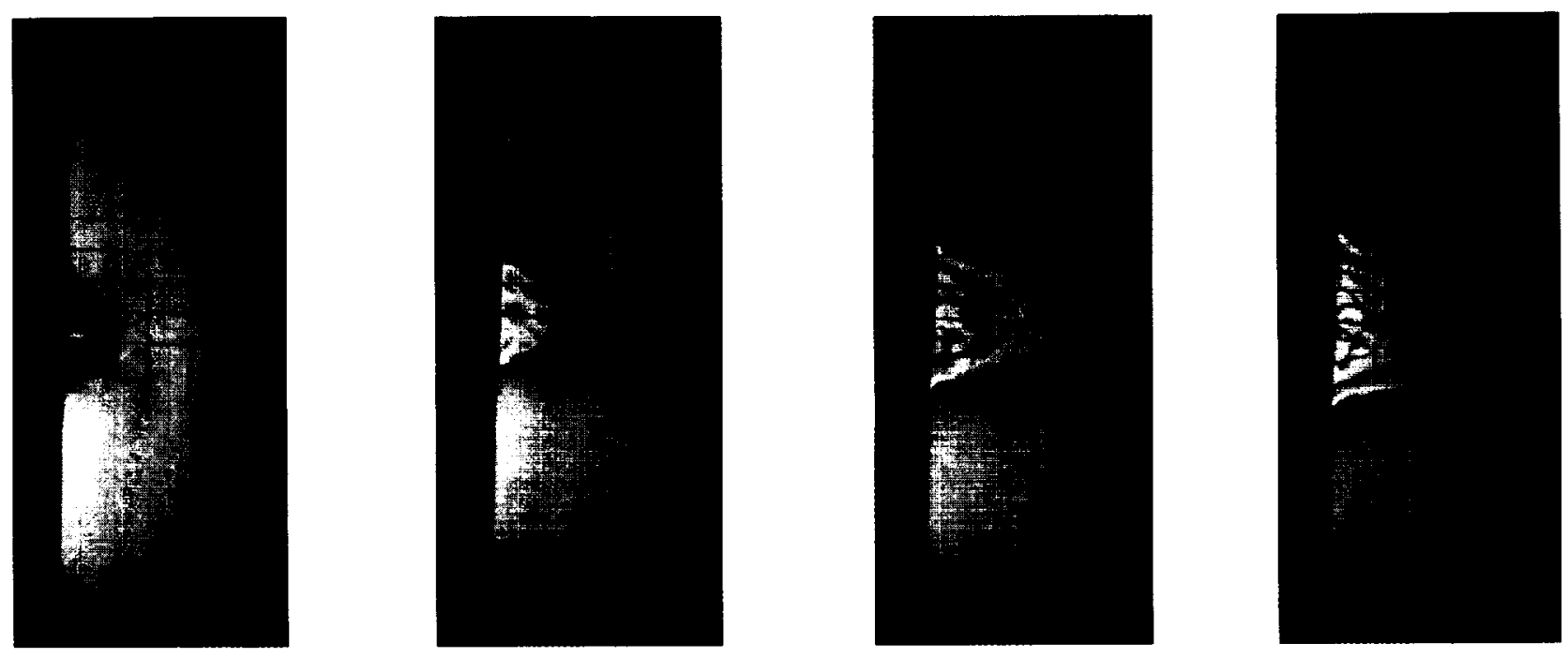

40,000 psi

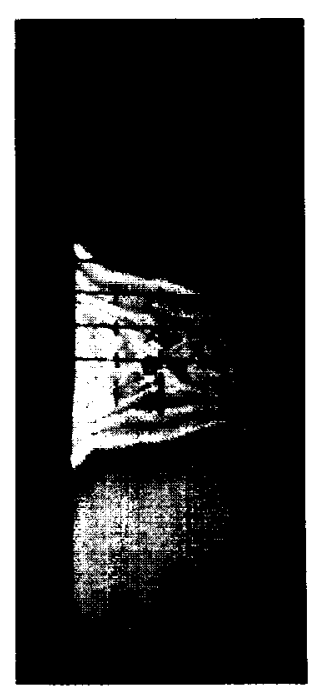

$44,000 \mathrm{psi}$

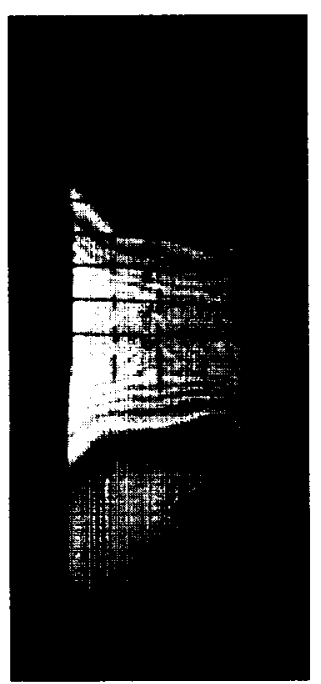

$46,000 \mathrm{psi}$

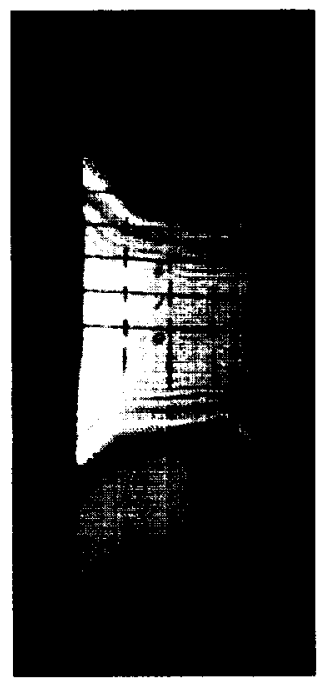

Residual

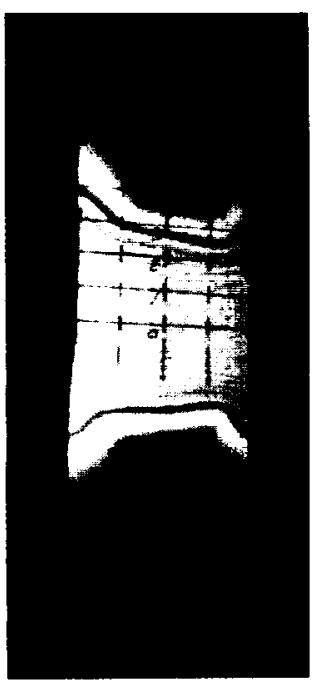

Figure 29. Photostress evaluation of a weld test specimen as the load increases (from Dr. S.C. Gambrell, University of Alabama: Report No. BER 591-97). 


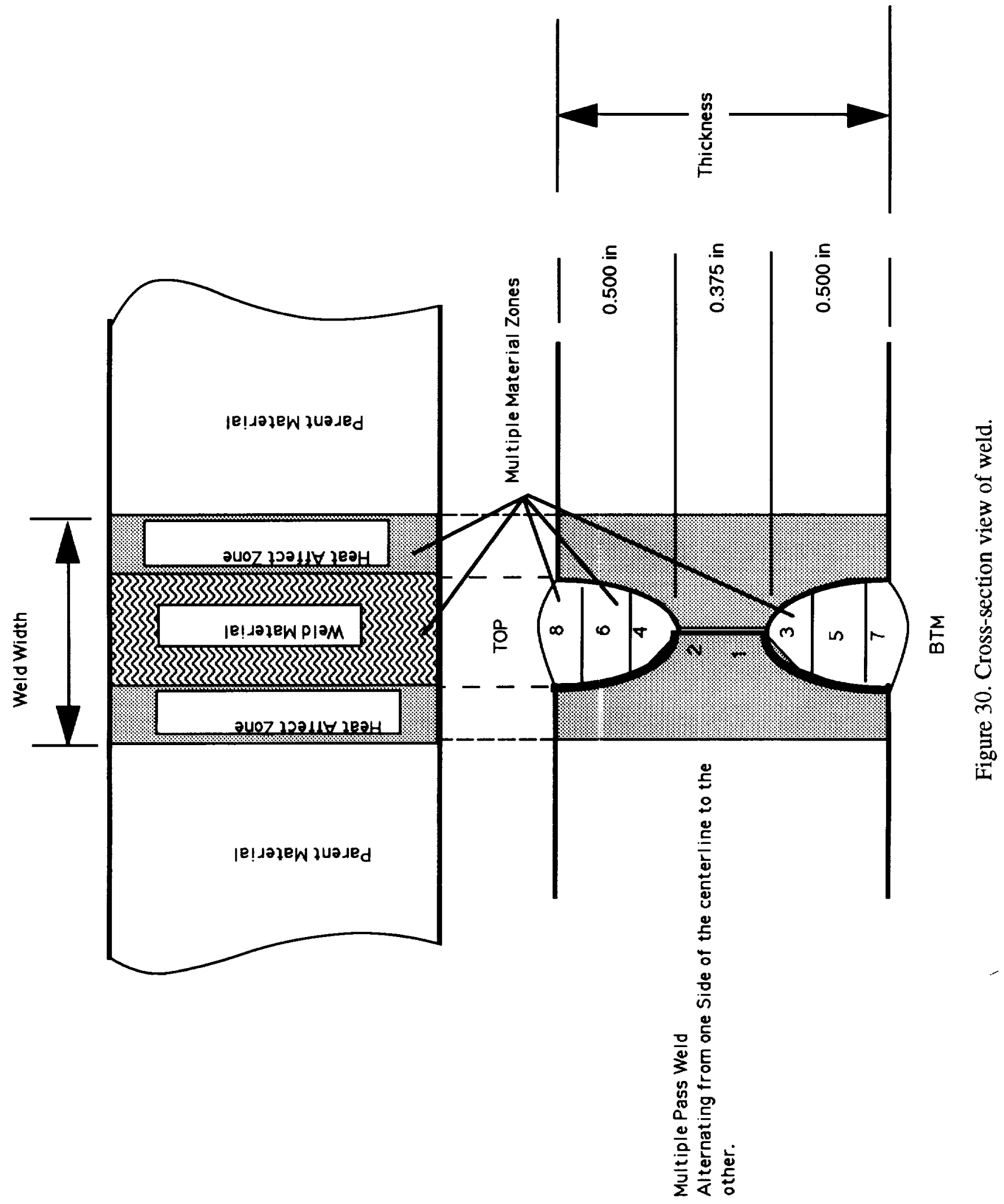



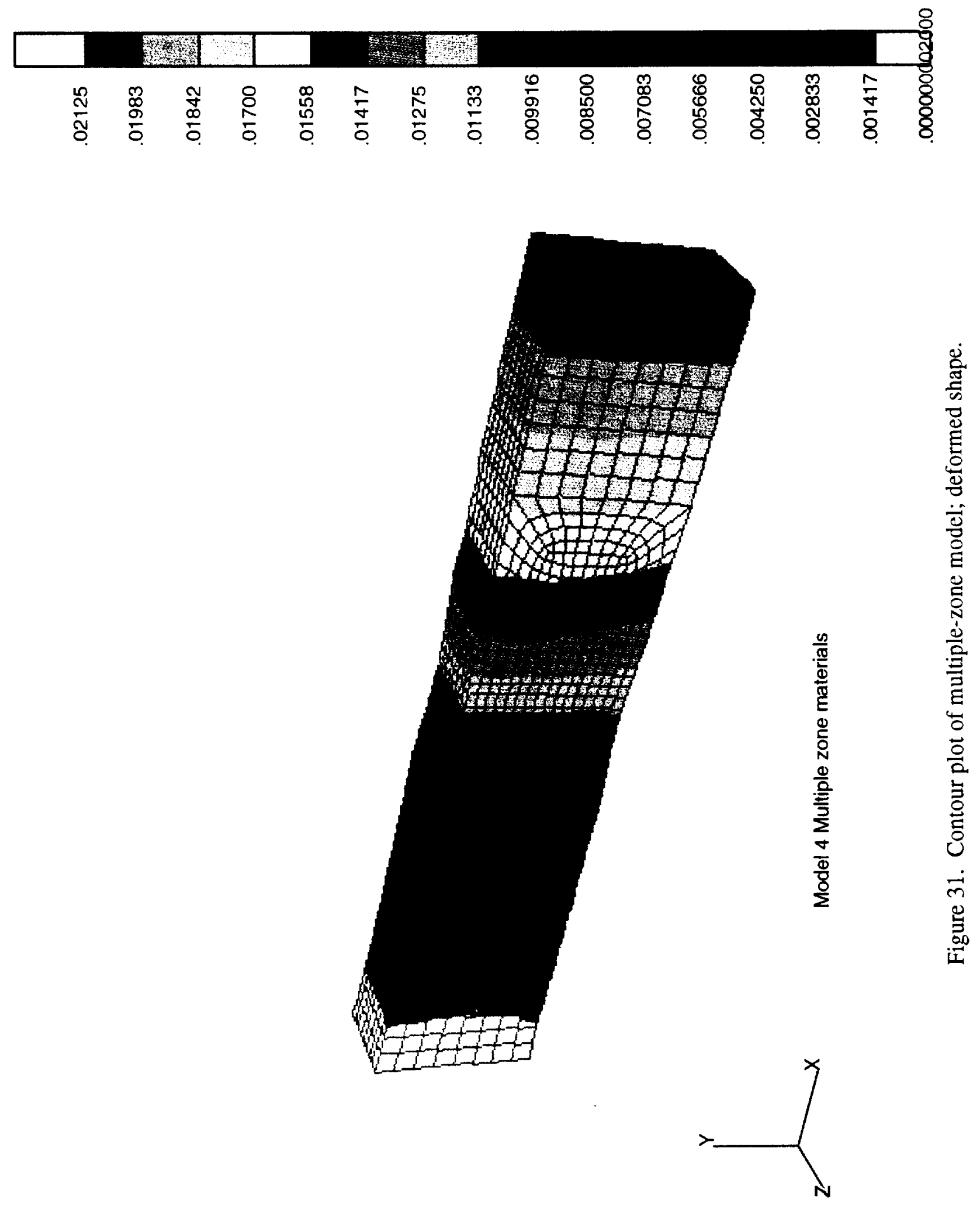


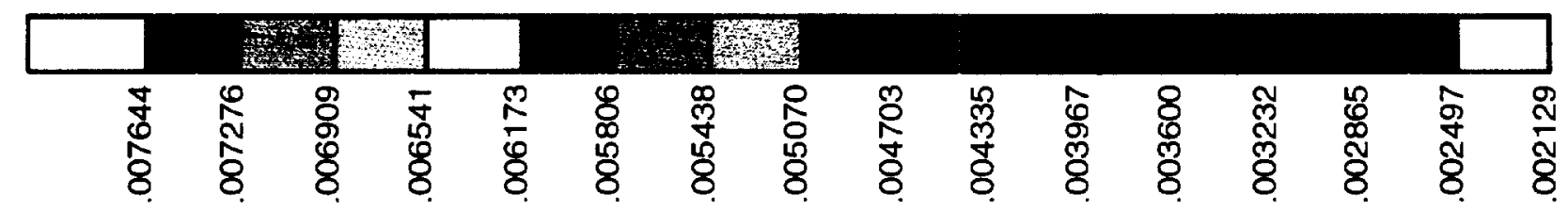

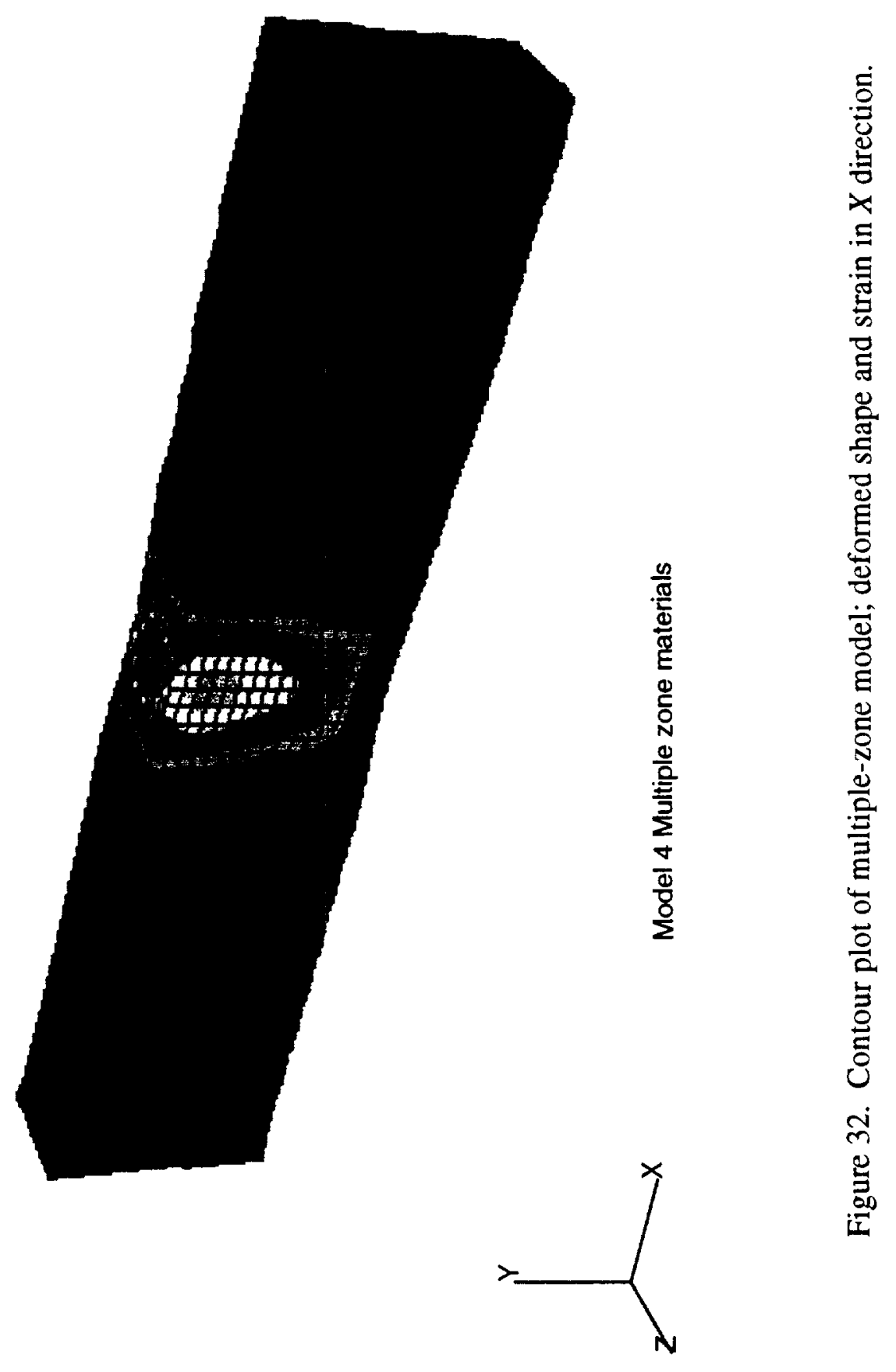




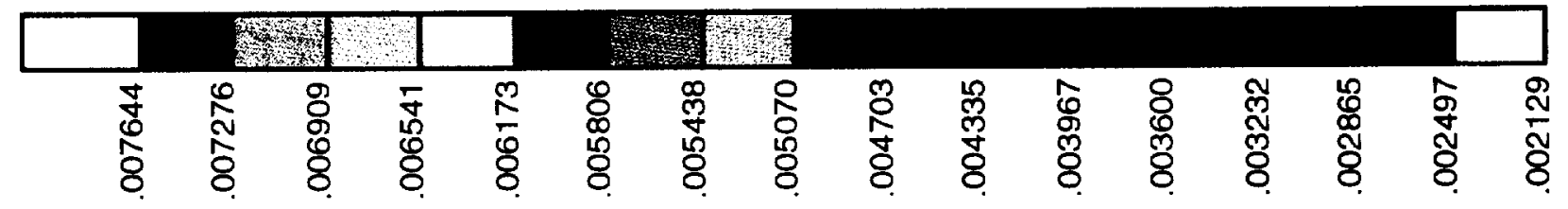

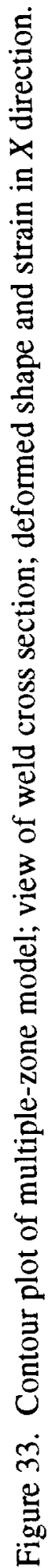



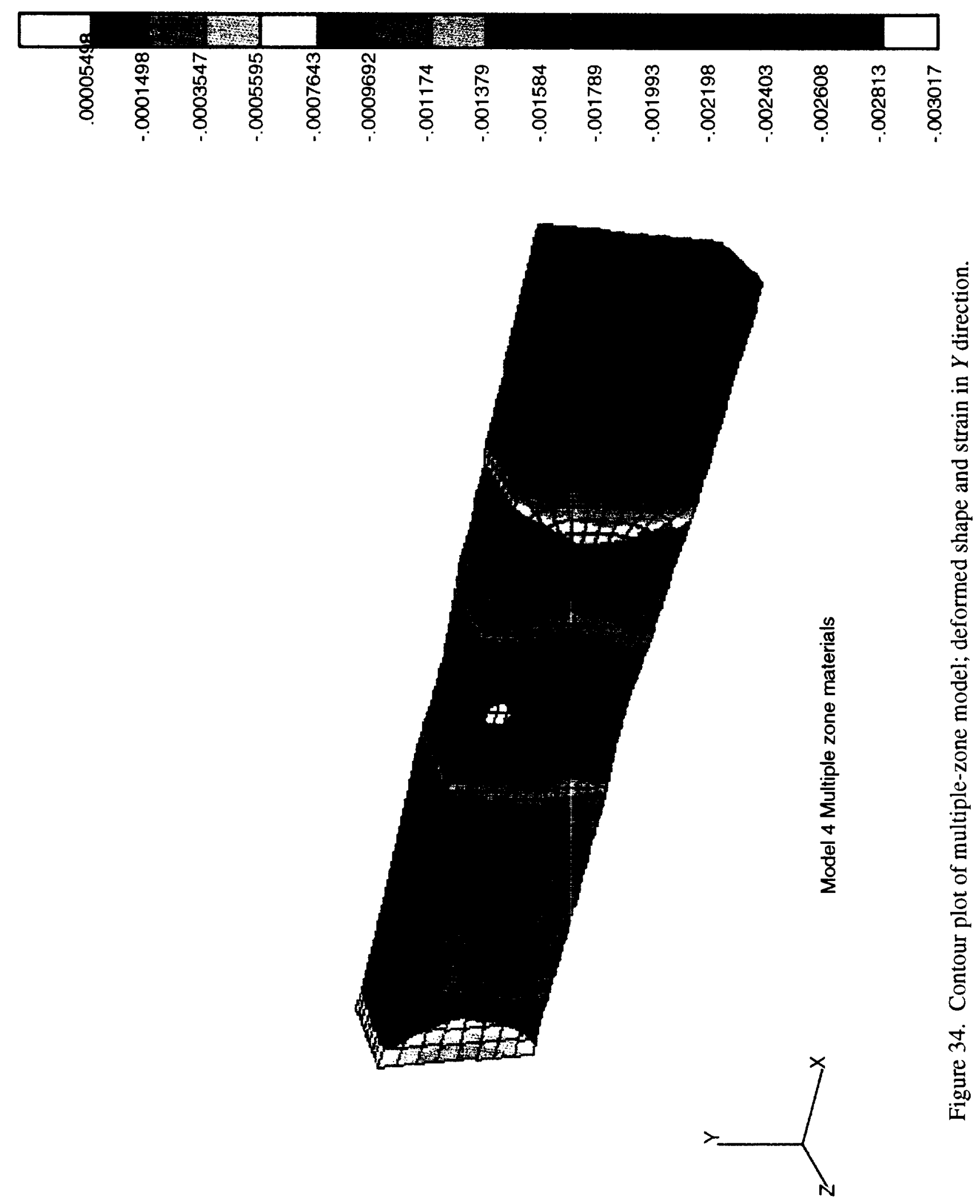


\begin{tabular}{|c|c|c|c|c|c|c|c|c|c|c|c|c|c|c|c|}
\hline $\begin{array}{l}\text { पे } \\
\text { पे } \\
8 \\
8\end{array}$ & $\begin{array}{l}\frac{\infty}{9} \\
\frac{9}{8} \\
\frac{8}{8} \\
!\end{array}$ & 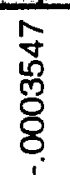 & $\begin{array}{l}0 \\
0 \\
0 \\
8 \\
8 \\
8 \\
i\end{array}$ & $\begin{array}{l}\text { P } \\
0 \\
8 \\
8 \\
8\end{array}$ & $\begin{array}{l}\text { N } \\
8 \\
8 \\
8 \\
8 \\
\end{array}$ & $\frac{N}{5}$ & $\frac{9}{\frac{9}{9}}$ & 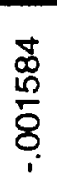 & $\frac{\stackrel{8}{8}}{\stackrel{8}{8}}$ & $\frac{m}{8}$ & $\frac{\stackrel{9}{o}}{\frac{9}{8}}$ & 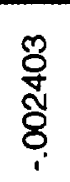 & 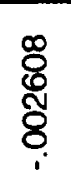 & $\begin{array}{l}\frac{m}{0} \\
\stackrel{0}{0} \\
\delta\end{array}$ & 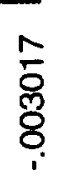 \\
\hline
\end{tabular}
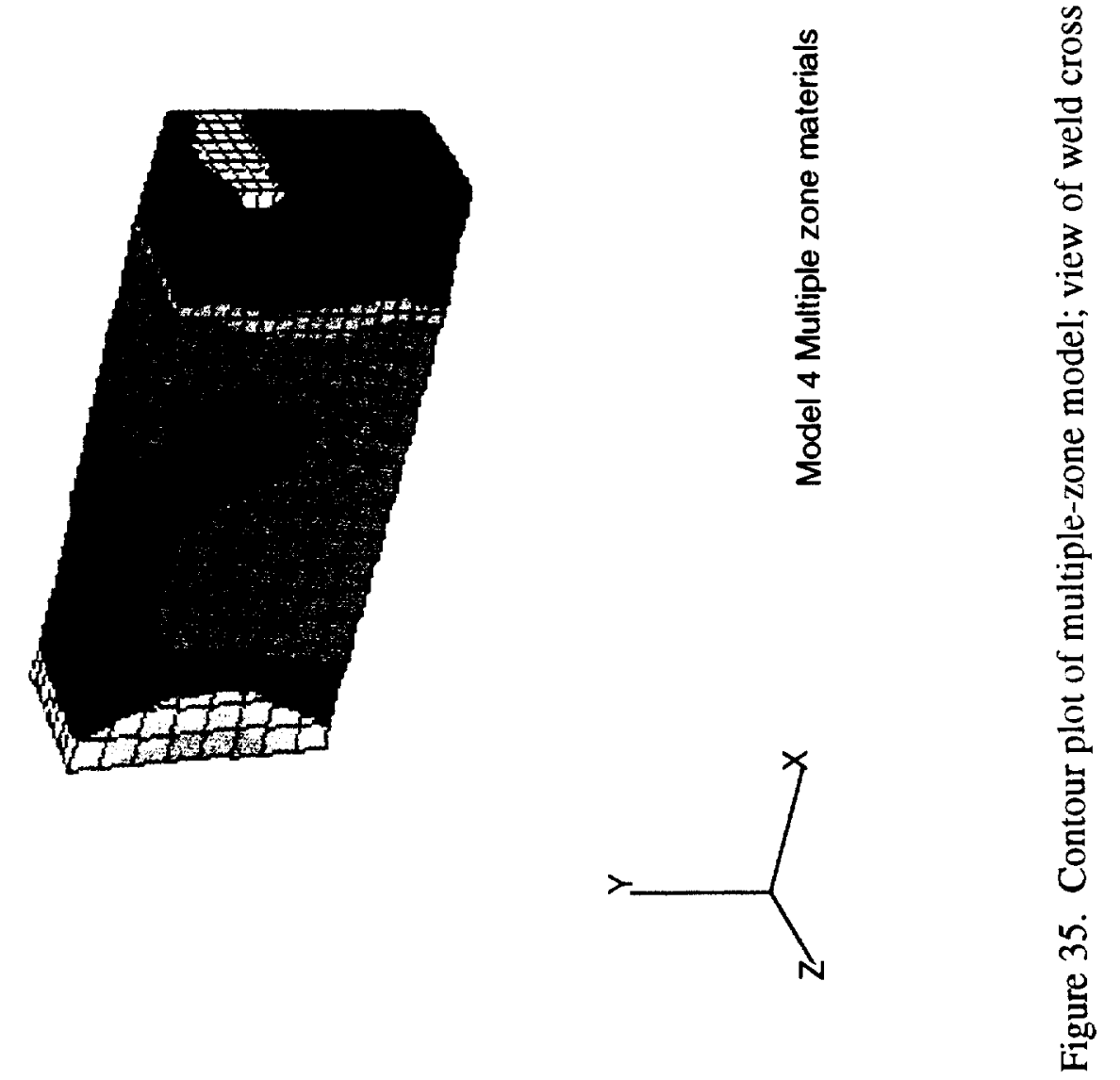


\section{CONCLUSIONS AND RECOMMENDATIONS}

An approach for modeling and verifying the response of welds to uniaxially-applied loads has been successfully developed and implemented. The methods of analysis were compared to experimental results to determine the behavior and the accuracy of the analysis methods. The computational-model axial-strain predictions compared very well with longitudinal-weld experimental data but did not correlate very well with transverse strain data. Additional elements and material property inputs are not expected to increase the accuracy of the solution because the $A B A Q U S$ finite-element code assumes constant-volume deformation, while the experimental data indicates otherwise. The predictions of the model were significantly different from the experimental data beyond the linear elastic regime because the anisotropic nature of the weld test specimen was not included in the computational model. However, it may be possible to reformulate the 1-D stress-strain model with an appropriate Poisson's ratio, and then modify the computational model to provide more accurate weld-stress analyses.

The results obtained in this study showed a limitation in the finite-element code $A B A Q U S$ and illustrated the need for developing a model with an anisotropic Poisson's ratio. In addition, it demonstrated that uniaxial test data may not provide adequate material properties for thick welds. It should also be interesting to investigate the cold work phenomenon on welds of varying thickness to determine the sensitivities of the material properties to the weld thickness. 


\section{REFERENCES}

1. Rybicki, E.F., and Stonesifer, R.B.: "Computation of Residual Stresses Due to Multipass Welds in Piping Systems.” Journal of Pressure Vessel Technology, vol. 101, pp. 149-154, May 1979.

2. Papazoglou, V.J., and Masubuchi, K.: "Numerical Analysis of Thermal Stresses During Welding Including Phase Transformation Effects." The American Society of Mechanical Engineers, Pressure Vessels and Piping Conference, Paper No. 82-PVP-44, June 1982.

3. Agapakis, J.E. et al.: "Study of Residual Stresses and Distortion in Structural Weldments in HighStrength Steels." Final report of contract N00014-75-C-(0469, M.I.T., OSP No. 82558, Massachusetts Institute of Technology, Department of Ocean Engineering, November 1982.

4. Kavikondala, K.: "Experimental-Numerical Analysis of Welded Aluminum Joints." Masters thesis, Department of Engineering Mechanics, The University of Alabama, Tuscaloosa, AL, 1993.

5. Gambrell, S.C.: "Use of Photostress Techniques to Characterize the Mechanical Behavior of Weldments." NASA/ASEE Fellowship Program, The University of Alabama, Tuscaloosa, AL, 1991.

6. Gambrell, S.C.: "Use of Photostress to Characterize the Mechanical Behavior of Weldments." The University of Alabama College of Engineering Bureau of Engineering Research, report No. 570-97, Tuscaloosa, AL, 1992.

7. Gambrell, S.C.: "Use of Photostress Techniques to Characterize the Mechanical Behavior of Weldments." The University of Alabama College of Engineering Bureau of Engineering Research, report No. 591-97, Tuscaloosa, AL, 1993.

8. Verderaime, V.: "Plate and Butt-Weld Stresses Beyond Elastic Limit, Material and Structural Modeling." NASA/Marshall Space Flight Center, TP-3075, Huntsville, AL, 1991.

9. Phillips, A.: "Introduction to Plasticity." The Ronald Press Company, NY, 1956.

10. Bridgman, P.W.: "Effects of High Hydrostatic Pressure on the Plastic Properties of Metals." Reviews of Modern Physics, vol. 17, 1945, pp. 3-14.

11. Morrison, J.L.M.: "An Experimental Investigation of Plastic Stress-Strain Relations." The Institution of Mechanical Engineering, vol. 163, 1950, pp. 1-17.

12. Ivey, H.J.: "Plastic Stress-Strain Relations and Yield Surfaces for Aluminum Alloys." Journal of Mechanical Engineering Science, vol. 3, No. 1, 1961, pp. 15-31. 


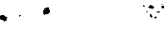




\section{APPENDIX A}

REDUCTION OF EXPERIMENTAL DATA

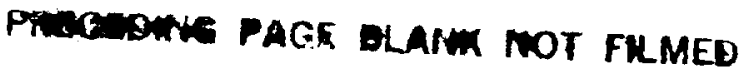

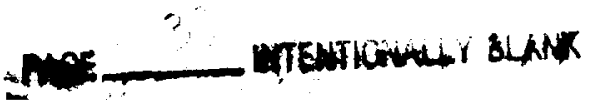




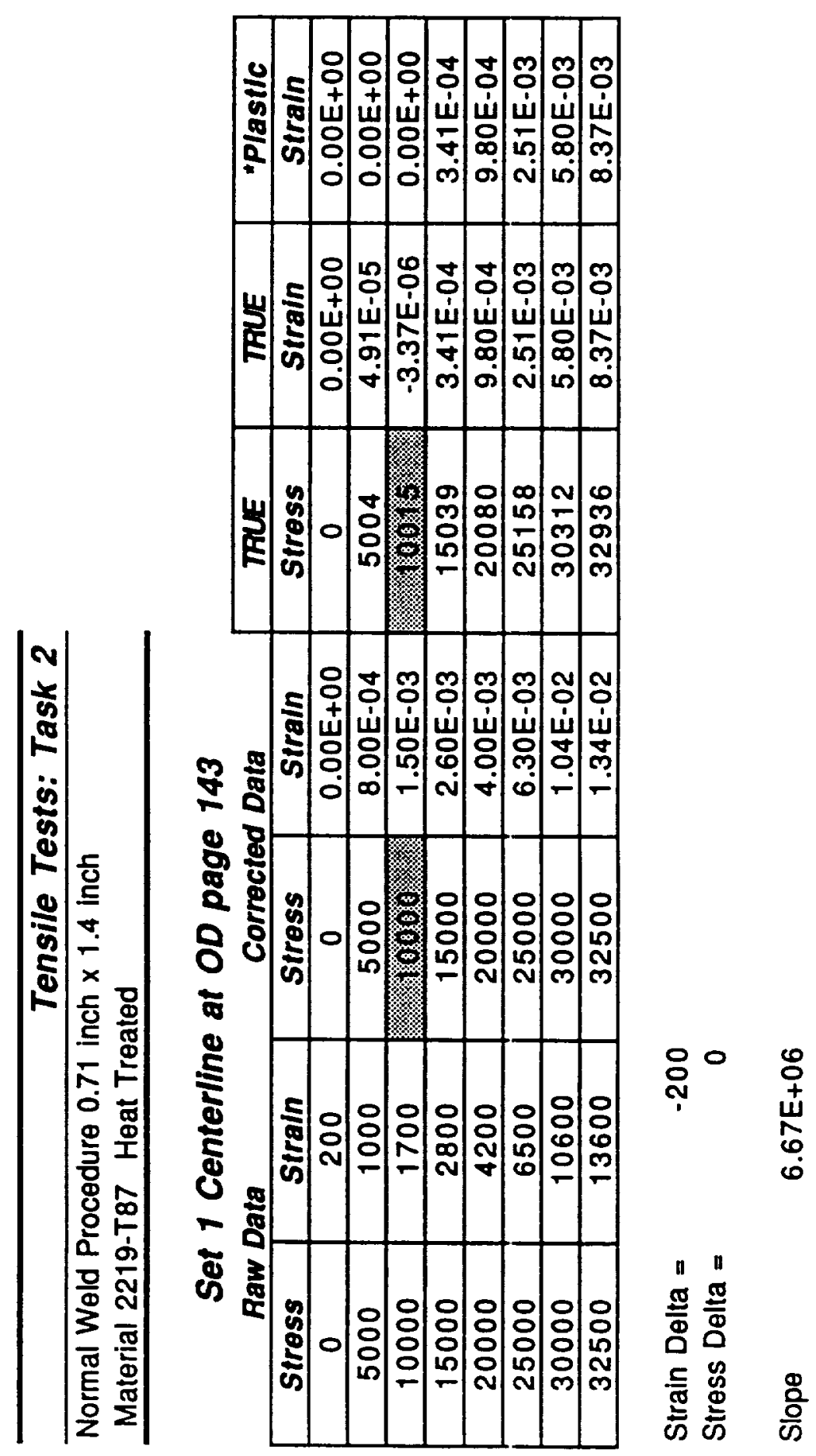




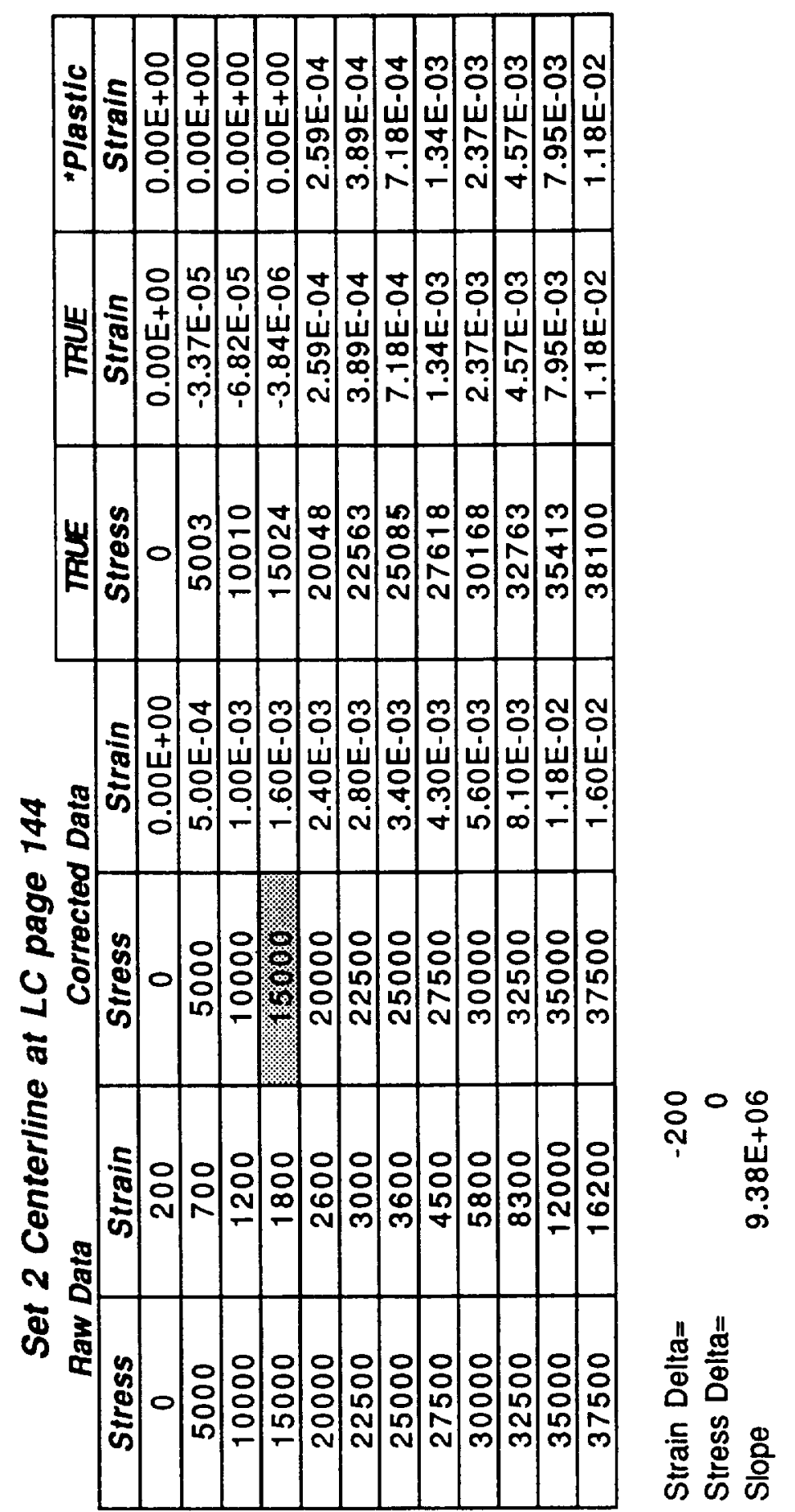




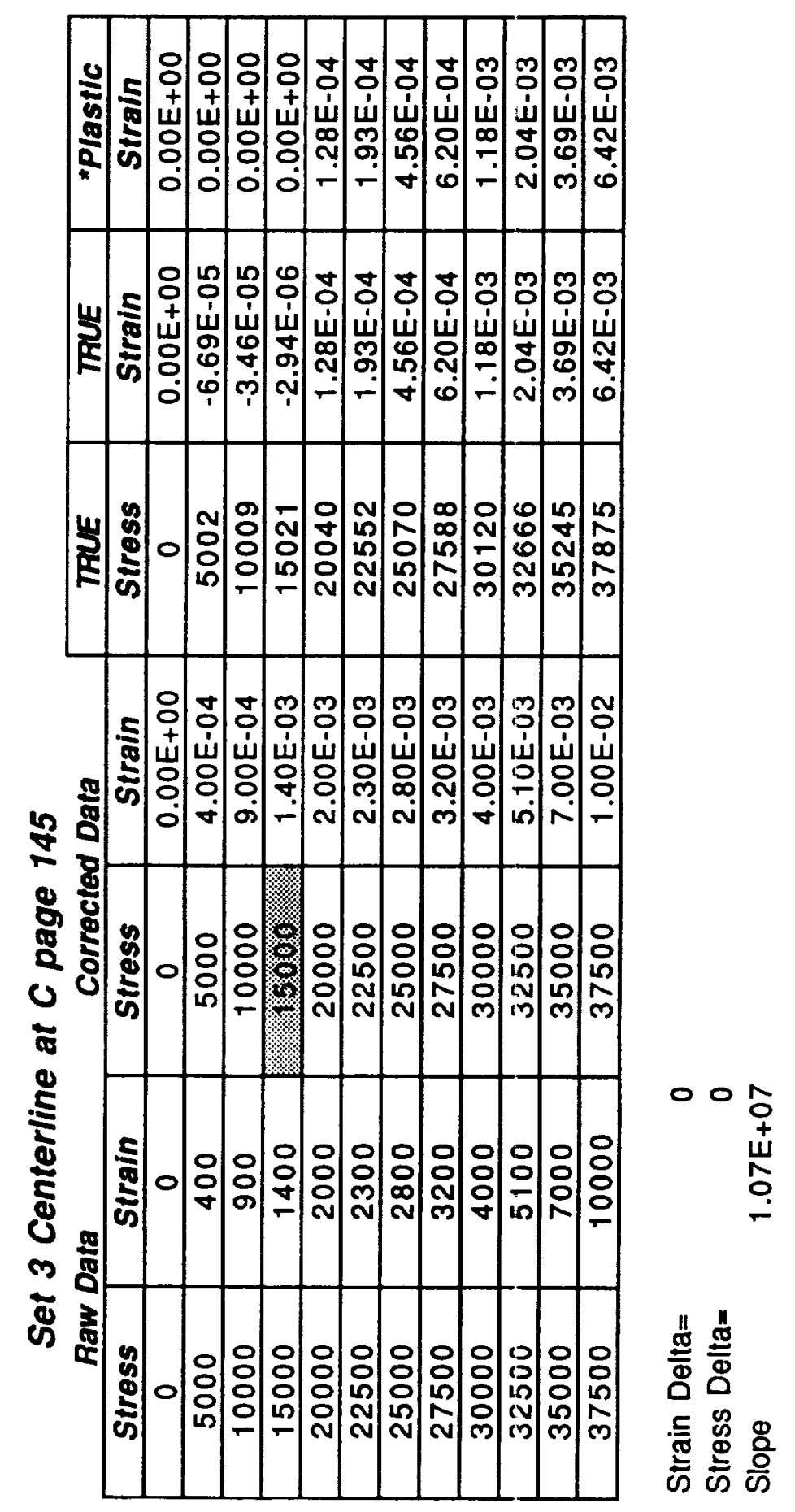




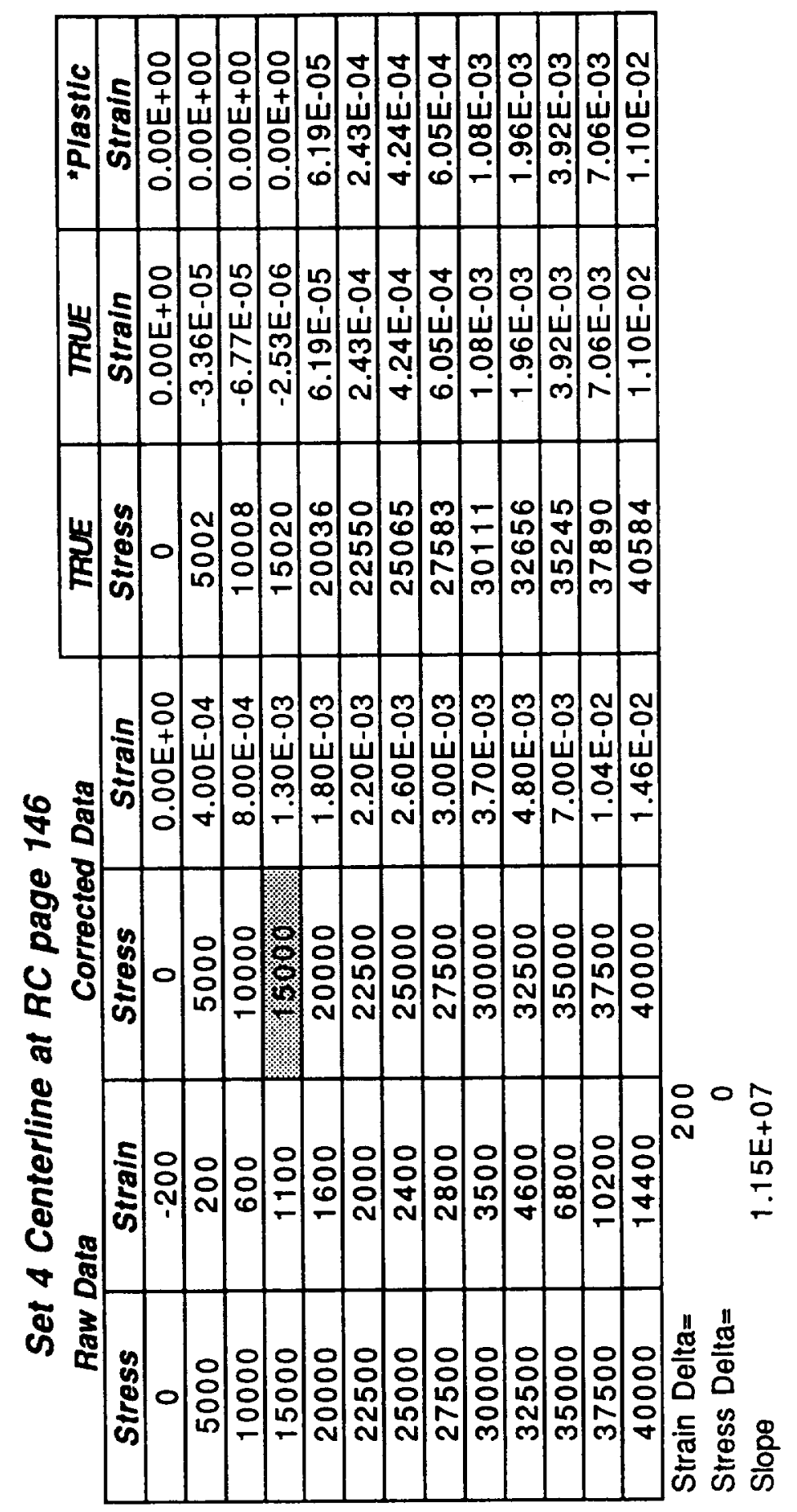




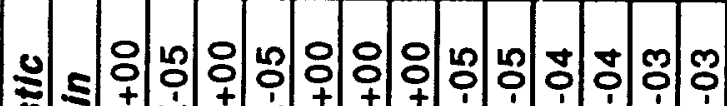

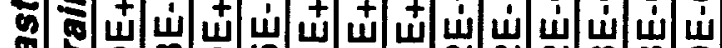

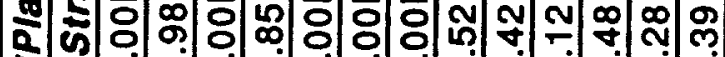

:

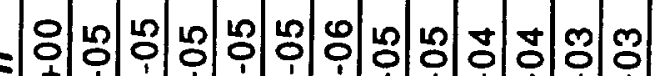

ب.

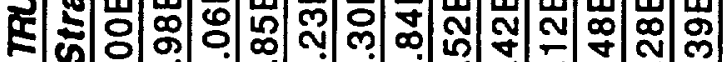

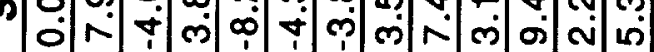

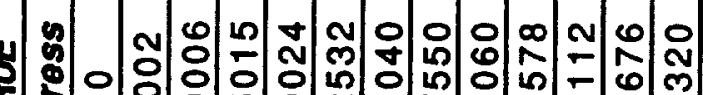

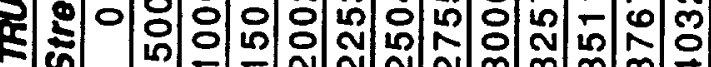

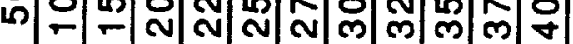

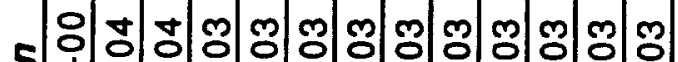

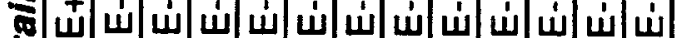

\&

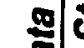

喜

12

के

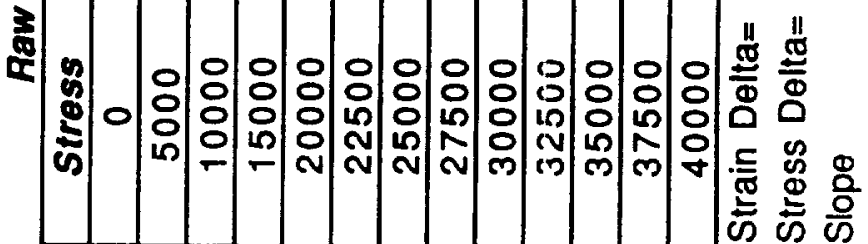




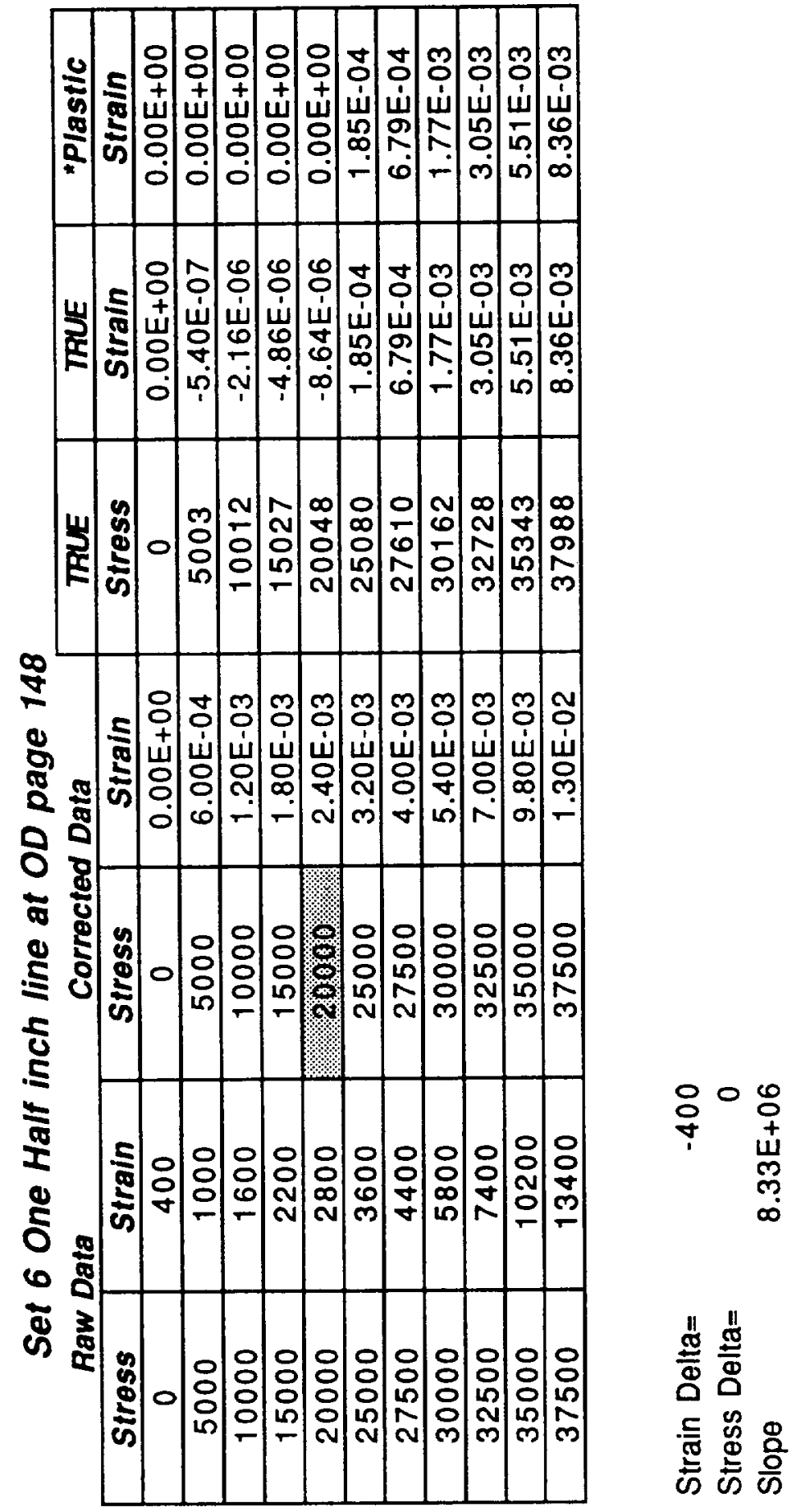




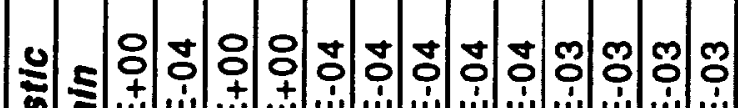

g

๙

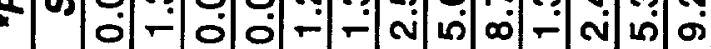

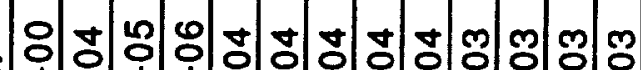

w5 5 +

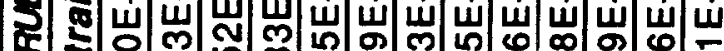

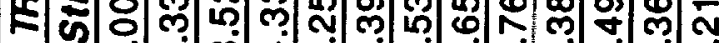

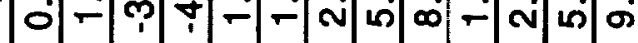

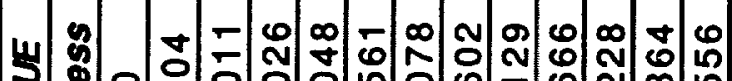

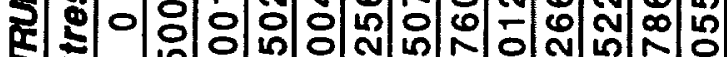

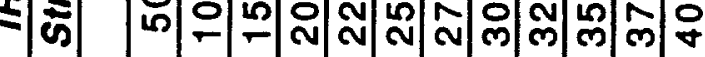

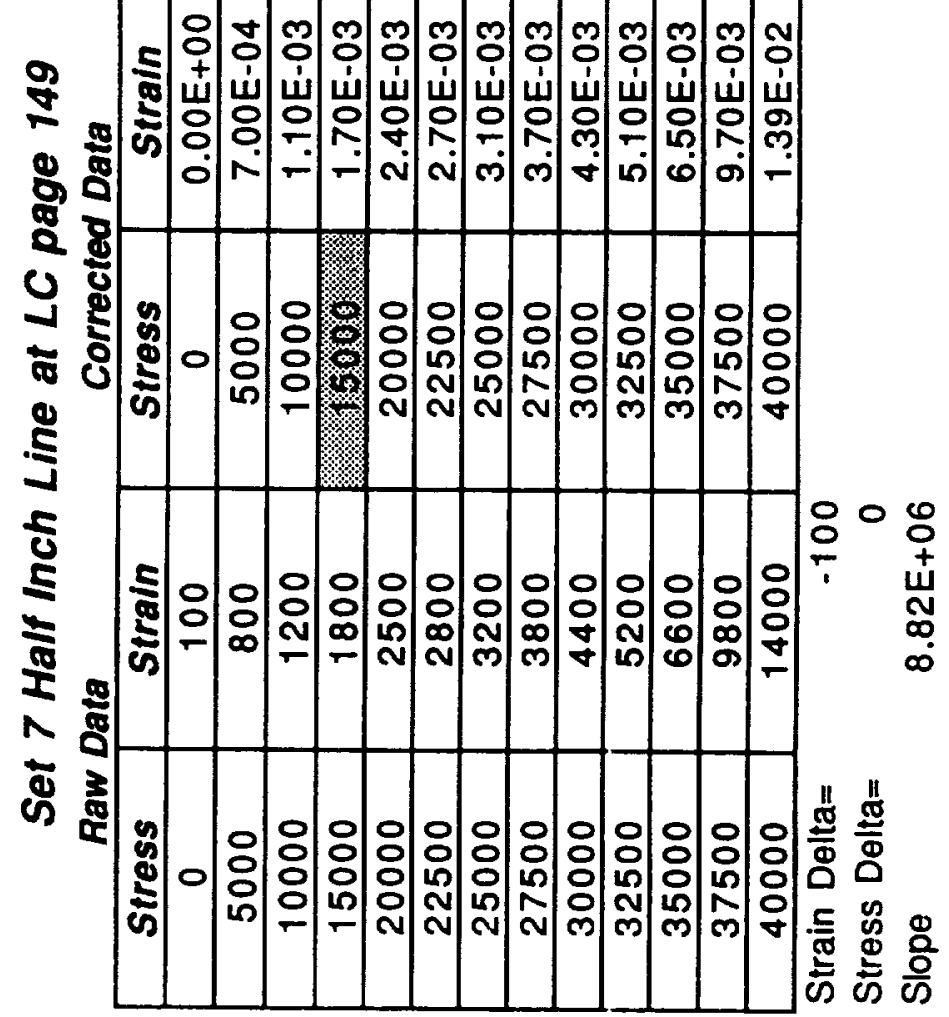




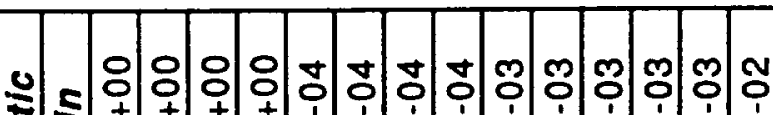

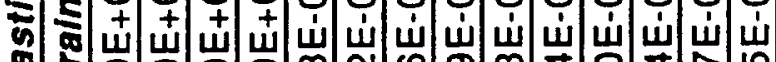

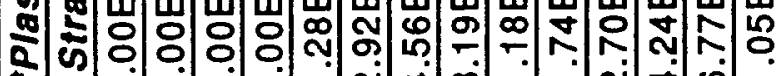

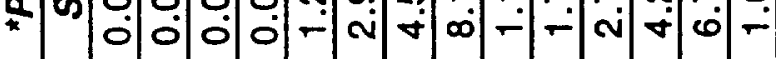

s

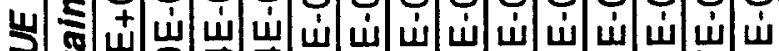

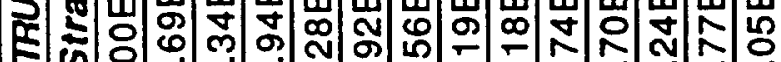

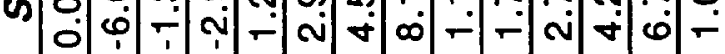

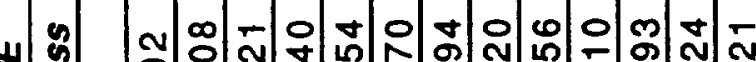

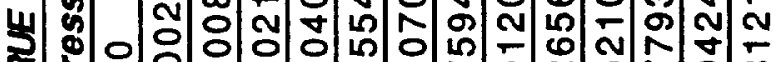

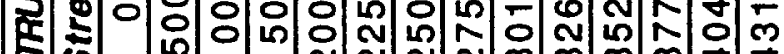

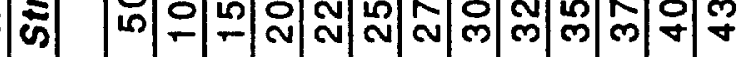

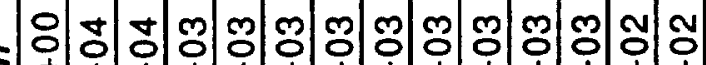
c

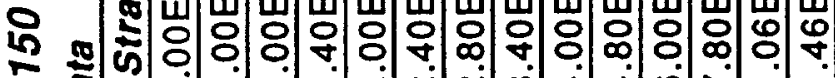

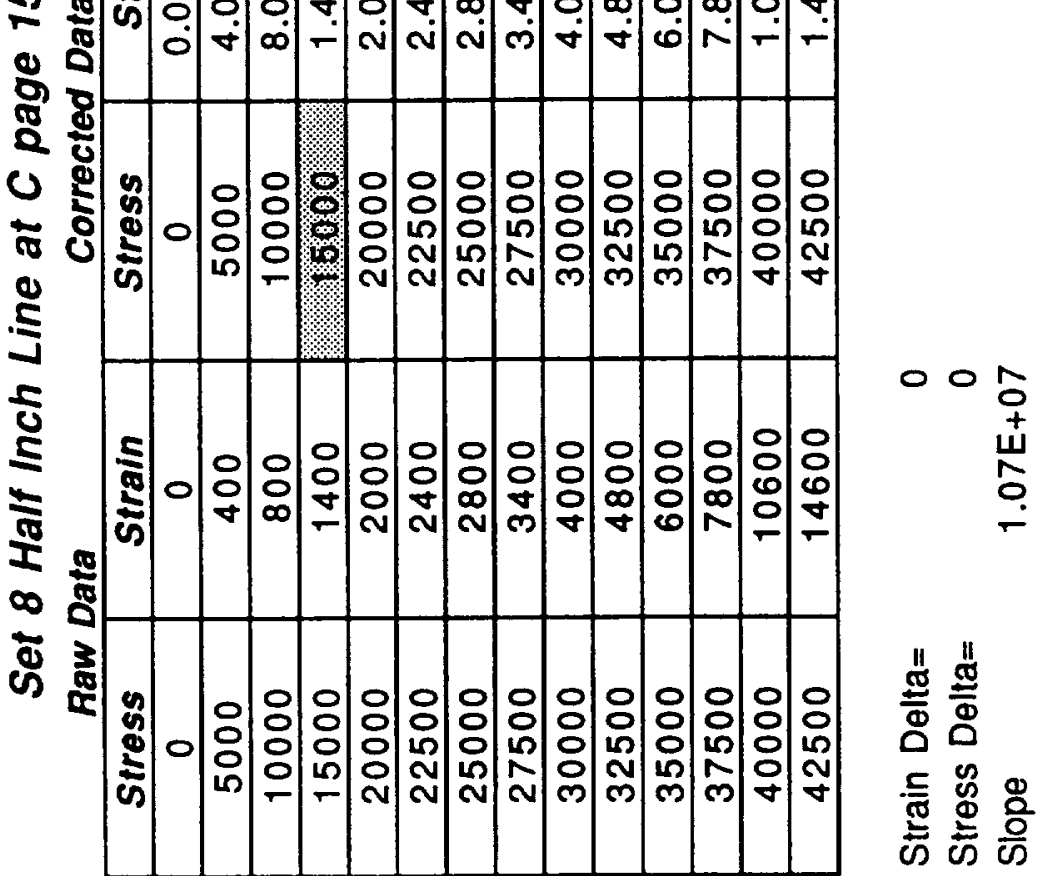




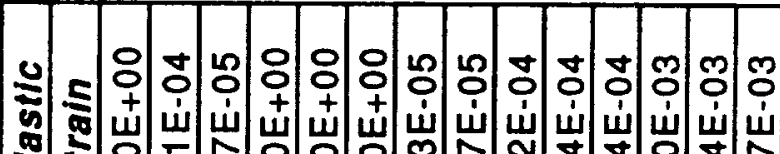

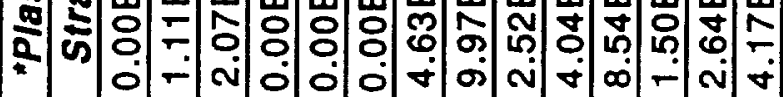

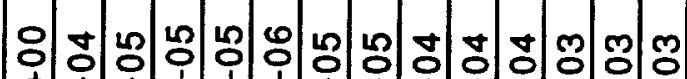

بأ.

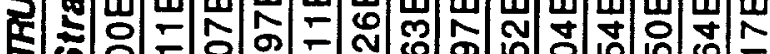

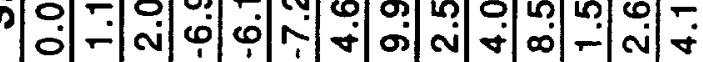

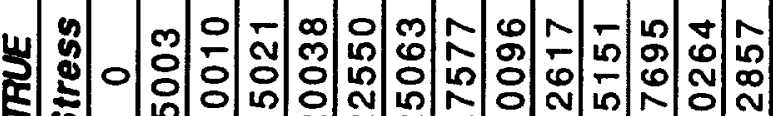

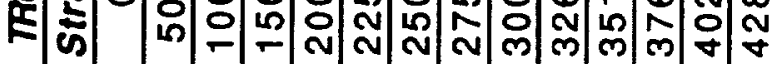

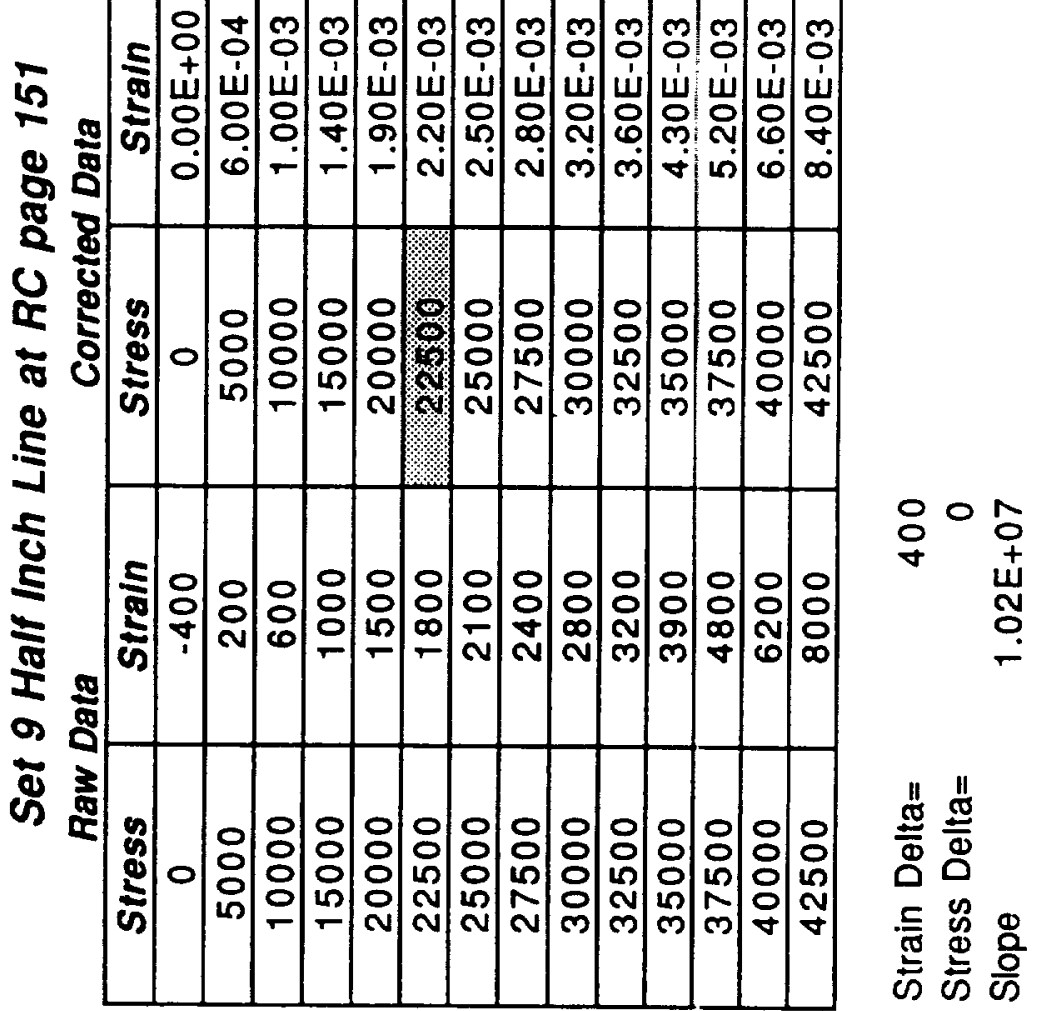




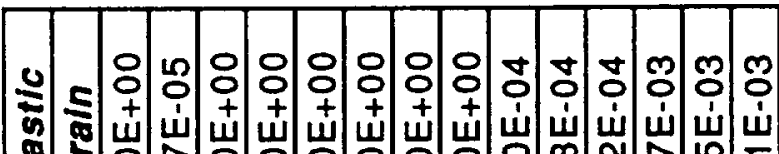

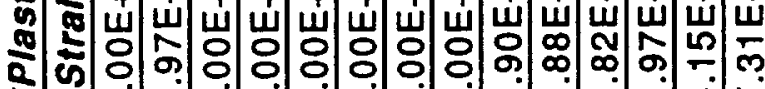

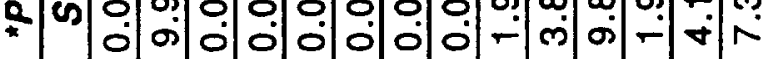

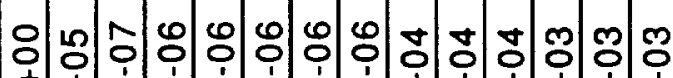

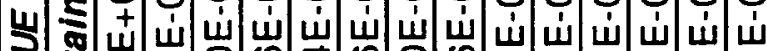

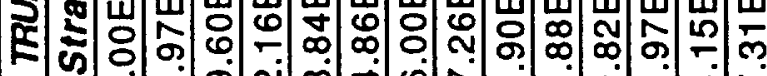
0

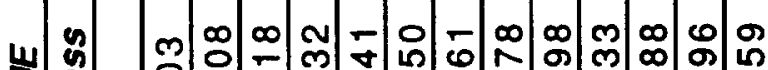

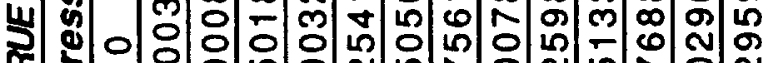

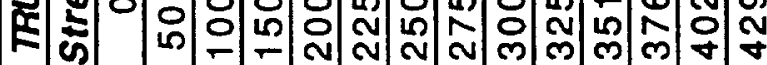

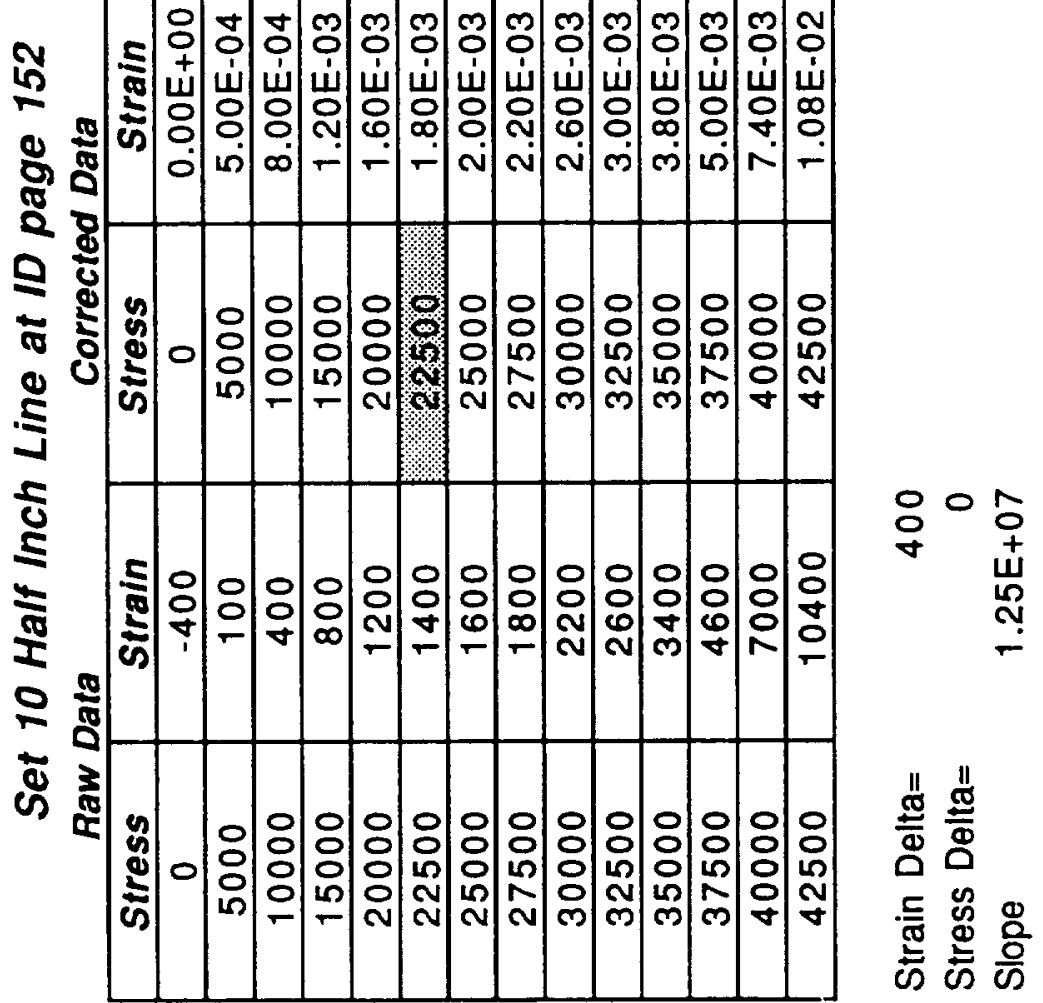




\section{APPENDIX B}

\section{ABAQUS MATERIALS PROPERTY INPUT}


** Material Properties Input 10/7/93

*SOLID SECTION, ELSET=PID17, MATEKIAL=PLATE

*MATERIAL, NAME=PLATE

*ELASTIC

$10.8 \mathrm{E} 6,0.33$

*SOLID SECTION, ELSET=PID18, MATERIAL=FORGING

*MATERIAL, NAME=FORGING

${ }^{*}$ ELASTIC

$10.8 \mathrm{E} 6,0.33$

*SOLID SECTION, ELSET=PID10, MATERIAL=MID10

*MATERIAL, NAME=MID10

*ELASTIC

6.67E6,0.33

*PLASTIC

$10000,0.00 \mathrm{E}+00$

$15000,3.41 \mathrm{E}-04$

20000, 9.80E-04

$30000,5.80 \mathrm{E}-03$

$32500,8.37 \mathrm{E}-03$

${ }^{\star}$ SOLID SECTION, ELSET=PID11, MATERIAL=MID11

*MATERIAL, NAME=MID11

*ELASTIC

7.22E6,0.33

*PLASTIC

$10000,0.00 \mathrm{E}+00$

$15000,2.84 \mathrm{E}-04$

20000,8.17E-04

$30000,4.84 \mathrm{E}-03$

$32500,6.98 \mathrm{E}-03$

*SOLID SECTION, ELSET=PID12, MATERIAL=MID12

*MATERIAL, NAME=MID12

*ELASTIC

$7.5 \mathrm{E} 6,0.33$

*PLASTIC

$10000,0.00 \mathrm{E}+00$

$15000,2.28 \mathrm{E}-04$

20000, 6.55E-04

30000, 3.87E-03 
32500, 5.59E-03

*SOLID SECTION, ELSET=PID13, MATERIAL=MID13

*MATERIAL, NAME=MID13

*ELASTIC

7.77E6,0.33

*PLASTIC

$10000,0.00 \mathrm{E}+00$

$15000,1.71 \mathrm{E}-04$

20000, 4.92E-04

$30000,2.91 \mathrm{E}-03$

$32500,4.20 \mathrm{E}-03$

*SOLID SECTION, ELSET=PID14, MATERIAL=MID14

${ }^{*}$ MATERIAL, NAME=MID14

*ELASTIC

8.05E6,0.33

*PLASTIC

$10000,0.00 \mathrm{E}+00$

$15000,1.15 \mathrm{E}-04$

20000, 3.29E-04

$30000,1.95 \mathrm{E}-03$

$32500,2.81 \mathrm{E}-03$

*SOLID SECTION, ELSET=PID15, MATERIAL=MID15

*MATERIAL, NAME=MID15

*ELASTIC

8.33E6,0.33

*PLASTIC

$10000,0.00 \mathrm{E}+00$

$15000,5.79 \mathrm{E}-05$

$20000,1.67 \mathrm{E}-04$

$30000,9.86 \mathrm{E}-04$

$32500,1.42 \mathrm{E}-03$

*SOLID SECTION, ELSET=PID20, MATERIAL=MID20

*MATERIAL, NAME=MID20

*ELASTIC

8.29E6,0.33

*PLASTIC

$10000,0.00 \mathrm{E}+00$

$15000,2.27 \mathrm{E}-04$

20000, 7.40E-04

$30000,4.66 \mathrm{E}-03$

$32500,7.11 \mathrm{E}-03$

*SOLID SECTION, ELSET $=$ PID21, MATERIAL=MID21

*MATERIAL, NAME=MID2 1 
*ELASTIC

8.36E6,0.33

*PLASTIC

$10000,0.00 \mathrm{E}+00$

$15000,1.90 \mathrm{E}-04$

20000, 6.17E-04

$30000,3.88 \mathrm{E}-03$

$32500,5.93 \mathrm{E}-03$

*SOLID SECTION, ELSET $=$ PID22, MATERIAL=MID22

*MATERIAL, NAME=MID22

${ }^{\star}$ ELASTIC

8.39E6,0.33

*PLASTIC

$10000,0.00 \mathrm{E}+00$

$15000,1.52 \mathrm{E}-04$

20000, 4.94E-04

$30000,3.11 \mathrm{E}-03$

$32500,4.75 \mathrm{E}-03$

*SOLID SECTION, ELSET=PID23, MATERIAL=MID23

*MATERLAL, NAME=MID23

*ELASTIC

$8.43 \mathrm{E} 6,0.33$

*PLASTIC

$10000,0.00 \mathrm{E}+00$

$15000,1.14 \mathrm{E}-04$

20000, 3.71E-04

$30000,2.34 \mathrm{E}-03$

$32500,3.57 \mathrm{E}-03$

*SOLID SECTION, ELSET=PID24, MATERIAL=MID24

*MATERIAL, NAME=MID24

*ELASTIC

8.46E6,0.33

*PLASTIC

$10000,0.00 \mathrm{E}+00$

$15000,7.64 \mathrm{E}-05$

20000, 2.49E-04

$30000,1.56 \mathrm{E}-03$

$32500,2.39 \mathrm{E}-03$

*SOLID SECTION, ELSET=PID25, MATEKIAL=MID25

*MATERIAL, NAME=MID25

*ELASTIC

8.50E6,0.33

*PLASTIC 
$10000,0.00 \mathrm{E}+00$

$15000,3.86 \mathrm{E}-05$

20000, 1.26E-04

$30000,7.92 \mathrm{E}-04$

$32500,1.21 \mathrm{E}-03$

*SOLID SECTION, ELSET=PID30, MATERIAL=MID30

*MATERIAL, NAME $=$ MID30

*ELASTIC

$9.91 \mathrm{E} 6,0.33$

*PLASTIC

$10000,0.00 \mathrm{E}+00$

$15000,1.14 \mathrm{E}-04$

20000, 5.00E-04

$30000,3.51 \mathrm{E}-03$

$32500,5.84 \mathrm{E}-03$

*SOLID SECTION, ELSET=PID31, MATERIAL=MID31

*MATERIAL, NAME=MID31

*ELASTIC

9.50E6,0.33

*PLASTIC

$10000,0.00 \mathrm{E}+00$

$15000,9.49 \mathrm{E}-05$

$20000,4.17 \mathrm{E}-04$

$30000,2.93 \mathrm{E}-03$

$32500,4.87 \mathrm{E}-03$

*SOLID SECTION, ELSET=PID32, MATERIAL=MID32

*MATERIAL, NAME $=$ MID32

*ELASTIC

9.29E6,0.33

*PLASTIC

$10000,0.00 \mathrm{E}+00$

$15000,7.60 \mathrm{E}-05$

20000, 3.34E-04

$30000,2.35 \mathrm{E}-03$

$32500,3.90 \mathrm{E}-03$

*SOLID SECTION, ELSET $=$ PID33, MATERIAL=MID33

*MATERIAL, NAME $=$ MID33

*ELASTIC

$9.08 \mathrm{E} 6,0.33$

*PLASTIC

$10000,0.00 \mathrm{E}+00$

$15000,5.71 \mathrm{E}-05$

20000, 2.51E-04 
$30000,1.76 \mathrm{E}-03$

32500, 2.93E-03

*SOLID SECTION, ELSET=PID34, MATERIAL=MID34

${ }^{\star}$ MATERIAL, NAME=MID34

${ }^{\star}$ ELASTIC

8.87E6,0.33

*PLASTIC

$10000,0.00 \mathrm{E}+00$

$15000,3.82 \mathrm{E}-05$

20000, 1.68E-04

$30000,1.18 \mathrm{E}-03$

32500, 1.96E-03

*SOLID SECTION, ELSET=PID35, MATERIAL=MID35

*MATERIAL, NAME=MID35

${ }^{*}$ ELASTIC

8.66E6,0.33

*PLASTIC

$10000,0.00 \mathrm{E}+00$

$15000,1.93 \mathrm{E}-05$

20000, 8.49E-05

$30000,5.97 \mathrm{E}-04$

$32500,9.93 \mathrm{E}-04$

*SOLID SECTION, ELSET=PID40, MATERIAL=MID40

*MATERIAL, NAME=MID40

${ }^{\star}$ ELASTIC

$11.5 \mathrm{E} 6,0.33$

*PLASTIC

$15000,0.00 \mathrm{E}+00$

20000, 2.59E-04

$22500,3.89 \mathrm{E}-04$

$25000,7.18 \mathrm{E}-04$

$27500,1.34 \mathrm{E}-03$

$30000,2.37 \mathrm{E}-03$

$32500,4.57 \mathrm{E}-03$

*SOLID SECTION, ELSET=PID41, MATERIAL=MID41

*MATERIAL, NAME=MID41

*ELASTIC

10.6E6,0.33

*PLASTIC

$15000,0.00 \mathrm{E}+00$

20000, 2.16E-04

$22500,3.25 \mathrm{E}-04$

25000, 5.99E-04 
$27500,1.12 \mathrm{E}-03$

$30000,1.97 \mathrm{E}-03$

32500, 3.81E-03

*SOLID SECTION, ELSET=PID42, MATERIAL=MID42

*MATERIAL, NAME=MID42

*ELASTIC

$10.2 \mathrm{E} 6,0.33$

*PLASTIC

$15000,0.00 \mathrm{E}+00$

20000, 1.73E-04

22500, 2.60E-04

$25000,4.80 \mathrm{E}-04$

27500, 8.98E-04

$30000,1.58 \mathrm{E}-03$

32500, 3.05E-03

*SOLID SECTION, ELSET=PID43, MATERIAL=MID43

*MATERIAL, NAME $=$ MID43

${ }^{*}$ ELASTIC

9.74E6,0.33

*PLASTIC

$15000,0.00 \mathrm{E}+00$

20000, 1.30E-04

$22500,1.95 \mathrm{E}-04$

25000, 3.61E-04

$27500,6.75 \mathrm{E}-04$

$30000,1.19 \mathrm{E}-03$

$32500,2.30 \mathrm{E}-03$

*SOLID SECTION, ELSET=PID44, MATERIAL=MID44

*MATERIAL, NAME $=$ MID44

*ELASTIC

9.29E6,0.33

*PLASTIC

$15000,0.00 \mathrm{E}+00$

20000, 8.69E-05

22500, 1.31E-04

$25000,2.41 \mathrm{E}-04$

$27500,4.52 \mathrm{E}-04$

$30000,7.95 \mathrm{E}-04$

32500, 1.54E-03

*SOLID SECTION, ELSET=PID45, MATERIAL=MID45

*MATERIAL, NAME=MID45

*ELASTIC

$8.82 \mathrm{E} 6,0.33$ 


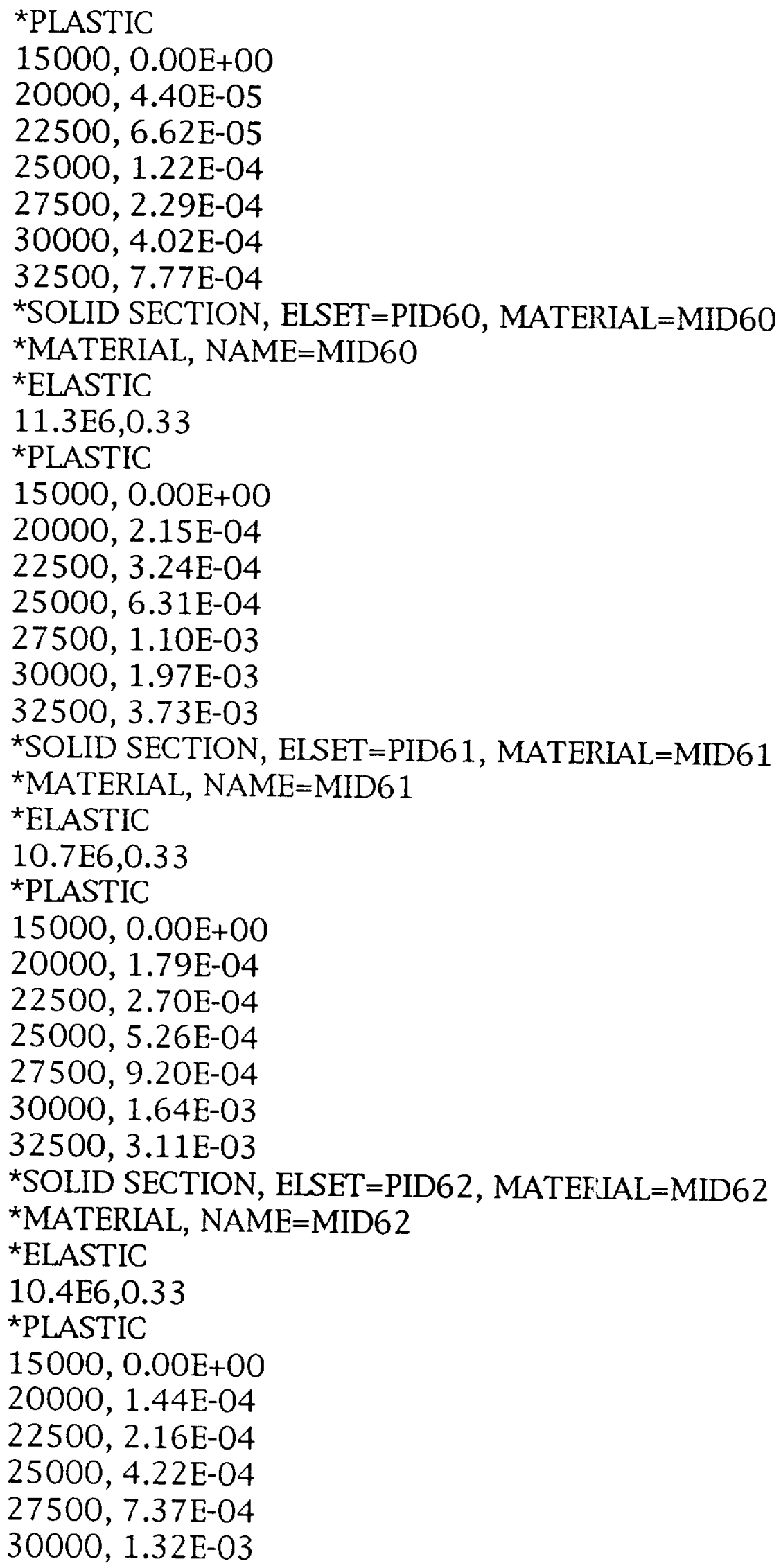


$32500,2.49 \mathrm{E}-03$

*SOLID SECTION, ELSET=PID63, MATERIAL=MID63

*MATERIAL, NAME=MID63

*ELASTIC

10.1E6,0.33

*PLASTIC

$15000,0.00 \mathrm{E}+00$

20000, 1.08E-04

$22500,1.63 \mathrm{E}-04$

25000, 3.17E-04

$27500,5.54 \mathrm{E}-04$

$30000,9.90 \mathrm{E}-04$

$32500,1.87 \mathrm{E}-03$

*SOLID SECTION, ELSET=PID64, MATERIAL=MID64

*MATERIAL, NAME=MID64

*ELASTIC

9.76E6,0.33

*PLASTIC

$15000,0.00 \mathrm{E}+00$

$20000,7.22 \mathrm{E}-05$

$22500,1.09 \mathrm{E}-04$

25000, 2.12E-04

$27500,3.71 \mathrm{E}-04$

$30000,6.62 \mathrm{E}-04$

$32500,1.25 \mathrm{E}-03$

*SOLID SECTION, ELSET=PID65, MATERIAL=MID65

*MATERIAL, NAME=MID65

*ELASTIC

9.45E6,0.33

*PLASTIC

$15000,0.00 \mathrm{E}+00$

20000, 3.66E-05

$22500,5.50 \mathrm{E}-05$

$25000,1.07 \mathrm{E}-04$

$27500,1.88 \mathrm{E}-04$

$30000,3.35 \mathrm{E}-04$

$32500,6.34 \mathrm{E}-04$

*SOLID SECTION, ELSET=PID70, MATERIAL=MID70

*MATERIAL, NAME $=$ MID70

*ELASTIC

11.0E6,0.33

*PLASTIC

$15000,0.00 \mathrm{E}+00$ 


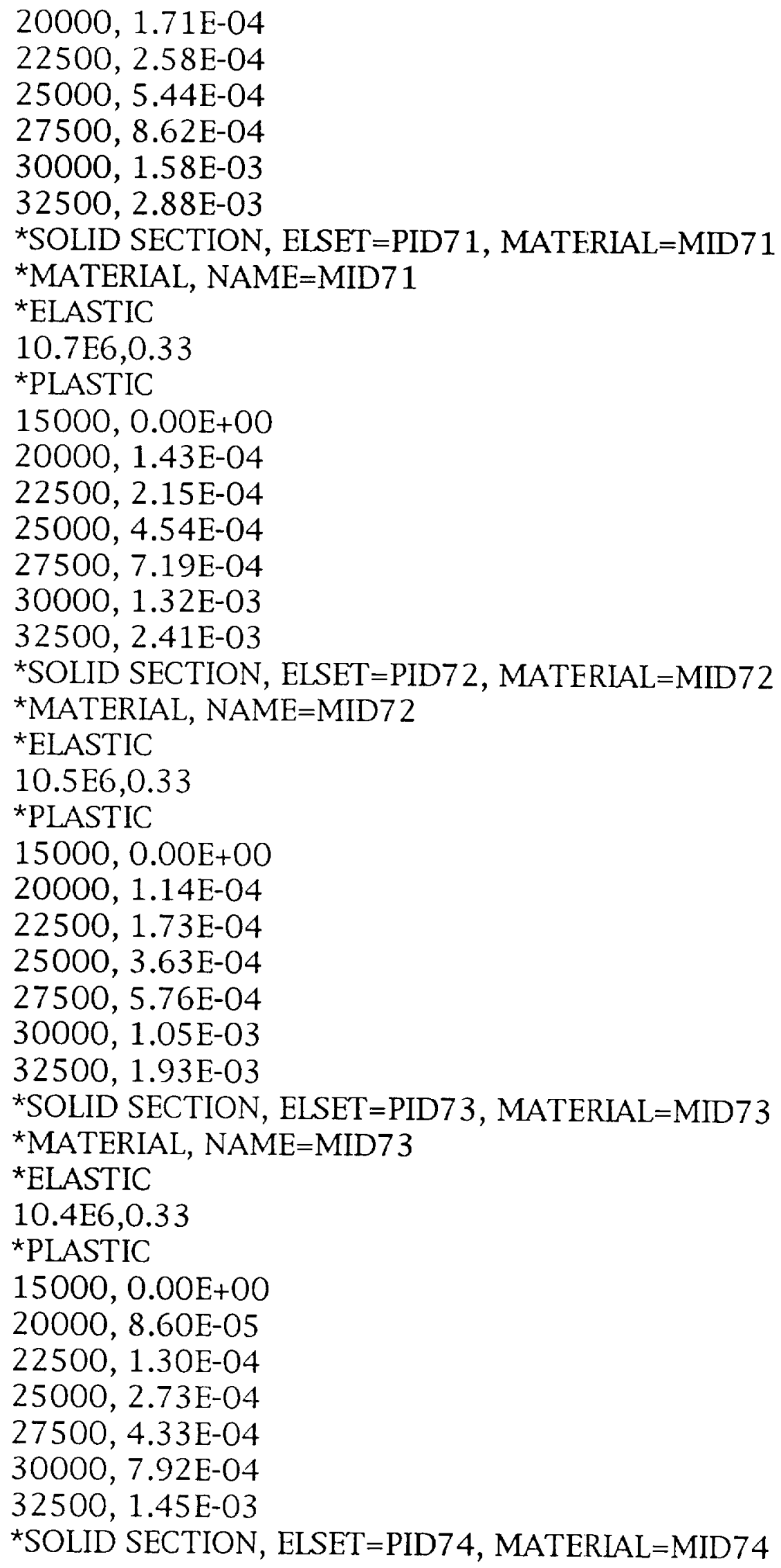




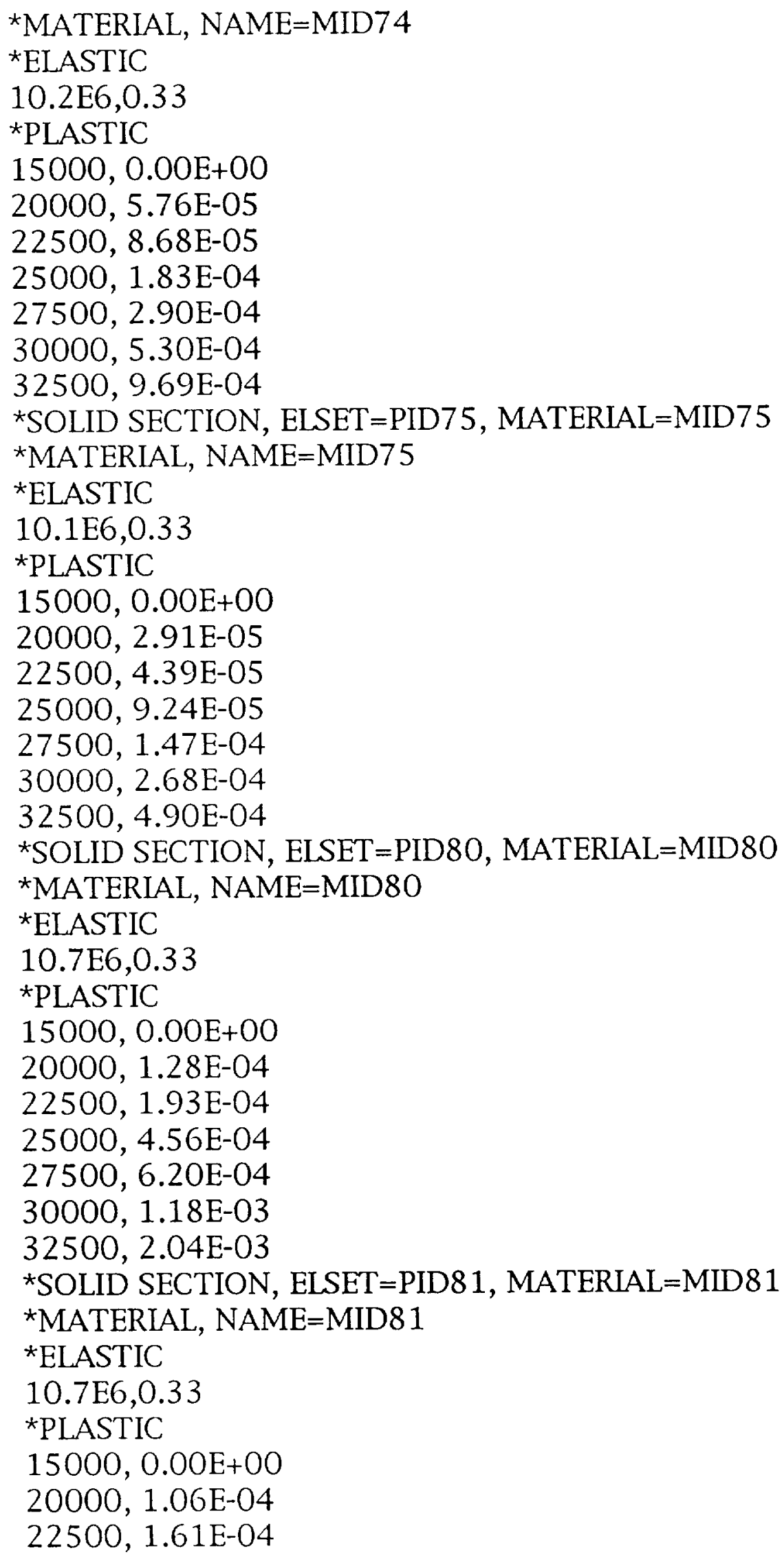


25000, 3.80E-04

$27500,5.17 \mathrm{E}-04$

$30000,9.85 \mathrm{E}-04$

32500, 1.70E-03

*SOLID SECTION, ELSET=PID82, MATERIAL=MID82

*MATERIAL, NAME=MID82

*ELASTIC

10.7E6,0.33

*PLASTIC

$15000,0.00 \mathrm{E}+00$

20000, 8.52E-05

22500, 1.29E-04

25000, 3.05E-04

$27500,4.14 \mathrm{E}-04$

$30000,7.89 \mathrm{E}-04$

$32500,1.36 \mathrm{E}-03$

*SOLID SECTION, ELSET $=$ PID83, MATERIAL $=$ MID83

*MATERIAL, NAME=MID83

*ELASTIC

10.8E6,0.33

*PLASTIC

$15000,0.00 \mathrm{E}+00$

$20000,6.41 \mathrm{E}-05$

$22500,9.66 \mathrm{E}-05$

25000, 2.29E-04

27500, 3.11E-04

$30000,5.93 \mathrm{E}-04$

$32500,1.02 \mathrm{E}-03$

*SOLID SECTION, ELSET=PID84, MATERIAL=MID84

*MATERIAL, NAME=MID84

*ELASTIC

10.7E6,0.33

*PLASTIC

$15000,0.00 \mathrm{E}+00$

20000, 4.29E-05

$22500,6.47 \mathrm{E}-05$

$25000,1.53 \mathrm{E}-04$

$27500,2.08 \mathrm{E}-04$

$30000,3.97 \mathrm{E}-04$

$32500,6.85 \mathrm{E}-04$

*SOLID SECTION, ELSET=PID85, MATERIAL=MID85

*MATERIAL, NAME=MID85

${ }^{\star}$ ELASTIC 
10.7E6,0.33

*PLASTIC

$15000,0.00 \mathrm{E}+00$

20000, 2.17E-05

$22500,3.27 \mathrm{E}-05$

$25000,7.76 \mathrm{E}-05$

$27500,1.05 \mathrm{E}-04$

$30000,2.01 \mathrm{E}-04$

$32500,3.47 \mathrm{E}-04$

*SOLID SECTION, ELSET=PID100, MATERIAL=MID100

*MATERIAL, NAME=MID100

*ELASTIC

$10.8 \mathrm{E} 6,0.33$

*PLASTIC

$15000,0.00 \mathrm{E}+00$

20000, 1.06E-04

22500, 2.09E-04

$25000,4.46 \mathrm{E}-04$

$27500,6.15 \mathrm{E}-04$

$30000,1.15 \mathrm{E}-03$

32500, 2.01E-03

*SOLID SECTION, ELSET=PID101, MATERIAL=MID101

*MATERIAL, NAME=MID101

*ELASTIC

$10.8 \mathrm{E} 6,0.33$

*PLASTIC

$15000,0.00 \mathrm{E}+00$

20000, 8.82E-05

$22500,1.75 \mathrm{E}-04$

$25000,3.72 \mathrm{E}-04$

$27500,5.13 \mathrm{E}-04$

$30000,9.58 \mathrm{E}-04$

32500, 1.68E-03

*SOLID SECTION, ELSET=PID102, MATERIAL=MID102

*MATERIAL, NAME $=$ MID102

*ELASTIC

10.8E6,0.33

*PLASTIC

$15000,0.00 \mathrm{E}+00$

20000, 7.06E-05

22500, 1.40E-04

$25000,2.98 \mathrm{E}-04$

$27500,4.11 \mathrm{E}-04$ 
$30000,7.67 \mathrm{E}-04$

$32500,1.34 \mathrm{E}-03$

*SOLID SECTION, ELSET=PID103, MATERIAL=MID103

*MATERIAL, NAME $=$ MID103

${ }^{\star}$ ELASTIC

$10.8 \mathrm{E} 6,0.33$

*PLASTIC

$15000,0.00 \mathrm{E}+00$

20000, 5.31E-05

$22500,1.05 \mathrm{E}-04$

25000, 2.24E-04

27500, 3.09E-04

30000, 5.77E-04

$32500,1.01 \mathrm{E}-03$

*SOLID SECTION, ELSET=PID104, MATERIAL=MID104

*MATERIAL, NAME=MID104

*ELASTIC

$10.8 \mathrm{E} 6,0.33$

${ }^{\star P L A S T I C}$

$15000,0.00 \mathrm{E}+00$

20000, 3.55E-05

$22500,7.04 \mathrm{E}-05$

25000, 1.50E-04

27500, 2.07E-04

$30000,3.86 \mathrm{E}-04$

$32500,6.76 \mathrm{E}-04$

*SOLID SECTION, ELSET=PID105, MATERIAL=MID105

*MATERIAL, NAME=MID105

${ }^{*}$ ELASTIC

$10.8 \mathrm{E} 6,0.33$

*PLASTIC

$15000,0.00 \mathrm{E}+00$

20000, 1.80E-05

$22500,3.56 \mathrm{E}-05$

$25000,7.58 \mathrm{E}-05$

27500, 1.05E-04

$30000,1.95 \mathrm{E}-04$

32500, 3.42E-04

*SOLID SECTION, ELSET $=$ PID1 10, MAT 3 RIAL $=$ MID110

*MATERIAL, NAME=MID110

*ELASTIC

10.8E6,0.33

*PLASTIC 


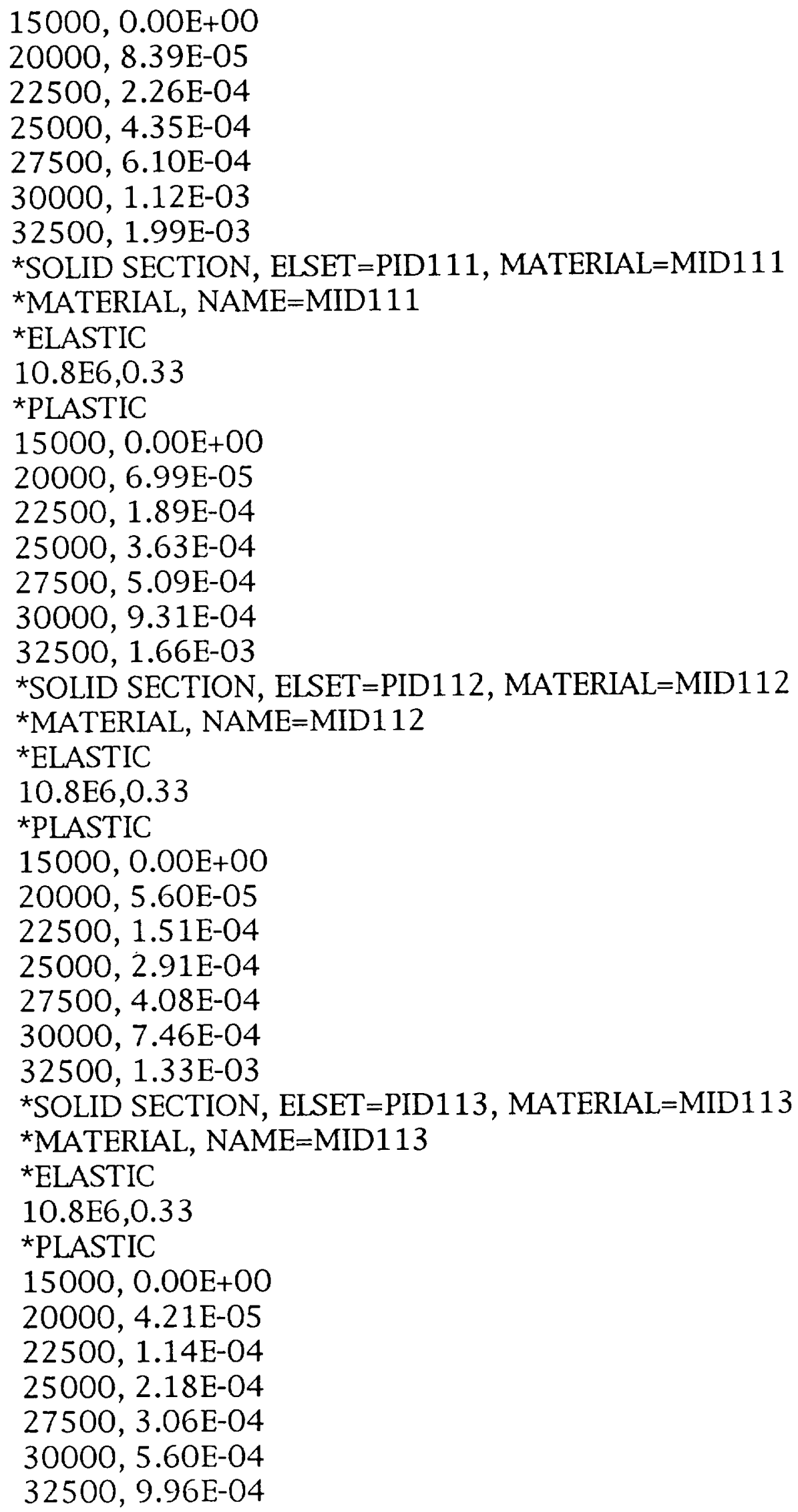


*SOLID SECTION, ELSET=PID114, MATERIAL=MID114

*MATERIAL, NAME=MID114

${ }^{\star}$ ELASTIC

$10.8 \mathrm{E} 6,0.33$

*PLASTIC

$15000,0.00 \mathrm{E}+00$

20000, 2.82E-05

$22500,7.60 \mathrm{E}-05$

25000, 1.46E-04

$27500,2.05 \mathrm{E}-04$

$30000,3.75 \mathrm{E}-04$

$32500,6.67 \mathrm{E}-04$

*SOLID SECTION, ELSET=PID115, MATERIAL=MID115

*MATERIAL, NAME=MID115

${ }^{*}$ ELASTIC

$10.8 \mathrm{E} 6,0.33$

*PLASTIC

$15000,0.00 \mathrm{E}+00$

20000, 1.43E-05

$22500,3.85 \mathrm{E}-05$

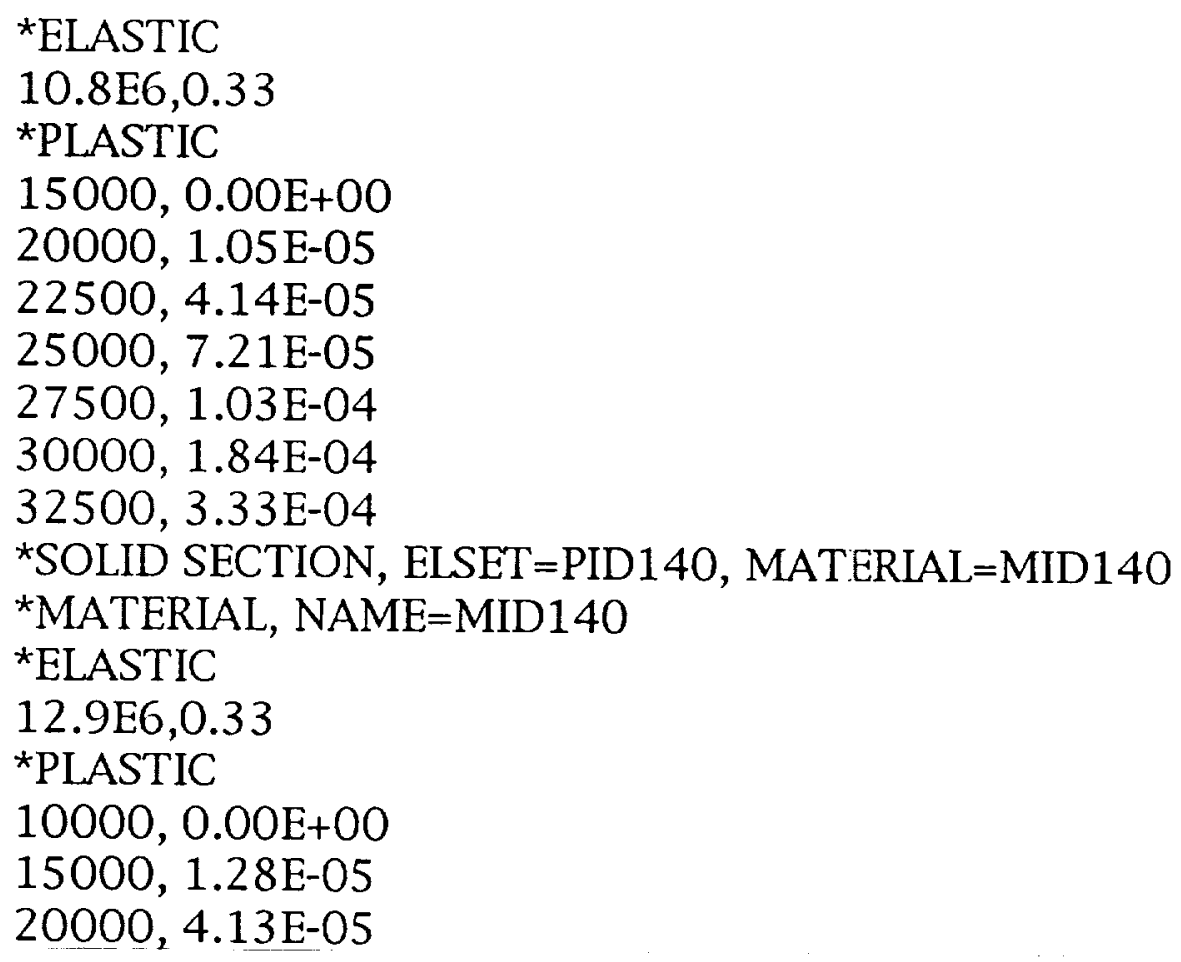

*ELASTIC

$10.8 \mathrm{E} 6,0.33$

*PLASTIC

$15000,0.00 \mathrm{E}+00$

20000, 1.05E-05

22500, 4.14E-05

$25000,7.21 \mathrm{E}-05$

$27500,1.03 \mathrm{E}-04$

$30000,1.84 \mathrm{E}-04$

$32500,3.33 \mathrm{E}-04$

*SOLID SECTION, ELSET=PID140, MATERIAL=MID140

*MATERIAL, NAME=MID140

*ELASTIC

12.9E6,0.33

*PLASTIC

$10000,0.00 \mathrm{E}+00$

$15000,1.28 \mathrm{E}-05$

20000, 4.13E-05 


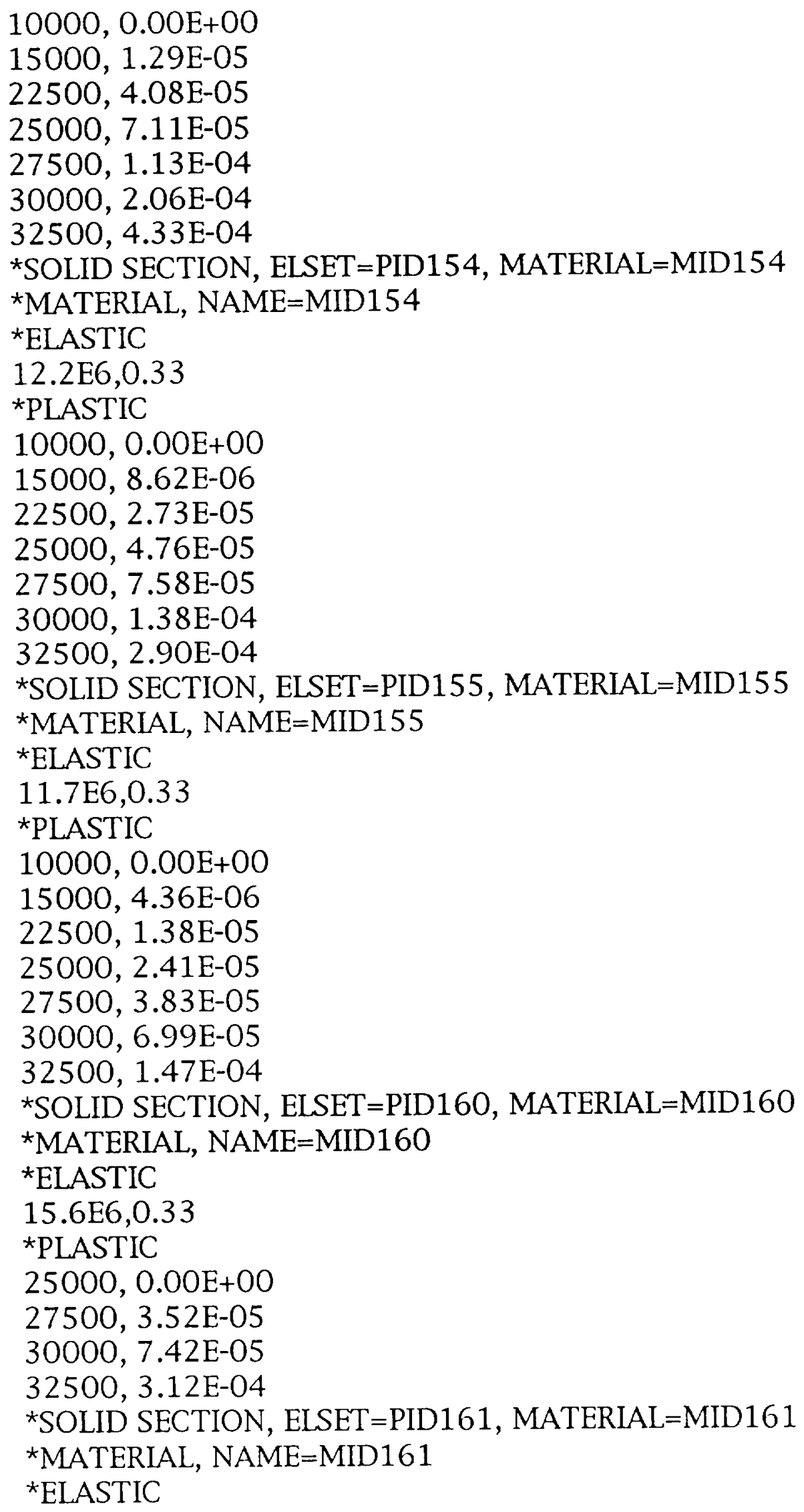


$14.6 \mathrm{E} 6,0.33$

*PLASTIC

25000, $0.00 \mathrm{E}+00$

27500, 2.94E-05

$30000,6.19 \mathrm{E}-05$

32500, 2.60E-04

*SOLID SECTION, ELSET=PID162, MATERIAL=MID162

*MATERIAL, NAME=MID162

*ELASTIC

$14.1 \mathrm{E} 6,0.33$

*PLASTIC

25000, 0.00E +00

27500, 2.35E-05

$30000,4.95 \mathrm{E}-05$

32500, 2.09E-04

*SOLID SECTION, ELSET=PID163, MATERIAL=MID163

*MATERIAL, NAME=MID163

*ELASTIC

13.6E6,0.33

${ }^{\star P L A S T I C}$

25000, 0.00E +00

$27500,1.77 \mathrm{E}-05$

$30000,3.72 \mathrm{E}-05$

$32500,1.57 \mathrm{E}-04$

*SOLID SECTION, ELSET=PID164, MATERIAL=MID164

*MATERIAL, NAME=MID164

${ }^{*}$ ELASTIC

13.0E6,0.33

*PLASTIC

$25000,0.00 E+00$

$27500,1.18 \mathrm{E}-05$

$30000,2.49 \mathrm{E}-05$

$32500,1.05 \mathrm{E}-04$

*SOLID SECTION, ELSET=PID165, MATERIAL=MID165

*MATERIAL, NAME=MID165

*ELASTIC

$12.5 \mathrm{E} 6,0.33$

*PLASTIC

25000, 0.00E+00

27500, 5.99E-06

$30000,1.26 \mathrm{E}-05$

$32500,5.31 \mathrm{E}-05$

** LOAD CASE 100 


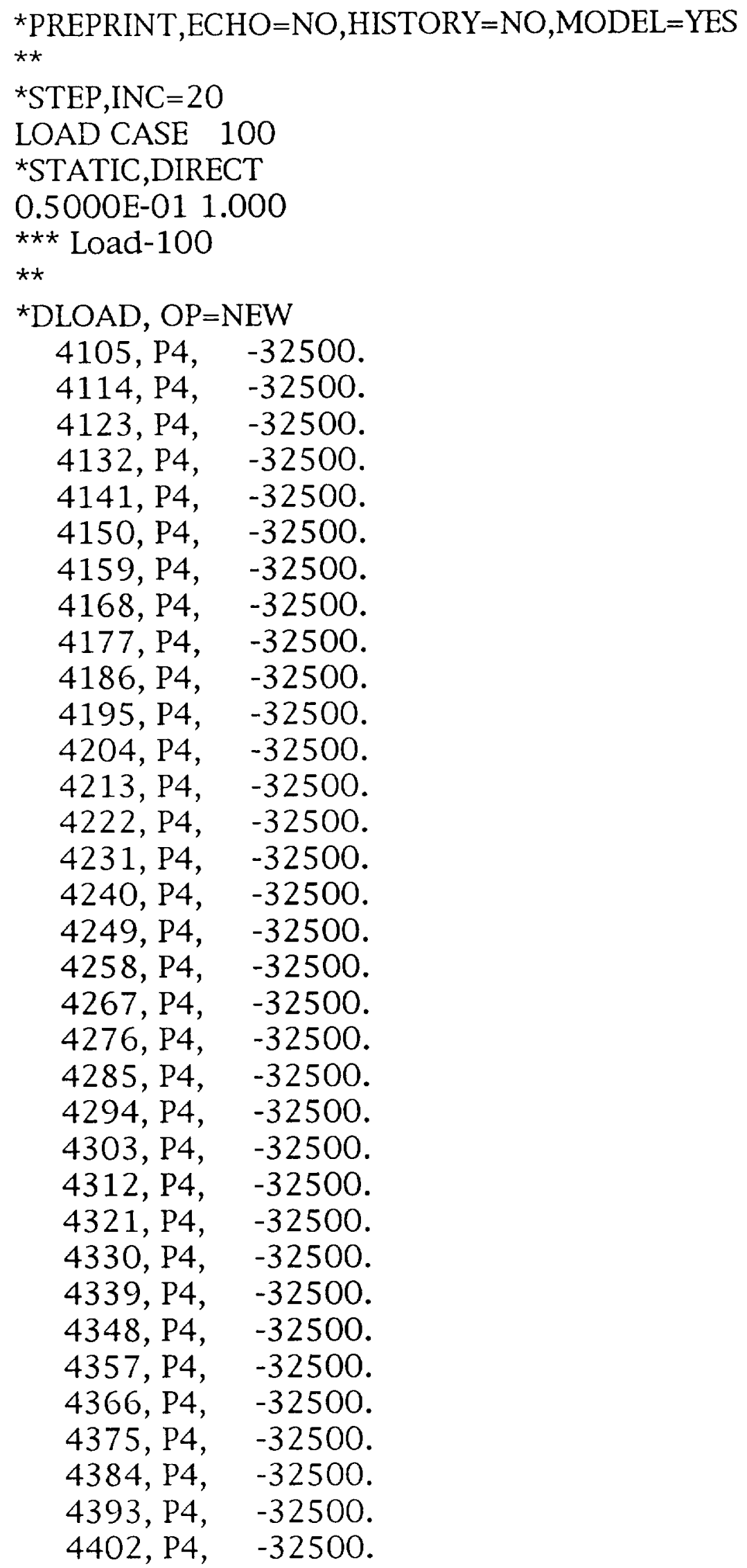




$$
\begin{array}{ll}
4411, \mathrm{P} 4, & -32500 . \\
4420, \mathrm{P} 4, & -32500 . \\
4429, \mathrm{P} 4, & -32500 . \\
4438, \mathrm{P} 4, & -32500 . \\
4447, \mathrm{P} 4, & -32500 . \\
4456, \mathrm{P} 4, & -32500 . \\
4465, \mathrm{P} 4, & -32500 . \\
4474, \mathrm{P} 4, & -32500 . \\
4483, \mathrm{P} 4, & -32500 . \\
4492, \mathrm{P} 4, & -32500 . \\
4501, \mathrm{P} 4, & -32500 . \\
4510, \mathrm{P} 4, & -32500 . \\
4519, \mathrm{P} 4, & -32500 . \\
4528, \mathrm{P} 4, & -32500 . \\
4537, \mathrm{P} 4, & -32500 . \\
4546, \mathrm{P} 4, & -32500 . \\
4555, \mathrm{P} 4, & -32500 . \\
4564, \mathrm{P} 4, & -32500 . \\
4573, \mathrm{P} 4, & -32500 . \\
4582, \mathrm{P} 4, & -32500 . \\
4591, \mathrm{P} 4, & -32500 . \\
4600, \mathrm{P} 4, & -32500 . \\
4609, \mathrm{P} 4, & -32500 . \\
4618, \mathrm{P} 4, & -32500 . \\
4627, \mathrm{P} 4, & -32500 . \\
4636, \mathrm{P} 4, & -32500 . \\
4645, \mathrm{P} 4, & -32500 . \\
4654, \mathrm{P} 4, & -32500 . \\
4663, \mathrm{P} 4, & -32500 . \\
4672, \mathrm{P} 4, & -32500 . \\
* * & \\
\hline &
\end{array}
$$

*FILE FORMAT ASCII

*EL PRINT,FREQ $=0$

*NODE PRINT,FREQ $=0$

${ }^{*}$ NODE FILE, GLOBAL $=$ YES,FREQ $=20$

$\mathrm{U}$

${ }^{\star}$ EL FILE,POSITION=CENTROIDAL,FREC $=1$

$S$

E

PE

${ }^{\star}$ END STEP 


\section{APPENDIX C}

COMPARISON OF ANALYTICAL RESULTS TO ABAQUS RESULTS 


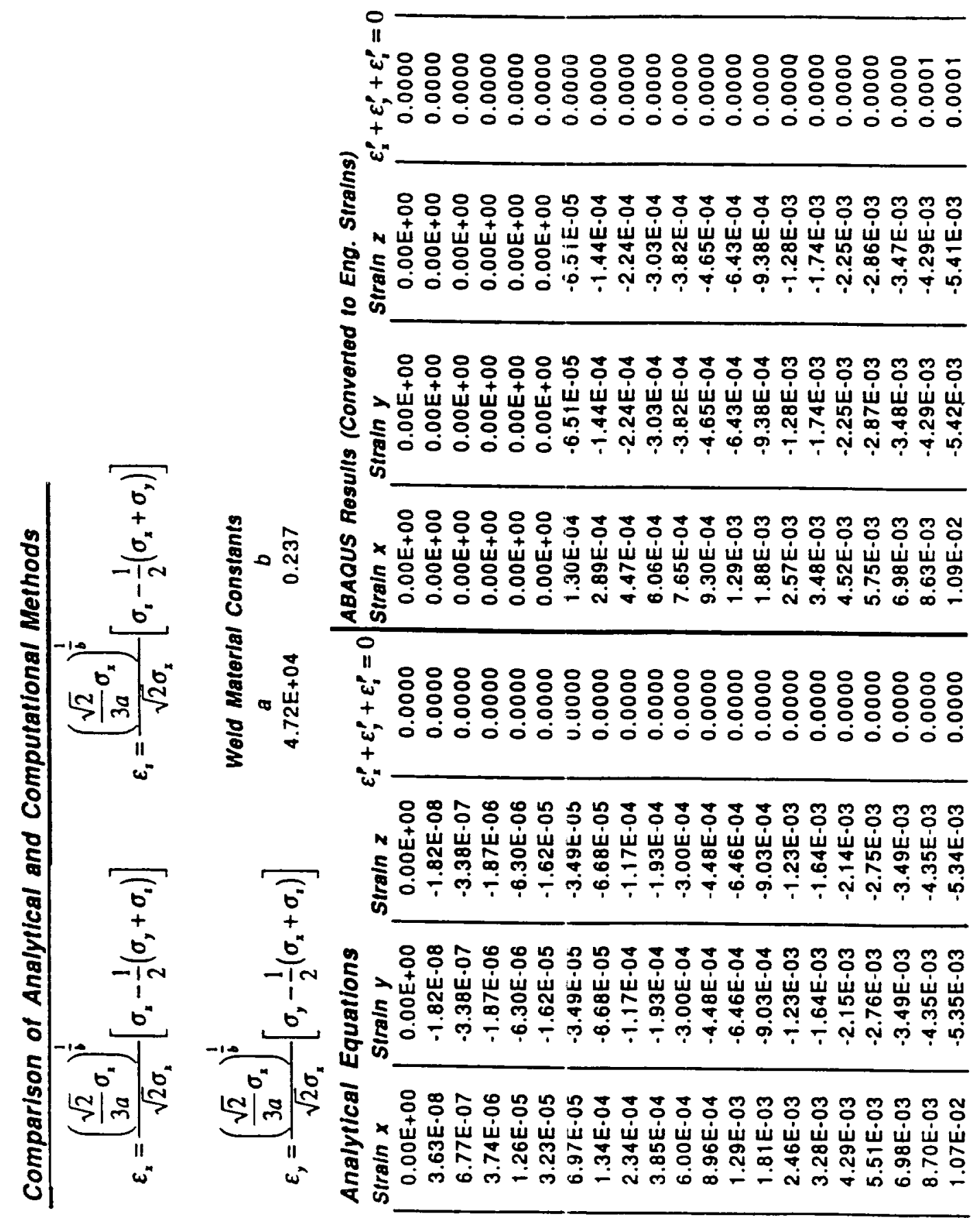





\section{REPORT DOCUMENTATION PAGE}

Public redorting burden for this collection of information is est mated to average 1 hour per esponse, includ ig the time for reviewing instructions, searching existing data sources, gathering and maintaining the data needed. and completing and reviewing the collection of information Ser d comments regarding this burden estimate or any other aspect of this Davis Highway, Sulte 1204. Arlington, VA 22202.4302, and to the Office of Management and Budget. Paperwirk Reduction Project (0704.0188), Washington, OC 20503.

\begin{tabular}{|l|l|l}
\hline 1. AGENCY USE ONLY (Leave blank) & $\begin{array}{r}\text { 2. REPORT DATE } \\
\text { September } 1994\end{array}$ & $\begin{array}{r}\text { 3. REPORT TYPE AND DA } \\
\text { Technical Paner }\end{array}$ \\
\hline
\end{tabular}

4. TITLE AND SUBTITLE

An Inelastic Analysis of a Welded Aluminum

Joint

6. AUTHOR(S)

R.E. Vaughan

7. PERFORMING ORGANIZATION NAME(S) AND ADDRESS(ES)

George C. Marshall Space Flight Center

Marshall Space Flight Center, Alabama 35812

8. PERFORMING ORGANIZATION REPORT NUMBER

$M-760$

9. SPONSORING/MONITORING AGENCY NAME(S) AND ADDRESS(ES)

10. SPONSORING / MONITORING

AGENCY REPORT NUMBER

National Aeronautics and Space Administration

Washington, DC 20546

NASA TP-3508

\section{SUPPLEMENTARY NOTES}

Prepared by Structures and Dynamics Laboratory, Science and Engineering Directorate.

12a. DISTRIBUTION/AVAILABILITY STATEMENT

12b. DISTRIBUTION CODE

Subject Category: 39

Unclassified-Unlimited

\section{ABSTRACT (Maximum 200 words)}

Butt-weld joints are most commonly designed into pressure vess:ls which then become as reliable as the weakest increment in the weld chain. In practice, weld material properties are determined from tensile test specimen and provided to the stress analyst in the form of a stress versus strain diagram. Variations in properties through the thickness of the weld and along the width of the weld have been suspect but not explored because of inaccessibility and cost.

The purpose of this study is to investigate analytical and computational methods used for analysis of welds. The weld specimens are analyzed using classical elastic and plastic theory to provide a basis for modeling the inelastic properties in a finite-element solution. The results of the analysis are compared to experimental data to determine the weld behavior and the accuracy of prediction methods. The weld considered in this study is a multiple-pass aluminum 2219-T87 butt weld with thickness of 1.40 in.

The weld specimen is modeled using the finite-element code $A B A Q U S$. The finite-element model is used to produce the stress-strain behavior in the elastic and plastic regimes and to determine Poisson's ratio in the plastic region. The value of Poisson's ratio in the plastic regime is then compared to experimental data. The results of the comparisons are used to explain multipass weld behavior and to make recommendation; concerning the analysis and testing of welds. 14. SUBJECT TERMS
plastic analysis, nonlinear analysis, incremental strain theory, multipass welds,
thick welds

18

OF REPORT

Unclassified

NSN 7540-01-280-5500
15. NUMBER OF PAGES 81

16. PRICE CODE A05

20. LIMITATION OF ABSTRACT OF THIS PAGE Unclassified OF ABSTRACT Unclassified Unlimited 